\title{
The perceptions of practicing West Virginia K-3 reading teachers of working with Reading First coaches in Title I Distinguished Schools
}

\author{
Karen R. Davies \\ West Virginia University
}

Follow this and additional works at: https://researchrepository.wvu.edu/etd

\begin{abstract}
Recommended Citation
Davies, Karen R., "The perceptions of practicing West Virginia K-3 reading teachers of working with Reading First coaches in Title I Distinguished Schools" (2009). Graduate Theses, Dissertations, and Problem Reports. 2918.
\end{abstract}

https://researchrepository.wvu.edu/etd/2918

This Dissertation is protected by copyright and/or related rights. It has been brought to you by the The Research Repository @ WVU with permission from the rights-holder(s). You are free to use this Dissertation in any way that is permitted by the copyright and related rights legislation that applies to your use. For other uses you must obtain permission from the rights-holder(s) directly, unless additional rights are indicated by a Creative Commons license in the record and/ or on the work itself. This Dissertation has been accepted for inclusion in WVU Graduate Theses, Dissertations, and Problem Reports collection by an authorized administrator of The Research Repository @ WVU.

For more information, please contact researchrepository@mail.wvu.edu. 
The Perceptions of Practicing West Virginia K-3 Reading Teachers of Working with Reading First Coaches in Title I Distinguished Schools

Karen R. Davies

Dissertation submitted to the College of Human Resources \& Education at West Virginia University

In partial fulfillment of the requirements for the degree of

Doctor of Education in Educational Leadership Studies

Helen Hazi, Ph. D., Chair

Paul Chapman, Ph. D.

Richard Hartnett, Ed. D.

Erin Sullivan, Ed. D.

Richard Walls, Ph. D.

Department of Educational Leadership Studies

Morgantown, WV

2009

Key Words: Reading Coach, Reading First, Distributed Leadership, Educational Leadership Copyright 2009 Karen R. Davies 


\begin{abstract}
The Perceptions of Practicing West Virginia K-3 Reading Teachers of Working with Reading First Coaches in Title I Distinguished Schools
\end{abstract}

Karen R. Davies

This research was conducted to offer insight regarding how Reading First K-3 teachers working in West Virginia Title I Distinguished Schools perceive the role of the reading coach. The study examined the importance of reading coach activities in improving reading instruction as perceived by these K-3 teachers. It was further investigated whether differences existed between reading coach activities perceived by the teachers as important to improving reading instruction and knowledge by these teachers that the activities were performed by the coaches. An electronic survey was distributed to all Reading First K-3 teachers working in West Virginia Title I Distinguished Schools for a population of 160 participants in which 71 or $44 \%$ responded. Findings indicate that these K-3 teachers perceive reading coach activities as important in improving reading instruction and they are knowledgeable that the activities are performed by reading coaches within their schools. 


\section{DEDICATION}

This work is dedicated to the memory of my brother, first playmate, and only sibling, Jeffrey Scott Davies. Your daughter Tasha and her children, Logan and Reese are an amazing gift for which I am forever grateful. I also dedicate this work to my parents, Jack and Mary Davies, who modeled early for me the importance of education, hard work, and commitment. After more than twenty years of experience as an educator I have truly come to appreciate your endless support and guidance. I love both of you dearly. Education is in my blood and yes, I am glad I followed in your footsteps dad. 


\section{ACKNOWLEGEMENTS}

West Virginia University is a special place and the professors I have worked with over the past few years deserve to be acknowledged for their assistance and support of this work: Dr. Helen Hazi, Dr. Richard Walls, Dr. Richard Hartnett, and Dr. Paul Chapman. A special thanks to my chairperson, Dr. Helen Hazi whose expectations have made me a better writer, thinker, and educator. I would also like to offer a special thanks to Dr. Richard Walls for his assistance with my understanding of research statistics. You are an incredible teacher!

I would also like to thank two of my colleagues at the West Virginia Department of Education, Jan Stanley and Erin Sullivan, for their continued support and assistance. Your motivation and dedication to continuously improve education throughout West Virginia is truly inspiring. 


\section{TABLE OF CONTENTS}

CHAPTER I: INTRODUCTION AND STATEMENT OF THE PROBLEM................ 1

Research Justification.................................................... 3

Statement of Purpose and Research Questions................................. 4

Research Design....................................................... 6

Definition of Terms...................................................... 7

Organization of Document.............................................. 9

CHAPTER II: REVIEW OF THE LITERATURE................................. 10

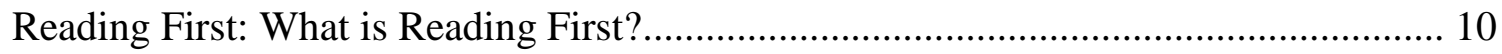

History of the Initiative.................................................. 15

Concerns and Criticisms of Reading First.................................. 19

Reading First in West Virginia.............................................. 24

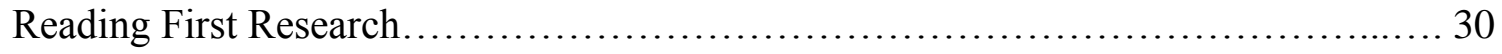

Leadership Research.................................................... 32

Distributed Leadership and Instructional Coaching Research...................... 34

CHAPTER III: RESEARCH DESIGN $\ldots \ldots \ldots \ldots \ldots \ldots \ldots \ldots \ldots \ldots \ldots \ldots \ldots \ldots \ldots \ldots \ldots \ldots \ldots . \ldots \ldots$

Research Theoretic..................................................... 45

Research Participants................................................... 46

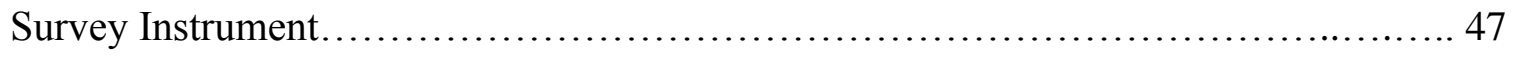

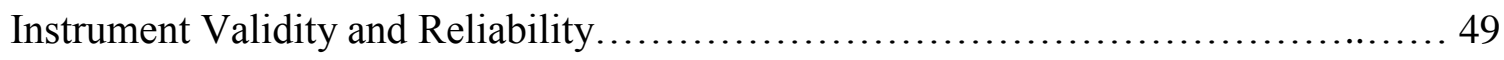

Data Dissemination and Collection...................................... 52

Data Analysis......................................................... 54 
CHAPTER IV: DATA ANALYSIS AND INTERPRETATION .............................. 58

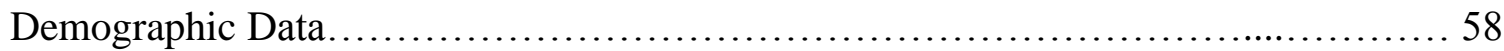

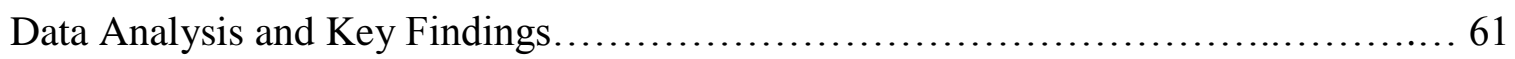

CHAPTER V: SUMMARY, STUDY CONCLUSION, DISCUSSION, AND

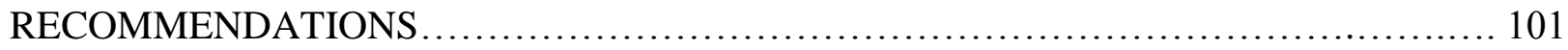

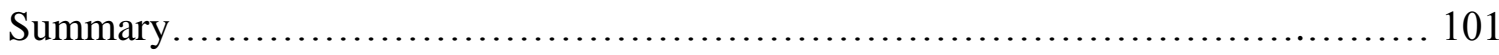

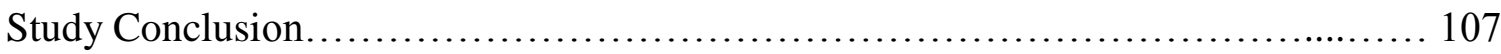

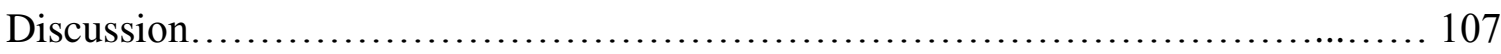

Recommendations for Administrators and Policy Makers.......................... 112

Recommendations for Further Research...................................... 115

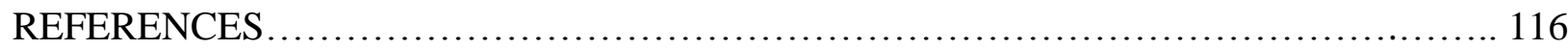

APPENDICES

APPENDIX A: West Virginia Reading First Mentor Teacher Model Job Description. 124 APPENDIX B: West Virginia Reading First Schools............................ 125

APPENDIX C: West Virginia Reading First K-3 Reading Teachers Working in Title I

Distinguished Schools....................................................... 126

APPENDIX D: K-3 Teacher Survey Introduction................................ 127

APPENDIX E: Reading First K-3 Classroom Reading Teacher Survey............... 128

APPENDIX F: Survey Development Matrix .................................. 134

APPENDIX G: Panel of Experts E-mail......................................... 137

APPENDIX H: Panel of Experts Survey Directions.............................. 138

APPENDIX I: Panel of Experts Feedback Matrix................................... 140

APPENDIX J: Superintendent Survey Letter.................................... 141 
APPENDIX K: K-3 Teacher Survey Letter Request.......................... 142

\section{TABLES}

TABLE 1: Participant Teaching Experience by Frequency and Percentage ............ 59

TABLE 2: Participant Hours Working With Reading Mentor Teacher by Frequency and

Percentage............................................................. 60

TABLE 3: Reading Mentor Teacher Assignment by Frequency and Percentage......... 60

TABLE 4: Importance of Reading First Administration Activities................... 63

TABLE 5: Importance of Professional Development Activities...................... 67

TABLE 6: Importance of Instruction and Assessment Activities.................... 73

TABLE 7: Knowledge the Reading Mentor Teacher Performed Reading First

Administration Activities....................................................... 80

TABLE 8: Knowledge the Reading Mentor Teacher Performed Professional

Development

Activities.............................................................. 83

TABLE 9: Knowledge the Reading Mentor Teacher Performed Instruction and

Assessment Activities.................................................... 86

\section{FIGURES}

FIGURE 1: Comparison of Reading First Administration Activities: Importance and

Knowledge of Performance.............................................. 90

FIGURE 2: Comparison of Professional Development Activities: Importance and

Knowledge of Performance............................................. 92

FIGURE 3: Comparison of Instruction and Assessment Activities: Importance and

Knowledge of Performance............................................... 95 


\section{CHAPTER I: INTRODUCTION AND STATEMENT OF THE PROBLEM}

\section{Introduction}

Reading First is a federally supported initiative which has provided a significant amount of funding to states with the goal of improving reading instruction to ensure all children become successful readers. Substantial resources have been allocated at state and local levels for the purpose of targeting the country's most impoverished schools with the largest percentage of struggling readers.

The National Reading Panel, appointed by the United States Department of Health and Human Services (2000), strongly recommended attention to every primary level classroom to ensure quality instruction across a school's primary grades. This recommendation became the emphasis of the Reading First program which stressed the importance of sustained professional development to improve reading instruction and student achievement. Guidance for the Reading First Program specifically mentions coaching as an important component of the initiative which must be considered as essential in developing high-quality professional development (United States Department of Education, 2002). West Virginia requires the placement of a "reading mentor teacher" (synonymous term for reading coach) in each participating Reading First school. The primary responsibility of the Reading First coach is to provide technical assistance to every K-3 reading teacher for the purpose of improving reading instruction (West Virginia Department of Education, 2002).

Each school accepting Reading First funding must provide 120 minutes of reading instruction per day and include instruction which addresses the components of reading (i.e., phonemic awareness, phonics, vocabulary, fluency, and comprehension). Moreover, the program includes the utilization of on-going formative assessment used to identify student deficiencies 
and drive instruction. Once individual deficiencies are identified, struggling students receive small group or individual intervention.

Reading First follows several national attempts to increase student reading success. This was due largely to a growing national concern regarding the substantial number of school-age children arising from all social classes struggling with significant difficulties in learning to read (Snow, Burns, \& Griffin, 1998). By the mid-1900s the United States Department of Education had spent more than $\$ 8$ billion dollars annually to support 14 national literacy programs with minimal effect on student reading achievement (Olson, 1997).

In 1998 the Reading Excellence Act provided a significant amount of funding to support the improvement of reading instruction for academically at-risk children from low socioeconomic families. The act focused on improving teacher instructional practices at the most critical period for children - during the primary grades. All states were eligible to apply for three year competitive grants to support the improvement of reading instruction in districts and schools (United States Department of Education, 1999).

In 2008 Congress drastically reduced Reading First funding largely due to concern regarding program conflicts-of-interest and bias from the federal administrative level. Further, the most recent budget did not include an appropriation to continue to support the program. The elimination of Reading First funding will undoubtedly affect the major components of the initiative including the reading coach position. The employment of a reading coach is the most costly expenditure in a school's Reading First budget. State and local education agencies (LEAs) will not likely be able to provide the funding necessary to continue funding these coaching positions. Therefore, a study pertaining to the State's reading coach role will provide valuable 
information regarding whether the reading coach role is a viable option for future reading programs at national, state and local levels.

Chapter one provides the framework for this study to include the research justification, the study's three research questions, and an overview of the study design. This chapter also includes a definition of terms relevant to the study and a description of the organization of the document.

Research Justification

The role of the public school administrator has changed drastically within the last few decades placing a multitude of responsibilities upon public school principals. However, no leader can efficiently accomplish the tasks of the leadership role alone (Leithwood, Louis, Anderson, \& Wahlstorm, 2004). Highly successful leaders develop and actively seek leadership contributions from others within the organization. One alternative to addressing this issue is the consideration of distributed leadership whereas others within the school assume leadership roles.

Coaching, a promising example of distributed leadership, provides sustained support by focusing on building collective leadership and continuous improvement of teacher instructional capacity and student learning. Moreover, coaching appears promising since its purpose is designed to blend effective professional development with school-specific content and climate needs (Barr, Simmons, \& Zarrow, 2003a).

West Virginia's Reading First program requires the placement of a reading coach in every school implementing the initiative. The intention of Reading First, officially known as Title I, Part B of the No Child Left Behind Act of 2001, is to provide support to primary teachers for the purpose of ensuring that children become proficient readers. The state Reading First 
requirement to provide support to K-3 teachers through the assignment of a coaching position provides a prime situation for study of the state's Reading First coaching position.

This study will focus on three areas: 1) the perceptions of Reading First K-3 reading teachers working in Title I Distinguished Schools regarding the importance of reading coach activities, 2) the perceptions of Reading First K-3 reading teachers working in Title I Distinguished Schools regarding their knowledge these activities are performed by reading coaches, and 3) whether differences exist between the reading coach activities perceived by K-3 teachers as important to improving reading instruction and the activities performed by reading coaches.

The primary responsibility of a Reading First coach is to provide sustained technical assistance to every primary level reading teacher within the school to improve instruction and student achievement. The particular activities of the reading coach have been identified based on an extensive review of the literature and a thorough examination of the State Reading First job description.

Recently, Congress made the decision not to continue to fund Reading First beginning with the 2009-2010 school year. Since the program is a costly endeavor, West Virginia is also unlikely to allocate funding to maintain the program. Without a considerable amount of continued funding, the program's coaching role will potentially vanish. Therefore, the findings from this study will provide valuable information regarding whether the coaching role is a viable option for future reading programs at national, state, and local levels.

\section{Statement of Purpose and Research Questions}

The purpose of this study is to examine the importance of reading coach activities in improving reading instruction in Title I Distinguished Schools as perceived by K-3 reading 
teachers. In addition, the study will serve to investigate whether differences exist between the reading coach activities perceived by K-3 teachers as important to improving reading instruction and those activities performed by reading coaches. The research will serve to offer insight to educational leaders regarding how teachers perceive the role of a relatively new educational position - a reading coach.

Similar to a dissertation completed by Christy (2007), a doctoral student at the University of Virginia, this study will consider the criteria involved in defining a Title I Distinguished School. The National Association of State Title I Directors (NASTID) authorizes states to recognize schools as Title I Distinguished Schools. All states have a unique accountability system; therefore, each state has some flexibility in determining the criteria of a Title I Distinguished School (National Association of State Title I Directors, 2008). A West Virginia Title I Distinguished School must:

- be in operation as a Title I school for at least three or more consecutive years,

- have full West Virginia accreditation status, and

- have made AYP separately in reading and mathematics for three or more consecutive years (West Virginia Department of Education, 2008).

This study will focus on three research questions:

1) How do K-3 reading teachers in Title I Distinguished Schools perceive the importance of the activities of reading coaches in the areas of: Reading First administration, professional development, and instruction and assessment in improving reading instruction? 
2) What do reading coaches do in the areas of: Reading First administration, professional development, and instruction and assessment, as perceived by K-3 reading teachers in Reading First Title I Distinguished Schools?

3) What differences exist between the reading coach activities perceived by K-3 teachers as important to improving reading instruction and those activities performed by reading coaches?

\section{Research Design}

Survey research was used to support the study's collection of data pertaining to K-3 teacher perceptions regarding the importance of reading coach activities in improving reading instruction and to identify whether the teachers were knowledgeable these activities were being performed by reading coaches. The study population included all Reading First K-3 teachers for a total population of 160 teachers working in 21 Title I Distinguished Reading First Schools located in 14 LEAs throughout West Virginia. An electronic, web-based, self-reporting survey, developed using Survey Monkey, was used to collect data. The survey instrument was developed based on coaching research and the specific job responsibilities of the state's Reading First coach. The instrument was developed using a four stage process to ensure validity and reliability. Three types of information were collected utilizing the survey instrument: 1) demographic data, 2) teacher perceptions pertaining to the activities of reading coaches in improving reading instruction, and 3) teacher perceptions regarding knowledge the activities were performed by reading coaches. The demographic data consisted of three questions (i.e., the number of years of classroom teaching experience, the average number of hours per week the teacher spent working with the school's Reading First coach, and whether the school employed a full or part time reading coach) which were analyzed and presented as descriptive information. 
K-3 teachers also responded according to their perception regarding listed reading coaching activities in improving reading instruction. Responses were based on a rating scale with a 1 representing low importance through a 5 representing high importance. Finally, the teachers responded according to their perception regarding whether they had knowledge the reading coach performed each of the identical reading coach activities. Participants were requested to indicate either "yes, knowledge the reading coach performed the activity" or "no, no knowledge the reading coach performed the activity".

The survey, developed using Survey Monkey, was disseminated and collected over a four week period to both encourage participation and discourage procrastination. Data collected from Survey Monkey was tabulated using Microsoft Excel and participant responses were recorded using number code references or according to the rating scale. Descriptive (i.e., frequencies, means and standard deviations) and inferential (analysis of variance) statistics were utilized to address the 3 research questions. When significant differences of the components were determined through the analysis of variance it became necessary to conduct a multiple comparison test (i.e., Tukey Test) to identify where the differences existed. Results were displayed in tabular and graphic form along with a description of the study's conclusions.

\section{Definition of Terms}

No Child Left Behind Act of 2001 (NCLB): Signed into law on January 8, 2002, this act is a revision to the Elementary and Secondary Act of 1964. Title I, Part B officially authorizes the Reading First program. The Guidance for the Reading First Program explicitly states the importance of the program's reading coach role, "Adequate time must be available for teachers to learn new concepts and to practice what they have learned. Coaches, mentors, peers and 
outside experts provide feedback as new concepts are put into practice” (United States Department of Education, 2002, p. 7).

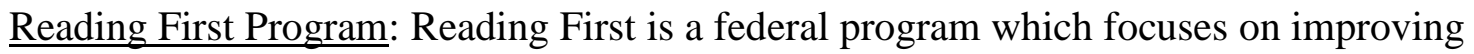
reading instruction for teachers of K-3 students to ensure all children can read at or above grade level by the end of third grade. Emphasis is placed on providing reading teachers in grades K-3 with intensive, sustained, research-based professional development opportunities in reading instruction and assessment practices. Reading First is a requirement of the No Child Left Behind Act of 2001 as outlined in Title I, Part B of the legislation.

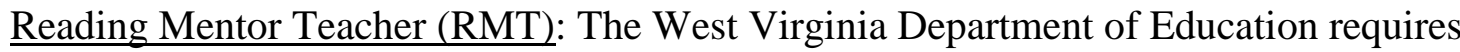
each school implementing a Reading First program to employ a reading coach which is termed a "reading mentor teacher" in West Virginia. The purpose of this role is to assist with program implementation and provide embedded professional development opportunities to every K-3 reading teacher (e.g., classroom, special education, Title I, interventionists, speech teachers) throughout the school year for the duration of the grant (West Virginia Department of Education, 2002).

Title I Distinguished School: The National Association of State Title I Directors authorizes states to recognize Title I schools as distinguished based on flexible accountability criteria developed by each state. By definition, a West Virginia Title I Distinguished School must: 1) be in operation as a Title I school for at least three or more consecutive years, 2) have full state accreditation status, and 3) meet AYP in reading and mathematics for three or more consecutive years (West Virginia Department of Education, 2008).

Title I Schools: Annual federal financial assistance which is provided to schools with high percentages of poverty for the purpose of providing supplemental resources (e.g., funding to 
support additional reading specialists, professional development and parental involvement opportunities) to assist at-risk students in meeting state standards - especially in reading and mathematics. LEAs target Title I funds to public schools with the highest percentages of children from low-income families based on student free or reduced meals.

Organization of Document

This document is divided into five chapters beginning with the study's introduction and research justification in Chapter 1. A thorough review of the literature is described in Chapter 2 to include: the Reading First program from a national and state perspective; the intended role and duties of a Reading First coach; a history of the initiative; and concerns and criticisms of Reading First. Further, the research review includes a review of several research topics to support the study's rationale: Reading First research; leadership; distributed leadership, and instructional coaching. Chapter 3 provides a detailed description of the study's research design including methods regarding the study's procedures, data collection and analysis. Chapter 4 involves a description of the research data and interpretation. And finally, Chapter 5 presents a study summary, the major conclusion, discussion, and recommendations based on the study's findings. 


\section{CHAPTER II: REVIEW OF THE LITERATURE}

Nearly $100 \%$ of all nationally funded Reading First schools include a reading coach position (United States Department of Education, 2006). Such a position, labeled a reading mentor teacher (RMT) in West Virginia's Reading First schools, provides sustained support to K-3 reading teachers to effectively implement the program's goals. In particular, the RMT provides on-going technical assistance to every primary level reading teacher within the school to assist with the improvement of reading instruction. In many schools, principals lack adequate time and expertise to effectively work with every primary reading teacher for improvement purposes. Therefore, the addition of a RMT with the expertise and time to support teachers as a respected peer in improving instructional strategies is intended to provide teacher support to ensure all children are able to read on or above grade level upon completion of the primary grades.

The intent of the literature review section is to provide a description of the Reading First program from both the national and state levels and a thorough review of the research pertaining to the topics concerned with this study. Namely, the review begins with a depiction of Reading First including the role of the coaching position, a history of the program, and program concerns and criticisms. The review culminates with research concerning the Reading First program, leadership, distributed leadership, and coaching.

Reading First: What is Reading First?

\section{Program Purpose}

Reading First is a federally funded initiative which focuses on incorporating proven methods of early reading instruction into classrooms throughout the country. Title I, Part B of NCLB authorized the Reading First program, a federal initiative designed to ensure all children 
can read at or above grade level by the end of third grade. The purpose of the initiative was predicated on scientifically research-based findings that high quality reading instruction, focused upon the primary grades, significantly reduces the number of children experiencing reading difficulties in later years. Substantial resources allocated at state and local levels were intended to ensure that kindergarten through third grade teachers incorporate research-based reading programs, strategies, and materials. In addition, the program was intended to increase access to quality professional development for all K-3 reading teachers including special education, Title I and additional reading interventionists. Reading First places a third emphasis on the utilization of assessments to monitor student progress and for early identification of reading disabilities. Such assessments assist teachers to screen for, identify, and overcome barriers impeding a student's ability to read at or above grade level (United States Department of Education, 2006). The Reading First coach is an important component to the program since their primary purpose is to provide sustained technical assistance to every K-3 reading teacher to support the improvement of reading instruction.

\section{Federal Allocation of Funding to States}

In 2002, an initial $\$ 900$ million dollars was appropriated by Congress to support the national Reading First program. Congress continued to increase the amount of funding for the program through fiscal year 2007, with the exception of a slight decrease in 2006, for a total program appropriation of more than $\$ 6$ billion dollars (United States Department of Education, 2007). However, largely due to Congressional concern regarding program conflicts-of-interest and bias from the federal administrative level, Reading First funding was slashed drastically from more than $\$ 1$ billion in 2007 to $\$ 393$ million in 2008 (Brownstein, 2008). Even more disturbing was news regarding the Congressional decision in early spring of 2008 to eliminate 
Reading First from the 2009 federal budget. Two issues were referenced as the culprit: 1) issues surrounding the release of a federal investigative report citing federal administrative mismanagement of the program, and 2) evidence of a mixed national Reading First evaluation interim report released in mid-2006. The program was temporarily kept alive through a continuing resolution of the 2009 federal education budget which granted the program a sixmonth reprieve in the fall of 2008, "flat-funding the grants at their \$393 million FY 2008 levels" (No Child Left Behind Compliance Insider, 2008). However, Congress did not include Reading First funding in the most recently approved national budget.

Since the beginning of the program, the Congressional intent of Reading First has been to generate a national impact on reading instruction and student achievement. By April 2006, all 50 states and other jurisdictions (e.g., District of Columbia, Bureau of Indian Affairs) had received federal approval to implement a state designed Reading First plan. According to the United States Department of Education (2006), the initial number of sub grantee awards increased from 40 LEAs during the 2001-2002 school year to 1,563 LEAs during the 2004-2005 school year. Subsequently, the number of schools participating in the initiative increased from 193 schools during the 2001-2002 school year to 5,431 schools during the 2004-2005 school year.

Receipt of program funding was dependent upon federal approval of a Reading First plan submitted by each state. Similar to the intent of Title I (Part A) basic funding Reading First funding provided supplemental resources for the purpose of increasing the academic achievement of economically disadvantaged children. Upon state plan approval, funding was appropriated based on the state's proportion of school-aged children from families with an income below the poverty level. State grants were issued for a six year period subject to 
Congressional appropriation and upon submission and review of mandated state progress reports (United States Department of Education, 2002).

Once allocated to states, $80 \%$ of funding was awarded through a competitive sub grant process to eligible LEAs. Remaining funds were reserved by states to provide LEA technical assistance and for state administration and program reporting purposes (No Child Left Behind Act of 2001, 2002). Although the LEA is fiscally responsible for oversight and management of Reading First funding, a sub grant is earmarked to support the implementation of the initiative at a specific school(s) within each LEA.

LEAs are considered eligible for funding based on need provided the district meets both of two criteria. First, the LEA must contain the highest percentage of K-3 children reading below grade level (as determined by state standardized assessment). In addition, the LEA must have a significant percentage of Title I schools identified for improvement. Moreover, a stipulation allows eligibility to districts with the highest percentage of children in poverty as compared to other districts within the state (No Child Left Behind Act of 2001, 2002).

According to the United States Department of Education (2002), sub grants for Reading First were required to be issued in an amount of sufficient size and scope (i.e., amount of annual grant funding per school and amount of time allotted for implementation) to encourage a significant impact on improving reading instructional practices. State funding was determined based upon the proportion of school-aged children in poverty and each state was required to justify a reasonable number of LEAs and schools to receive program funding.

\section{Intended Role of the Reading First Coach}

Reading First placed an emphasis upon the inclusion of sustained, high-quality professional development activities for K-3 reading teachers and principals aimed toward both 
improving reading instruction and increasing student reading achievement. Guidance for the Reading First Program specifically mentions the importance of professional development activities: "Research has shown that teachers who participate in well-designed professional development activities get better results from students" (United States Department of Education, 2002, p. 7).

Reading First guidance also specifically mentions coaching "feedback from coaches, mentors, and outside experts" as one of six essential considerations in developing high-quality professional development (United States Department of Education, 2002, p. 7). Further, the guidance states, "Adequate time must be available for teachers to learn new concepts and to practice what they have learned. Coaches, mentors, peers, and outside experts provide feedback as new concepts are put into practice" (United States Department of Education, 2002, p.7). While federal legislation does not specifically mandate a coaching position in Reading First schools, West Virginia does require each participating school to hire a Reading First coach. Despite the lack of an exclusive mandate in the federal legislation, nearly all states require Reading First schools to employ a reading coach. In fact, principals in 98\% of Reading First schools have a person designated as a reading mentor coach (United States Department of Education, 2006).

The foremost role of the reading coach is to assist teachers in developing the skills needed to effectively implement reading instruction. According to the West Virginia Reading First Mentor Teacher Model Job Description, “The Reading First Mentor Teacher's primary responsibility will be to provide technical assistance in the Reading First school site to every K-3 teacher during the school day and throughout the school year for the duration of the Reading First grant" (West Virginia Department of Education, 2002, p. 20). Each RMT is required to 
attend on-going and substantial professional development both with and without the school's K-3 reading teachers. The main duties of each school's RMT include: individually coaching regular and special education teachers, meeting quarterly with the principal and central office program director to monitor program effectiveness, assisting teachers needing assistance in implementing content, skills and strategies to promote successful student readers, observing and providing teacher feedback, modeling effective classroom instruction, assisting staff in selecting appropriate instructional materials, strategies, and programs, coordinating sustained professional development within the school, and serving as the school's liaison for assessment coordination (West Virginia Department of Education, 2002, p. 1). A specific listing of the roles and responsibilities of the RMT is included in the West Virginia Reading First Mentor Teacher Model Job Description located in Appendix A.

$$
\text { History of the Initiative }
$$

\section{History of Reading Instruction}

The Reading First program follows a history of national efforts focusing on the issue of improving opportunities for children to become proficient readers. An examination of the history of American reading instruction provides insight regarding the reasoning behind the program's basic elements which target research-based early reading instruction to reach the nation's most at-risk students.

It is no secret that the field of reading education has historically been marked by controversies and disagreements. For decades, "reading wars" have existed as a form of debate regarding reading research as scholars have argued regarding the most effective method of teaching children to read (Snow, et al., 1998). Some researchers believed (and continue to believe) that reading instruction should focus on a phonemic approach, while others contend a 
whole language or "look and say" approach is most effective. Phonics instruction focuses on the sounds of speech as represented by letters and spelling. In contrast, the "whole language" instructional method emphasizes gaining meaning through text and the teaching of reading, writing, and other subjects simultaneously (Reyhner, 2003).

According to Sweeney (1996), an emphasis on phonics once made America the most literate nation on earth from colonial times until the latter part of the $19^{\text {th }}$ century. Moreover, illiteracy was almost unknown at the turn of the century among those who attended school. The emphasis on drill and repetition led to the rejection of phonics as the reigning instructional practice by several influential educational philosophers. In the mid-1800s, Horace Mann, Massachusetts' Secretary of Education, heavily influenced the "look and say" (e.g., Dick and Jane, Spot and Puff memorization technique) instructional method focusing on teaching children to read by association of words and pictures. John Dewey of Teachers College at Columbia University, nationally renowned as the Father of Progressive Education, was another chief proponent of this technique. By the early $20^{\text {th }}$ century, the "look and say" or "whole word" theory of reading instruction broadened as the primary method taught in the nation's teacher preparation schools.

In the 1960s, Ken Goodwin, Frank Smith and other "Deweyites" promoted a reading philosophy labeled "whole language" which also evaded phonics. These theorists believed that children are taught to read by listening, repetition of reading, and by using context, pictures and the beginning and ending letter sounds of words to deduce meaning. For over three decades whole language has dominated the curricula of each of the 50 states in the United States and has been the central principle of reading instruction in virtually all American teacher preparation programs (Sweeney, 1996). 


\section{Reading as a National Priority}

By the mid-1900s there was growing national concern regarding the substantial numbers of school-age children arising from all social classes struggling with significant difficulties in learning to read. In addition, the expansion of a global and competitive economy began to increase the demand for higher levels of literacy, creating more grievous consequences for persons lacking adequate literacy skills. Reading has long been considered an essential skill affecting success in our society and is imperative for social and economic advancement (Snow, et al., 1998).

In 1997, Congress requested the National Institute of Child Health and Human Development to work in consultation with the United States Department of Education to convene a national panel for the purpose of assessing the status of research-based knowledge related to the effectiveness of various reading instructional approaches. The panel was comprised of 14 individuals proficient as reading researchers, representatives from colleges of education, reading teachers, administrators, and parents. The result of the panel's work was the release of the 1998 National Reading Report (United States Department of Health and Human Services, 2000).

The panel's central recommendation within the report focused on the importance of quality instruction to prevent reading difficulties. Specifically, the committee strongly recommended attention in every primary grade classroom to the full array of early reading accomplishments: the alphabetic principle, reading sight words, reading words by mapping speech sounds to parts of words, mastery of fluency, and comprehension. This recommendation emphasized the importance of ensuring quality instruction across a school's primary grades. For example, a child's progress may be impeded for a year when spent with a teacher practicing low quality instructional strategies, but the same child can overcome the setback when exposed to 
more adequate teaching in subsequent years (United States Department of Health and Human Services, 2000). The work of Slavin and Madden (1994) highly supported the importance of an emphasis on early reading instruction considering that academic success can be predicted with reasonable accuracy by identifying a child's reading level at the end of third grade.

The committee also utilized demographic research conducted as early as the 1960s to stress the importance of the urgency to address the needs of the nation's most at-risk and economically disadvantaged readers. For example, researchers such as Coleman, Campbell, Hobson, McPartland, Mood, Weinfeld, and York (1966) described pronounced differences in literacy achievement among children due to socio-economic status. Such differences defined an educational deficit of children from economically disadvantaged families which is present at school entry and increases with each year the child stays in school. More recently, between 1980 and 1995, the National Assessment of Education Progress (NAEP) provided evidence of continued accumulation of differences in reading achievement when considering socio-economic status (National Assessment of Educational Progress, 1981 \& 1995).

\section{Reading Excellence Act}

According to Olson (1997), by the mid-1990s the United States Department of Education had spent more than $\$ 8$ billion dollars annually to support 14 national literacy programs. In addition, since the inception of the Title I program in 1965, $\$ 100$ billion dollars had been spent to aid economically disadvantaged children largely through funding focused on training teachers to provide supplemental reading instructional services. Despite the vast amounts allocated to promote reading literacy, studies show minimal effect on student reading achievement (Olson, 1997). An analysis of the NAEP report of 1994 clearly indicated nearly $40 \%$ of the nation's fourth graders fell short of being able to read at the basic level. The report further revealed that 
more than $60 \%$ of African-American and Hispanic fourth graders were unable to read at grade level (United States Department of Education, 1999).

On October 21, 1998, in a bold response targeting the challenge to assist all children to become proficient readers, President Clinton signed into legislation the Reading Excellence Act. The act, an amendment of the Elementary and Secondary Act of 1965, provided \$260 million dollars for the addition of a specialized reading component. This reading component was added to provide support for academically at-risk children from low socio-economic families with the readiness skills needed for every child to read on level by the end of grade three. The key elements of the act supported professional development, extended school day tutoring, and family literacy by focusing on improving teacher instructional practices at the most critical period for children - during the primary grades. For the first time in national history, the Reading Excellence Act required states accepting funding to incorporate K-3 reading instructional programs supported with scientific research (Olson, 1997). The act allowed all state education agencies to apply for three year competitive grants, $85 \%$ of which supported local reading improvement sub grants to LEAs and the remainder to provide state technical assistance to local grantees (United States Department of Education, 1999).

Concerns and Criticisms of Reading First

\section{Program Criticism and Controversy}

Reading First has been plagued with criticism and controversy from the inception of the program. The credibility of the program has been consistently under question by a variety of followers and dogged by accusations of impropriety (Feller, 2006). Ohanian (2005) described criticisms of the program as supporting "an over-prescriptiveness, a lack of transparency, and conflicts of interest between program consultants and commercial interests" (p. 2). 
An examination of the literature addressing the criticism and controversy surrounding the Reading First program resulted in the categorization of five topics of concern.

1) Continuation of the reading wars: To some extent the controversies of Reading First reflected the older debate over reading instruction - pitting phonics advocates against whole language practitioners (Grunwald, 2006). Early in the program's federal application review process, speculation grew regarding favoritism of phonics instruction as opposed to whole language instruction by the program's federal administration (Berger, 2006). Claims from various state education departments across the nation, reading researchers, and reading curriculum and instruction developers supported the belief that Reading First funding was steered by the program's federal administration toward the hounding of state and local district administrators to choose phonics-based reading programs, professional development, and assessment methods.

2) Federal mandates imposed upon state and local education: Local control of education is an American tradition and has long been promoted to encourage common culture and equal opportunity. The Reading First federal administration was accused of being both self-serving and encouraging one-size-fits-all solutions by micro-managing state decision making in a manner that violates federal legislation. NCLB (2002) clearly communicates the prohibition of the authorization of officers or individuals employed by the federal government to mandate, direct, review, or control a state or LEA. Moreover, the same stipulations apply in regard to a school's instructional content, curriculum, and related activities. 
3) Professional decision-making versus prescriptive curriculum and instruction: Stager (2006) described the Reading First program as "reducing teachers to scriptreading robots and reading to an onerous task" (p. 1). Others supported this concern proclaiming the right of classroom teachers to choose reading programs and instructional practices (Berger, 2006). As early as 2002, the National Council of Teachers of English (NCTE) claimed that states could only obtain federal funding upon committing to professional development based upon the view of reading instruction embodied in the Reading First initiative. Furthermore, the program encouraged the replacement of professional judgment and decision making with packaged materials marketed by corporate publishers (National Council of Teachers of English, 2002).

4) Limitations of the recognition of scientifically research-based reading research: There is support within the literature to suggest that the Reading First program has placed limitations on reading instructional programs, professional development, and instructional methods which are adequately supported with scientific research. Grunwald (2006) accused federal officials and influential contractors of strong-arming states and districts into adopting a limited group of unproven textbooks and reading programs with little scientific rigor and virtually no supportive peer-reviewed research. The United States Department of Education was also charged with promoting programs endorsed by a national reading panel which could describe virtually any reading program rather than accentuating the promotion of programs advocating scientifically based research.

5) A tainted state application review process: Almost immediately upon review of 
state applications, the federal government was accused of circumventing legislative requirements in relation to the selection of panel members and the actual application review process. Berger (2006) referred to the panel selection process as a "bonanza" in which half a dozen experts set guidelines favoring the selection by schools of textbooks and assessments authored by numerous Reading First panel members. In addition, specific reading textbook publishers, program developers, and assessment developers whose products were selected by various Reading First schools across the country were appointed as members of the panel (Berger, 2006). As early as the fall of 2004, speculation grew regarding favoritism of other components of the application review process such as preference by program administrators and panelists toward the teaching of reading according to phonics instruction versus whole language professional development programs and assessment methods (Grunwald, 2006).

\section{Federal Investigation of Reading First}

By the spring of 2005, wide-ranging complaints resulted in an initiation by the United States Department of Education's (ED’s) Office of Inspector General to investigate the Reading First program. In addition to aforementioned concerns, reports began to surface regarding the evidence of financial gain by some and financial loss by others plagued by Reading First administrative favoritism. While many developers and retailers of educational programs or materials were frozen from receiving federal Reading First dollars and saw business plummet, others benefited in an opposite, profitable manner. An example is the business Voyager Passport which was valued at approximately $\$ 5$ million prior to Reading First and was sold afterward for \$380 million. This particular company was also accused of making major Republican 
contributions and employing the former secretary of education and another ED colleague who was a major contributor in the design of the Reading First program (Grunwald, 2006).

Representatives from the Inspector General's Office conducted an investigation of the Reading First program beginning in late September of 2005 through July of 2006. Reading First department and general counsel staff were interviewed and program guidance and other relevant documentation were reviewed. Twelve Reading First state applications and completed review forms for each state were examined. In addition, officials from 10 of the states in the sample were interviewed. Finally, extensive interviews and an analysis of documentation relating to the nomination of the expert panel were conducted.

In the final report issued in September of 2006, the Office of the Inspector General concluded that ED officials failed to maintain a controlled environment exemplifying management integrity and accountability, obscured the program's statutory requirements, inappropriately intervened to influence reading programs implemented by state and local agencies, and took actions calling into question a violation of the prohibitions included in the Department of Education Organization Act. This act prohibits ED officials from exercising any direction, supervision, or control over the curriculum or instructional program of any educational institution, school, or school system (Office of Inspector General, 2006).

Despite the lengthy investigation revealing numerous concerns, the program remained strongly popular among teachers and principals and has resulted in noticeable gains on several state and national tests (Title I Monitor, 2008). However, the timing of the release of the interim report occurred just prior to the annual meeting of the appropriations committees of the Senate and House to determine future funding for a program in which many believed was "politically toxic” (Title I Monitor, 2008, p. 4). 


\section{The Fate of Reading First}

Congress made a bold move by reducing the Reading First funding allocation by $61 \%$, from \$1 billion in 2007 to \$393 million in 2008 (Brownstein, 2008). Congressional approval remained frozen at the 2008 level, pending the decision in the fall of 2008 to grant the program a six month reprieve allowing time for a thorough review of the final national Reading First evaluation report (No Child Left Behind Compliance Insider, 2008). Despite the reprieve, Congress chose not to include Reading First funding in the most recently approved budget.

The massive cut and the elimination of Reading First funding will especially affect the major components of the initiative. Personnel costs associated with the employment of the program's reading coaching position are the most costly of expenditures within a school's Reading First budget. State and local education officials are left to make major decisions regarding the continuation of a reading coach position in the program's current schools. While some LEAs have chosen to locally support reading coaches in various capacities, others struggle financially and will find it difficult, if not impossible, to fund a position often considered supplementary to teaching positions in subject areas required by state policy. Therefore, the effect of the current and substantial budget loss must be considered in relation to the effectiveness as well as the continuation of the reading coach position.

\section{Reading First in West Virginia}

\section{WV Reading First Funding and Program Sites}

In mid-2004, West Virginia received an initial allocation of \$6.3 million dollars to support the state's Reading First program. According to the United States Department of Education (2007), the state received additional funding for each subsequent year for a total appropriation of \$42.4 million dollars. 
Initial funding supported the incorporation of a Reading First program into 36 schools located throughout the state within 21 eligible LEAs. These 36 schools initiated the program in the summer of 2004 marking the fall 2009-2010 school year as the sixth year of implementation.

In the spring of 2006, West Virginia expanded Reading First to support six additional schools resulting in a total of 42 schools within 25 eligible LEAs. These schools initiated the program in the summer of 2006 marking the fall 2009-2010 school year as the forth year of implementation. A list of West Virginia Reading First Schools is included in Appendix B. Note that actual school names have been amended to fictional names for the intention of preserving anonymity.

Each school implementing a Reading First program received a significant amount of funding over a three year period (i.e., in West Virginia that amount was approximately $\$ 200,000$ per each of the three years and is based on the number of school-aged children in poverty residing in each school's attendance area). In order to maximize student achievement efforts and to ensure each school received a grant of sufficient size and scope, LEAs were encouraged to concentrate funding in one to three schools (West Virginia Department of Education, 2002). At the end of three years, schools successful in raising student achievement, as determined by reported and monitored measureable data, received additional funding for program continuation. State Reading First Professional Development Requirements

Reading First professional development opportunities were delivered through a variety of methods with the majority of experiences led by West Virginia Reading Cadre members. Cadre members are comprised primarily of classroom teachers although some members are administrators. The cadre participated in extensive and sustained professional development 
experiences designed to increase the capacity of state administration and to support reading instructional improvement throughout the state.

LEAs are assigned a state level Reading First designee (i.e., Department personnel or a reading cadre member) to continuously provide technical assistance with the development of a professional development plan designed to address the particular needs of each school. In addition, schools receive state guidance to assure the use of a variety of professional development formats (i.e., graduate courses, classroom modeling and coaching, online and onsite technology, book or study groups, research studies, and reading academies).

For decades, teachers in West Virginia have been required to obtain 18 hours of "continuing education" annually. These hours occurred during the school day when students were excused from instruction. One of the most prevalent changes for educators implementing Reading First was the state requirement of a minimum of 100 hours of reading professional development for each participating K-3 teacher (e.g., classroom, special education, Title I, interventionists, speech therapists) rather than the expectation of 18 continuing education credits. Such a mandate has forced the programs' principals and teachers to change their mindset regarding the calculation of annual professional development opportunities. Traditionally, educators have calculated professional development hours exclusively based upon onsite training experiences. However, the state's Reading First educators include all hours pertaining to a variety of professional development experiences (e.g., in-classroom modeling of effective instructional techniques, observing and providing constructive feedback to teachers, participating in lesson videotaping).

State Reading First Coaching Role and Certification Mandates

West Virginia requires eligible LEAs to select a practicing teacher to serve as a Reading 
First reading coach or RMT for each participating school. Within the state's Reading First grant application, the West Virginia Department of Education (2002) describes this position as one of three key players forming the instructional leadership team for each LEA. Additional members of the instructional team included the LEA project director and Reading First principals.

Stressing the importance of the teacher coaching role, the state required each LEA to incorporate a budget provision supporting a RMT in each Reading First school. Furthermore, the West Virginia Department of Education (2002) mandated that a minimum of at least $25 \%$ of the LEAs Reading First budget must reflect the inclusion of the coaching provision. The majority of the state's RMTs are employed on a full time basis to perform coaching duties, although some schools with small student enrollments employ one RMT to work part time with one school or full time transitioning between two schools.

The primary responsibility of each school's RMT was to provide technical assistance to every K-3 reading teacher during the school day and throughout the school year for the duration of the grant period (West Virginia Department of Education, 2002). The West Virginia Department of Education (2002) defines the duties and responsibilities of the RMT as follows:

1) attend 26 days of coaching professional development over a two year period (in addition to the 100 hours of training attended by all teachers).

2) model effective classroom instruction, observe K-3 teachers and provide constructive feedback to individual teachers.

3) coordinate and assess the daily operation of the Reading First program.

4) assist staff in selecting appropriate instructional programs, strategies, and programs.

5) attend local, state, and national professional development sessions.

6) meet at least monthly with the site principal and district program manager for 
program planning, implementation, and evaluation.

7) coordinate sustained, school-based professional development.

8) meet and plan with the school's assigned state reading liaison.

9) serve as the school liaison for assessment coordination. (p. 19)

West Virginia state policy defines the requirements for teacher certification. All teachers specifically hired to teach Title I reading must have reading certification. In addition to reading certification, the following minimum qualifications are required for consideration as a Reading First RMT:

1) a Master's degree in reading.

2) prior West Virginia Department of Education specialized training.

3) verification of scientifically based reading research expertise of reading relating to instructional programs, strategies, materials, intervention, and assessment.

4) verification of attendance and presentation of reading workshops or seminars.

5) involvement in school, district, and state level curriculum development.

6) evidence of prior effectiveness in a leadership role. (West Virginia Department of Education, 2002, p. 18)

All districts were responsible for hiring a RMT to support teachers in each Reading First school utilizing funds from the local sub grant. The job duties of the RMT included the aforementioned minimum requirements. However, the duties of some RMTs varied based upon district or school needs (e.g., RMTs may serve one school in a part time position or divide time between two schools due to low student enrollment). In an effort to ensure that each district hired RMTs according to the defined requirements and to provide consistency, the West Virginia Department of Education provided each participating district with a RMT model job description 
(West Virginia Reading First Mentor Teacher Model Job Description - see Appendix A).

WV Reading First Budget Cuts

A national Reading First budget cut of $61 \%$ from 2007 to 2008 affected every state in the nation implementing Reading First including West Virginia. The recent decision by Congress to eliminate funding to support the Reading First program beginning with the 2009-2010 school year further complicates matters. Due to the large costs associated with the employment of a RMT, there must be consideration regarding the effect of these decisions upon the continuation of the Reading First RMT position.

The cost of a Reading First mentor teacher varies depending upon teacher experience, education, and the district of employment. RMTs are paid equivalent to a classroom teacher based on West Virginia Code $§ 18 \mathrm{~A}-4-2$ (School Laws of West Virginia, 2007). According to School Laws of WV (2007), the state minimum salary for teachers is based on years of teaching experience from 0 to 35 years and educational degree from a bachelor's to a doctorate. RMTs are required to have at least a master's degree although many have additional hours beyond this requirement ranging from plus 15 to 45 or more additional graduate credits. For example, a teacher with 0 years of experience and a master's degree would cost a county school system $\$ 28,755$, while a teacher with 35 years of experience and a master's plus 45 hours would cost a county school system $\$ 48,393$. Benefits (e.g., social security, worker’s compensation, medical insurance) are approximately $\$ 20,000$ per year, thus increasing the cost of the position to a range of $\$ 48,755$ to $\$ 68,393$. Districts may also provide optional salary increases beyond the state minimum calculations in order to attract and retain educators. 


\section{Reading First Research}

\section{National Reading First Research}

Federal statute requires the ED to contract with an external organization to conduct a five year evaluation of the Reading First program. The ED contracted with Abt Associates to conduct the Reading First Implementation Evaluation. The study consisted of a sample of Reading First (i.e., 550 newly funded schools in year one of implementation, and 550 mature schools in years two or more of implementation) and 550 non-Reading First schools construed purposefully to provide a context for understanding how reading programs differ from those in schools serving similar student populations (e.g., schools offering similar programs with a poverty level of at least $40 \%$ ). The study involved the use of a variety of study methods including surveys completed by teachers, principals and reading coaches. Two separate study reports were published: an interim report (released in the summer of 2006), and a final report (released in the fall of 2008).

The key conclusion of the interim report was that "Reading First schools appear to be implementing the major elements of the program as intended by the legislation (United States Department of Education, 2006). Specific reference was made to states and districts providing adequate supports to K-3 reading teachers in the areas of reading professional development and the selection and use of assessments to inform instruction (United States Department of Education, 2006). Several major differences were derived from the data analysis when comparing schools implementing the Reading First program to non-Reading First schools. Two of these components, assessments and professional development, are most related to the duties of the reading coach which may make a difference in schools where Reading First coaches have been placed to support teacher efforts. 
The most important information provided in the final report in relation to this study is the analysis of data regarding reading coaches. According to the United States Department of Education (2008):

- Reading First schools (99\%) were significantly more likely to have a reading coach than were non-Reading First schools (57\%), and

- Reading First coaches (75\%) reported spending larger proportions of their time coaching (i.e., full time coach) than coaches in non-Reading First schools (19\%).

Researchers also found limited, but statistically significant evidence, that successive cohorts of third and fourth grade students in Reading First schools improved their reading performance over time more quickly than their counterparts in non-Reading First schools. Moreover, in comparing third and fourth grade state reading assessments, the average effect sizes across 24 states indicated that Reading First schools gained between 2 and 3 percentage points more, on average, from pre- to post- Reading First implementation than non-Reading First schools in relation to the proportion of students meeting standards on state third and fourth grade reading assessments (United States Department of Education, 2008).

The final report, resembling the interim publication, also addressed the components of assessments and professional development which are most related to the duties of the reading coach. In particular, assessment was discovered as a more integral element of reading instruction in Reading First schools than in non-Reading First schools. For example, teachers in Reading First schools were more likely than those in non-Reading First schools to rate the use of assessment results as central to their instruction for such purposes as grouping students, identifying students in need of interventions, and measuring student progress (United States Department of Education, 2008). 
Three key findings were highlighted in relation to professional development. First, a greater percentage of teachers in Reading First schools reported participating in reading-related professional development activities than teachers in non-Reading First schools. Second, teachers in Reading First schools were more likely than teachers in non-Reading First schools to report participating in professional development involving the key dimensions of reading (i.e., comprehension, phonics, and phonemic awareness). And finally, a greater proportion of teachers in Reading First schools than those in non-Reading First schools reported participating in professional development activities addressing other features of reading instruction (e.g., grouping, assessment, struggling readers) which provided new information about effective teaching strategies to utilize during reading instruction (United States Department of Education, 2008).

\section{Leadership Research}

Effective leadership is an important component in every school implementing the Reading First program since the goal of the program is to support teachers in improving classroom reading instruction to ensure that all students are successful readers. This section will first provide a historical explanation of research pertaining to educational leadership beginning with the Coleman Report from the 1960s and will continue with research related to the Effective Schools Movement, distributed leadership and instructional coaching.

\section{The Coleman Report and The Effective Schools Movement}

Nearly 30 years ago James Coleman, a prominent educational researcher, released a report examining the effectiveness of American public education. The report, known as the Coleman Report, credited the student's family background as the foremost variable for student success in school and further concluded that schools didn't make a significant difference (Lezotte, 1996). 
Ronald Edmonds, then director for the Center for Urban Studies at Harvard University, and others (e.g., Brookover, Lezotte) responded vigorously to the report's conclusions by attempting to identify schools where students from low income families were performing successfully. The intention was to prove that schools can and do make a difference. Throughout the nation, the researchers were able to identify effective schools where impoverished students were learning. In an attempt to address the reason(s) why certain schools made a difference and others did not, Edmonds, Brookover, Lezotte, and other school effectiveness researchers compared successful schools to similar schools in comparable neighborhoods where children were not learning or learning at a low level (Lezotte, 1996).

The research concluded that public schools can and do make a difference regardless of the poverty level of students. Further, researchers identified unique characteristics which are common in schools where all children are learning regardless of family background. These original "correlates" have become expanded descriptions of what works in schools since the 1980 empirical research on effective schools. For over a decade, the 1980s through the early 1990s, the language of the correlates became the language of school improvement (Taylor, 2002). Edmonds, best known as the leader of effective schools research, identified the correlates to include: 1) a clear school mission, 2) high expectations for success, 3) instructional leadership, 4) frequent monitoring of student success, 5) opportunity to learn and student time on task, 6) a safe and orderly environment, and 7) home and school relations (Lezotte, 1996).

The effective schools movement has not been without criticism. In particular, opponents have persistently contended that most of the effective schools research was conducted in large urban school districts with a large minority and economically disadvantaged student population (Lezotte \& Barcroft, 1985). Disputing this assessment, the Spencerport Central School District 
located near Rochester, New York, consisting of predominately middle class Caucasian students, engaged in the implementation of the effective schools correlates in 1982. By 1985, the school system's use of the correlates verified the model's versatility and adaptability to a variety of school settings such as social classes, ethnicity of students, and rural vs. urban setting (Lezotte \& Barcroft, 1985).

\section{Distributed Leadership and Instructional Coaching Research}

\section{Distributed Leadership Research}

Distributed leadership is defined by Elmore (2000) as "multiple sources of guidance and direction, following the contours of expertise in an organization, made coherent through common culture" (p.15). This definition was derived based on the explanation that principals are expected to embody all types of exemplary skills and characteristics (e.g., a visionary leader, an effective facilitator, a conflict mediator, a master of human relations, an instructional leader). Teaching and learning is a knowledge-intensive enterprise making the performance of these complex tasks impossible without effective distribution of the responsibility of leadership.

This section will begin with a historical perspective of distributed leadership and will conclude with reference to four selected studies. These select distributed leadership studies focus on the assignment of a teacher as a specialist whose role is to provide technical support to their teaching peers in a sustained effort to improve instruction.

Bennett, Harvey, Wise, and Woods (2003) provided a historical perspective of distributed leadership through a review of the literature up through July 2002. This meta-analysis study was the result of an extensive literature search using keywords closely related to the topic and resulted in a total of 80 citations. An examination of the literature resulted in the reference by Bennett, et al., (2003) of distributed leadership as "leadership resting on expertise rather than 
position" (p. 9). Attention was drawn to the importance of teacher leaders having access to opportunities for professional development focusing on building leadership capacity. Both assumptions closely align to the Reading First coach employed as a reading specialist. Each school's Reading First coach is required to both participate in sustained professional development opportunities and provide sustained professional development to K-3 teachers.

Leithwood and Jantzi (2000) conducted a study concerned with empirically identifying the degree to which teacher leadership can be regarded as effective. The study was based on surveys of 2,727 teachers and 9,025 students in 110 elementary and secondary schools throughout Ontario, Canada. The study concluded that leadership can be seen as the exercise of influence: as socially constructed, rather than structurally defined on the basis of one's formal position in the organization. Further, leadership is exercised when someone is recognized as a leader by others who consent to be led and not derived from formal decisions at a senior level within the organization.

Beginning in 1999 and over a five year period, Spillane (2006) conducted the Distributed Leadership Study which involved 15 schools in the Chicago vicinity having a K-5 or K-8 grade span configuration. The purpose of the study was to create an understanding of leadership as a distributed practice. A variety of methods were utilized including teacher and principal questionnaires.

Many of the schools studied included teacher leaders who supported their teaching peers by leading sustained professional development. Professional development leadership within the schools involved at least the principal, a literacy coordinator, and one or more teacher leaders working together. 
From this study Spillane (2006) found that "the execution of leadership tasks is often distributed among multiple leaders" (p. 25). An example is one of the elementary school's which targeted the use of test scores to focus instructional improvement efforts on specific individual student learning needs. Resembling a focus similar to the Reading First program, sustained professional development was provided to both a lead teacher and other pertinent teachers within the building to support the analysis of data to drive instruction. Spillane (2006) depicted this distributed leadership practice as "in between" the leaders - the leadership practice takes form in the interactions among them. Spillane (2006) concluded the study by stating "Leadership is a system of practice made up of a collection of interacting component parts in relationships of interdependence in which the group has distinct properties over and above the individuals who make it up" (p.16).

Pustejovsky, Spillane, Heaton, and Lewis, (2008) conducted the Distributed Leadership for Middle School Mathematics Education Study for the purpose of designing and validating a series of research instruments to identify leadership for mathematics in middle schools. The study focused on both formally designated and informal leaders using a variety of methods including an online social network survey.

The survey was designed to focus on middle school mathematics instruction and to investigate the sources of instructional leadership that influence teacher instructional practice. The sample included 362 teachers and administrators in 21 urban schools. Survey questions pertained to activities and opinions related to school leadership in instructional improvement, expertise in mathematics leadership and the conditions associated with each. Participants were asked to indicate the people, resources, and activities they seek out to gain information and advice related to teaching in general, mathematics, and literacy. 
Pustejovsky, et al. (2008) found that participants most frequently sought advice or information from all leadership roles on a weekly and monthly basis. While advice or information was most sought from principals on a monthly basis, the advice of math and reading specialists was most frequently sought on a weekly basis. Based on these findings, the researchers concluded that mathematics or reading specialists were sought out twice as frequently as principals.

The Math in the Middle Institute Partnership was developed at the University of Nebraska at Lincoln and funded by the National Science Foundation. The project offered a 25month masters degree program for outstanding middle-level mathematics teachers assisting them to become intellectual leaders in their schools and districts. Mirroring the Reading First coaching concept, the partnership focused on providing professional development to teacher leaders and also on seeking evidence-based findings about learning, teaching, and leadership development.

A part of the research study of the mathematics partnership was to seek expertise from Northwestern University to study the project's theoretical and diagnostic framework of distributed leadership. Pustejovsky, et al. (2006) led the research by using a web-based survey instrument originally designed for the Distributed Leadership Study for Middle School Mathematics Education study. The electronic survey was administered to all Math in the Middle associates and the entire staff of the ten middle schools where each of the teacher associates worked.

The survey instrument examined the distributed leadership perspective by capturing data regarding interactions between leaders and followers as measured from the follower's perspective. Survey participants were asked to recall interactions in seeking advice from others followed by the request to describe the role or job description of the person identified and to 
characterize the interactions in terms of the frequency of interaction as well as the influence and content matter of provided advice.

An analysis of the surveys provided evidence that the Math in the Middle teacher associates act as leaders within their schools by providing instruction related advice to colleagues. The researchers also found evidence that the Math in the Middle teacher associates draw upon and contribute to a support network defined by participation in the Math in the Middle partnership program. According to the researchers, the findings were an encouraging sign that these mathematics teacher leaders are a valuable school resource, bridging between the school organization and external sources of information and ideas. Research from many different disciplines has demonstrated that access to information from outside of an organizational boundary is beneficial for innovation and productivity. Pustejovsky, et al. (2008) concluded that by both participating in the Math in the Middle support network and providing advice to other teachers within their schools, these teacher associates spread the ideas of the program beyond their own classrooms, acting as instructional leaders within their schools.

\section{Instructional Coaching Research}

Kowal and Steiner (2007) define an instructional coach as "someone whose primary professional responsibility is to bring practices that have been studied using a variety of research methods into classrooms by working with adults rather than students" (p. 2). Coaching programs vary based on local needs, but in general, a coach's duties involve spending a significant portion of their time offering classroom modeling, supportive feedback, and conducting specific observations of individual practicing methods. Further, Kowal and Steiner (2007) have identified three broad categories of skills that an effective coach should possess including pedagogical knowledge, content expertise, and interpersonal skills. 
According to Barr, et al. (2003a), instructional coaching is grounded in research which focuses on effective professional development and professional learning communities. Instructional coaching appears promising since its purpose is designed to blend effective professional development with school-specific content and climate needs.

There are only scant coaching studies regarding how the practice of coaching influences teacher practice. However, after a thorough review of coaching research, two studies are most influential and warrant providing further detail.

The most influential coaching professional development study was conducted in New York City's Community School District 2 (Elmore, 1997). It is likely that without this study, coaching would be less of an option for schools than it is today. The results of instructional reform in this district provided a compelling example of how coaching can support improved teacher instructional practices and increased student achievement when embedded in a sustained, coherent, district effort to improve instruction.

The study involved 22,000 students within the district from very diverse racial, ethnic, and cultural backgrounds. The purpose of the study was to address system-wide school reform directed toward improving student achievement.

According to Elmore (1997), preceding attempts at system school reform were unsuccessful due to a lack of focus on the knowledge required of teachers and principals to engage in the change necessary to impact teaching and learning. The superintendent invested heavily in teacher training and searched worldwide for the best educational practices. The district leadership contracted with literacy experts brought in from New Zealand and Australia, the two English-speaking nations with the world's highest literacy rates. These coaches were hired 
specifically to coach teachers in District 2 with focus on the development of teacher knowledge of effective instructional practices.

The intense coaching effort boosted the district's literacy achievement up from $10^{\text {th }}$ to $2^{\text {nd }}$ among the 32 school districts according to state standardized testing. The study sought to provide detailed information regarding the role of school districts in aligning school reform policy to classroom practice. A key finding was that change depends on effective professional development which is based on a clear set of principles, activities, and structures (Elmore, 1997).

Another extensive examination of professional development involving coaching was conducted by Neufeld and Roper (2003). This analysis was based primarily on longitudinal, qualitative studies of coaching as a component of a professional development approach conducted in several cities including Boston, Corpus Christi, Louisville, and San Diego. In addition, beginning in 2000 and over a period of six years, these researchers conducted hundreds of in-depth interviews with coaches, teachers who work with coaches, principals, and central office administrators in an effort to learn about the design, implementation, and influence of coaching on whole school, instructionally focused reform.

Neufeld and Roper (2006) believe that coaching, in combination with other professional development strategies, is a credible way to increase a school's instructional capacity. Particularly, the researchers argued that although coaching alone does not have the capacity to lead such a result, there is growing evidence that coaching can improve several areas of instruction by producing four influential outcomes. First, improved school-based professional development better addresses the learning needs of teachers based on student derived data. Second, teacher learning carries over into classroom practice as the coach consistently assists teachers in the implementation of learned strategies. Third, the placement of a coach assists with 
building the willingness among teachers to share instructional practices with one another and to seek learning opportunities from both peers and coaches. And finally, an instructional coach helps to facilitate the development of a school culture in which instruction is the focus of discussion and where teachers reflect on data to drive instructional improvement. Summary of the Literature Review

The literature review proved insightful in examining Reading First and the program's reading coach role. Beginning in 2002 and throughout the next several years, a substantial amount of federal resources have been allocated at both the state and local levels to support reading instruction where it can make the biggest difference - at the primary levels. Funding for the program was recently severed from the federal budget due largely to Congressional concern regarding program conflicts-of-interest and bias from the federal administrative level. This action will have a devastating impact on the continued role of the Reading First coach.

A history of national attention focusing on improving reading instruction and achievement precedes the Reading First program. This was initiated with the reading wars and continued through the more recent efforts such as the Effective Schools Movement and the Reading Excellence Act which stressed an emphasis on the utilization of research-based reading instructional strategies.

Issues pertinent to the reading coach role were examined in this section including research focusing on: the Reading First national evaluation, leadership, distributed leadership, and instructional coaching. The five year national Reading First evaluation found major differences to exist between Reading First and non-Reading First schools. Two of the differences, professional development and assessment, are most related to the duties of the Reading First coach. For example, teachers in Reading First schools received more professional 
development than those in non-Reading First schools. Further, K-3 reading teachers in Reading First schools were found to have received more support in selecting, administering, and interpreting reading assessments than those in non-Reading First schools. Reading First schools were also found to be significantly more likely to have reading coaches than non-Reading First schools.

An examination of distributed leadership research found that that "the execution of leadership tasks is often distributed among multiple leaders" (Spillane, 2006, p. 25). Moreover, leadership is perceived by others as based on expertise rather than seen as a formal position (Bennett, et al., 2003; Leithwood \& Jantzi, 2000; \& Spillane, 2006). And finally, Pustejovsky, et al. (2008) concluded that mathematics or reading specialists were sought out twice as frequently as principals to provide teachers instructional assistance.

Research pertaining to instructional coaching led to a compelling example by Elmore (1997) of how coaching can support improved teacher instructional practices and increased student achievement when embedded in a sustained, coherent district effort to improve instruction. Specifically, positive change depends on effective professional development based on a clear set of principles, activities, and structures (Elmore, 1997). And finally, Neufeld and Roper (2006) found that coaching effectively addresses teacher learning needs derived from student data; carries more seamlessly into classroom practice; builds a teacher willingness to share instructional practices with peers; and facilitates teacher reflection and discussion to focus on data driven instructional improvement.

As expected, the review of the literature provided a more in-depth understanding of the instructional coach. In particular, the research recognized that instructional coaches can play an important role in improving classroom practice. 


\section{CHAPTER III: RESEARCH DESIGN}

\section{Introduction}

The intent of this study was to examine the importance of reading coach activities in improving reading instruction in Title I Distinguished Schools as determined by K-3 reading teacher perceptions. In addition, the study served to investigate whether differences existed between reading coach activities perceived by K-3 teachers as important to improving reading instruction and knowledge of the performance of these activities by reading coaches. Based on this purpose, survey research was selected as the study method since it describes the way people view issues and topics and is typically concerned with assessing (among other areas) personal preferences (Gay, Mills, \& Airasian, 2006). A self-reporting web-based survey instrument developed utilizing Survey Monkey was distributed in 21 Reading First Title I Distinguished Schools to a population of 160 Reading First K-3 teachers throughout West Virginia. A comprehensive review of the literature pertaining to survey design was conducted for quality survey development. A four stage process was incorporated to ensure both validity and reliability of the study's survey. Dissemination and collection of the survey occurred over a four week period based on a pre-determined timeline developed to both encourage participation and discourage procrastination.

The survey was initiated by requesting demographic information from each participant (i.e., number of years of teaching experience, the approximate number of hours per week the teacher worked with the reading coach, and whether the school had a full or part time reading coach). Again, note that reading coaches are termed "reading mentor teachers" in West Virginia's Reading First schools which is labeled as such throughout the survey instrument. This 
information was analyzed and presented as descriptive information. The remainder of the survey focused on addressing the collection of data to address three research questions:

1) How do K-3 reading teachers in Title I Distinguished Schools perceive the importance of the activities of reading coaches in the areas of: Reading First administration, professional development, and instruction and assessment in improving reading instruction?

2) What do reading coaches do in the areas of: Reading First administration, professional development, and instruction and assessment, as perceived by $\mathrm{K}-3$ reading teachers in Reading First Title I Distinguished Schools?

3) What differences exist between the reading coach activities perceived by K-3 teachers as important to improving reading instruction and those activities performed by reading coaches?

Research Question 1 was addressed by collecting responses of K-3 reading teachers to determine their perception of the importance of the activities of Reading First coaches in relation to improving reading instruction. Respondents were requested to rate the importance of each provided reading coach activity on a 1 (low importance) through 5 (high importance) rating scale in relation to improving reading instruction. Research Question 2 was addressed by collecting responses from the K-3 reading teachers regarding either "yes, knowledge the reading mentor teacher performed this activity" or "no, no knowledge the reading mentor teacher performed this activity". Responses were tabulated based on an assigned numeral code with a response of "yes" assigned a 1 and a response of "no" assigned a 0. Finally, Research Question 3 was addressed through a comparison of cumulative survey data. The data collected using Survey Monkey were tabulated using Microsoft Excel to include descriptive (i.e., frequencies, means and standard 
deviations) and inferential (i.e., ANOVA) statistics and were utilized to determine if statistically significant differences existed among the three categories. If significant differences were concluded, it was necessary to conduct a multiple comparison test (i.e., Tukey Test) to determine where the differences existed. Results were displayed in tabular and graphic form for each research question in the three areas (i.e., Reading First administration, professional development, and instruction and assessment).

Demographic information (i.e., number of years of teaching experience, the approximate number of hours per week the teacher worked with the reading coach, and whether the school had a full or part time reading coach) were collected for analysis and presented in descriptive form. Results of the data analysis were described within the study's findings.

This chapter includes details regarding the study's research design: the research theoretic, research participants, survey instrument and development, survey validity and reliability (e.g., the panel of experts and pilot study), data dissemination and collection procedures, use of an electronic survey, and analysis of the survey data.

\section{Research Theoretic}

The objective of survey research is to determine and describe the way things are and may also describe the way people view issues and topics. According to Gay, et al. (2006), "a high percentage of research studies rely on surveys for data and as a result are descriptive in nature" (p. 159). The survey method is useful for investigating a variety of educational problems and issues and is typically concerned with assessing attitudes, preferences, demographics, practices, and procedures (Gay, et al., 2006). Based on this definition, a survey research design was chosen as the research method since the study's intention was to examine teacher perceptions.

A survey research method is guided by a set of six basic steps: 
1. identification of a topic or problem,

2. a thorough review of the literature related to the topic or problem,

3. selection of an appropriate sample of participants,

4. collection of valid and reliable data,

5. an analysis of collected data, and

6. a report regarding the conclusions of the data analysis (Gay, et al., 2006).

A Title I Distinguished School is principally recognized for consistent student academic mastery in reading and mathematics. Similar to a dissertation completed by Christy (2007), a doctoral student at the University of Virginia, this study considered the criteria involved in defining a Title I Distinguished School. The National Association of State Title I Directors (NASTID) authorizes state educational agencies to recognize a Title I school as distinguished. Since all states have a unique accountability system, each is given the flexibility to determine exclusive criteria which characterizes a Title I Distinguished School (National Association of State Title I Directors, 2008). By definition, a West Virginia Title I Distinguished School must:

- be in operation as a Title I school for at least three or more consecutive years,

- have full state accreditation status, and

- meet AYP in reading and mathematics for three or more consecutive years (West Virginia Department of Education, 2008).

This study included only recognized Reading First Title I Distinguished Schools which have met the expected criteria for academic mastery. This distinction provides a commonality between the participating schools. A total of 21 Reading First Title I Distinguished Schools were selected to participate in the study. 


\section{Research Participants}

According to Suskie (1996), the number of participants in a sample directly affects the amount of sample error (e.g., the possible difference between a study's findings and true results if it were possible to obtain valid responses from all participants). Further, when more participants are surveyed the sample error is smaller. Therefore, this study included all K-3 reading teachers in 21 of West Virginia's Reading First Title I Distinguished Schools for a total of 160 teachers. A list containing the number of West Virginia Reading First K-3 Reading Teachers Working in Title I Distinguished Schools is included in Appendix C. Note that actual school names have been amended to fictional names for the intention of preserving anonymity. These schools were chosen for the study due to the state requirement which places a reading coach (RMT) in every participating Reading First school. Each of these schools is currently in year six of Reading First implementation.

\section{Survey Instrument}

The self-reporting survey instrument included introductory information ( $K-3$ Teacher Survey Introduction located in Appendix D), and a six page document containing sections identified as A-G (The Reading First K-3 Classroom Reading Teacher Survey located in Appendix E). The survey introduction provided: background information pertaining to the purpose of the study and benefits of participation; required assurances (e.g., notice of voluntary participation, anonymity, and confidentiality); and a survey description.

The survey was divided into three major sections:

- Section A contained three questions pertaining to: 1) the number of years the K-3 teacher has been a classroom teacher (i.e., $0-4$ years or $5+$ years), 2) the average number of hours per week the teacher spends working with the school's Reading First 
coach (i.e., less than 5 hours, 6-10 hours, or 11+ hours), and 3) whether the school has a full or part time reading coach.

- Sections B-D requested respondents to rate identified reading coach activities on a 1 (low importance) to 5 (high importance) rating scale based on each K-3 reading teacher's perception of each activity in improving reading instruction. The reading coach activities were derived from a comprehensive review of the literature and based upon the State reading coach (RMT) model job description which was categorized into three sections: Reading First administration, professional development, and instruction and assessment.

- Sections E-G called for respondents to indicate, based on their perception, whether they had knowledge the Reading First coach performed each of the listed reading coach activities. The activities were duplicates of the identified coaching activities provided in sections B-D as sorted into the three categories. Participants responded to each coaching activity by indicating either "yes, knowledge the reading mentor teacher performed this activity" (assigned a number code of 1) or "no, no knowledge the reading mentor teacher performed this activity" (assigned a number code of 0 ).

\section{Survey Development}

The self-reporting survey instrument was developed based on the work of several researchers. For example, according to Suskie (1996), a quality survey questionnaire is written so that respondents clearly understand each item. In addition, there was consideration regarding the order of the placement of survey items. According to Fricke, Bachtinger, and Reips (1999), attrition rates were significantly lower when personal data were requested at the beginning of a web-based survey rather than at the end of the survey. "Placing the (personal) data at the 
beginning may be perceived as honesty on the part of the researcher. This helps to create an atmosphere of greater trust and builds a quality relationship" (Andrews, Nonnecke \& Preece, 2003, p. 15).

The reading coach activities identified in sections B-D and E-G of the survey were developed based on a comprehensive review of the literature and the State Reading First reading coach model job description (West Virginia Reading First Mentor Teacher Model Job Description - see Appendix A). The job description was used to both guide and categorize the development of each statement in the survey instrument which represents the performance responsibilities of the reading coach. The survey was divided into three categories as derived from the job description: 1) Reading First administration, 2) professional development, and 3) instruction and assessment. A thorough analysis was conducted to align each identified reading coach activity indicated on the Reading First coach model job description to research support within the literature. Documentation of this analysis is provided on the Survey Development Matrix located in Appendix F.

\section{Survey Instrument Validity and Reliability}

Central to the development of the self-reporting survey was consideration regarding the instrument's validity and reliability. Validity is the degree in which an instrument measures what it is intended to measure (e.g., all survey items relate to the research topic, mutually exclusive questions or statements). In contrast, reliability is the degree to which an instrument consistently measures what it is intended to measure (e.g., user-friendly administration, understandable format, clear directions) (Gay, et al., 2006). To adequately address the issues of both validity and reliability a four stage evaluation process was utilized: 
- Stage one (validity): The survey instrument was reviewed by a panel of experts knowledgeable of the Reading First program to ensure appropriateness of survey questions and statements.

- Stage two (reliability): A pilot study was conducted from a pool of K-3 teachers (one from each of grades K-3) teaching in a West Virginia Reading First Title I nondistinguished school.

- Stage three (validity and reliability): An observation and "think aloud" was conducted by the researcher of a pilot K-3 reading teacher while completing the survey followed by a retrospective interview. A K-3 reading teacher was randomly selected from a Reading First Title I non-distinguished school for participation.

- Stage four (validity and reliability): Final editing was completed based on feedback provided from previous evaluation stages.

\section{Panel of Experts}

The panel of experts included a four member panel consisting of: one national and three state Reading First experts. The national expert was Sharon Vaughn, co-author of the national Reading First program and a nationally recognized reading researcher and author of numerous reading journal articles, books, and research studies. The first state expert was Beverly Kingery, former state Reading First director, main author of the West Virginia Reading First grant, and currently a superintendent in a Reading First county. The remaining two state experts were Jane Massi and Rebecca Wood both of which are West Virginia reading cadre members responsible for providing Reading First training and the monitoring and evaluation of county Reading First programs. 
The panel of experts was contacted via e-mail to request participation. Upon acceptance, a second e-mail (Panel of Experts E-mail located in Appendix G) was sent to each panel member containing reference to three attachments: 1) reviewer directions for the panel of experts (Panel of Experts Survey Directions located in Appendix H); 2) a copy of the draft survey; and 3) a reference copy of the Reading First model job description (West Virginia Reading First Mentor Teacher Model Job Description located in Appendix A).

Based on suggestions provided by the Web Center for Social Research (2006), three questions were posed for the panel's consideration regarding the survey: 1) Do the questions and statements adequately address the study research questions (as guided by a comprehensive review of the literature and the State reading coach model job description)? 2) Do the questions and statements contain the necessary information to enable an adequate response by the respondent? 3) Is each question or statement biased or worded to encourage a particular response? As indicated on the Panel of Experts Survey Directions (Appendix H), these questions were central to each item included on the survey. The panel provided written feedback within a week via e-mail utilizing Microsoft Word's track changes. Feedback from the panel of experts was recorded using the Panel of Experts Feedback Matrix located in Appendix I.

\section{Pilot Study}

Stages three and four of the survey evaluation process involved a pilot study conducted from a pool of reading teachers (one from each of grades K-3) teaching in a West Virginia Reading First Title I non-distinguished school. These four teachers completed the online survey for the purpose of examining the reliability of the survey instrument. A group discussion followed the completion of the survey regarding the instrument's validity (i.e., survey items 
relate to the research topic, mutually exclusive questions or statements) and reliability (i.e., clear directions, understandable format, and user-friendly navigation).

One of the four K-3 teachers was randomly selected from this group to be observed by the researcher to participate in a "think aloud" while completing the survey followed by a retrospective interview. Feedback from the pilot study was considered for improving the survey instrument during the final survey editing stage.

\section{Data Dissemination and Collection}

The survey was presented to Reading First K-3 reading teachers working in Title I Distinguished Schools via a web-based computer survey using Survey Monkey designed for both the delivery and collection of data. Survey dissemination was preceded by conveyance of a courtesy postal letter informing each superintendent of the 14 participating LEAs regarding the invitation of K-3 teachers working in a school(s) within their county to participate in the survey (Superintendent Survey Letter - see Appendix J). Based on research (as detailed in the Electronic Surveys section below) and in an effort to maximize the response rate, the sample of K-3 teachers were invited up to four times to participate in the study using electronic means: 1) initiated with an invitational postal letter (K-3 Teacher Survey Letter Request - see Appendix K) directing potential participants to the web-based survey via the URL; 2) followed by up to three reminder e-mails sent to non-respondents as tracked electronically utilizing Survey Monkey.

Gay, et al. (2006) recommends providing two to three weeks for data completion which is sufficient time for respondents to adequately complete the survey, but also discourages procrastination. Based on this guidance and considering the coaxing of procrastinating respondents, the following timeline was initiated: 
- Week one: Invitational postal letter was mailed directing participants to the webbased URL.

- Week two: First e-mail was sent to non-respondents as a reminder to complete the electronic survey.

- Week three: Second e-mail was sent to non-respondents as a reminder to complete the electronic survey.

- Week four: Final e-mail was sent to non-respondents as a reminder to complete the electronic survey.

The anticipated participant return rate was determined based on survey research. According to Suskie (1996), most professional researchers desire a $70 \%$ to $80 \%$ response rate and consider $50 \%$ minimally adequate. Following this guidance, the goal was to receive a survey response rate of $70 \%$ to $80 \%$, but a $50 \%$ response was considered minimally adequate.

\section{Electronic Surveys}

The selection of the utilization of a web-based computer survey was supported by research citing advantages of the dissemination and collection of surveys using electronic verses traditional pencil and paper postal methods. According to Reynolds, Woods and Baker (2007), an electronic survey is defined as "one in which a computer plays a major role in both the delivery and collection of survey data from actual respondents" (p. 2). This is an attractive component of the utilization of an electronic survey since web-based surveys can be connected directly to a database where all completed survey data are categorized and stored for analysis (Lazar \& Preece, 1999).

The three most common reasons for selecting electronic surveys over a pencil and paper approach are: 1) decreased costs, 2) faster response rates, and 3) increased response rates (Lazar 
\& Preece, 1999; Operman, 1995; Saris, 1991). Further, research is beginning to confirm that electronic surveys provide strong advantages of speedy distribution and response cycles (Swoboda, Muehlberger, Weitunat, \& Schneeweiss, 1997; Yun \& Trumbo, 2000). However, Lazar \& Preece (1999) and Schmidt (1997) also warn researchers regarding the importance of emerging issues associated with the utilization of electronic surveys such as security, access, privacy, and ethical issues. These areas were considered during the development of the survey using Survey Monkey. For example, each participant was assigned a unique survey link allowing exclusive access to responses by the respondent and researcher.

\section{Data Analysis}

Participant responses were tabulated using a Microsoft Excel spreadsheet. The first column of the spreadsheet indicated a sequential number identifying each participant. Additional columns represented each of the survey questions or statements from sections A-G to record teacher responses of all teachers to a single item and a row containing the responses of a single teacher to all items. Specifically, the columns contained participant responses to:

- the three demographic questions from section $\mathrm{A}$,

- the 23 teacher perception ratings regarding the importance of coaching activities in the three categories from sections B-D (i.e., 7 Reading First administration, 8 professional development, and 8 instruction and assessment activities), and

- the 23 teacher perception ratings regarding the observation of coaching activities in the three categories from sections E-G (i.e., 7 Reading First administration, 8 professional development, and 8 instruction and assessment activities).

The analysis of survey responses focused on addressing each of the study's three research questions: 
- Research Question 1: Data analysis included descriptive (i.e., means and standard deviations) and inferential (i.e., ANOVA) statistics calculated using SAS software. Means and standard deviations were computed for each of the 23 behaviors (i.e., 7 Reading First administration, 8 professional development, and 8 instruction and assessment activities) in sections B-D. Further, a one-way, withinsubjects (repeated measures) analysis of variance (ANOVA) was used to calculate if a statistically significant $(p<.05)$ difference existed among the ratings of the behaviors in each of the three categories. For example, the calculation determined if there was a statistically significant difference between the Reading First administrative activities (independent variable) based on teacher ratings from a 1 (low importance) through a 5 (high importance) rating scale (dependent variable). If significant differences were concluded, it became necessary to conduct a multiple comparison test (i.e., Tukey Test) to determine where the differences existed. Results of the data analysis pertaining to Research Question 1 were displayed for each of the three categories in graphic and tabular form.

- Research Question 2: Data analysis included a tabulation of descriptive frequencies to conclude the number and percentage of teacher responses addressing "yes, knowledge the reading mentor teacher performed this activity" and "no, no knowledge the reading mentor teacher performed this activity" for each of the coaching activities (survey statements E-G). Results of the data analysis pertaining to Research Question 2 were displayed for each of the three categories in a table to include the number and percentage of yes and no knowledge of performance responses. 
- Research Question 3: Data analysis involved an examination of descriptive statistics to include the mean of teacher responses regarding the importance of coaching activities based on a 1 through 5 rating scale and the frequency of teacher yes or no knowledge of performance responses. The mean calculated in Research Question 1 for the independent variables in sections B-D was converted to a percentage (i.e., mean importance rating per each coaching activity divided by the highest possible rating of 5) and evaluated in relation to the percentage of teacher observations of the coaching activities in sections E-G (both yes and no knowledge of performance responses). Results of the data analysis pertaining to Research Question 3 were displayed in graphic form.

Finally, section A of the survey was included for the purpose of providing demographic participant information (i.e., number of years of teaching experience, the approximate number of hours per week the teacher works with the reading coach, and whether the school has a full or part time reading coach). These data were tabulated and presented as descriptive information.

\section{Summary}

Utilization of a self-reporting survey was selected as the study's research method since the intent was to examine the activities of Reading First coaches according to the perceptions of K-3 reading teachers working in Title I Distinguished Schools. The exclusiveness of the inclusion of Title I Distinguished Schools provided a commonality between participating schools since, among other criteria; each school has experienced previous prolonged success with academic mastery. The survey instrument, developed utilizing Survey Monkey, was distributed in 21 Reading First Title I Distinguished Schools to 160 K-3 teachers across West Virginia. 
A comprehensive review of the research supported the development of the survey and the process for collection. Further, the inclusion of a panel of expert reviewers and the incorporation of a pilot study served to increase the validity and reliability of the survey instrument. Each of the three research questions was examined through collection of the ratings of K-3 reading teacher perceptions using Microsoft Excel. Both descriptive (i.e., frequencies, means and standard deviations) and inferential (i.e., ANOVA) statistics were utilized for the analysis of the three research questions. Results were displayed in both tabular and graphic form for each research question in the three areas (i.e., Reading First administration, professional development, and instruction and assessment).

Demographic information (i.e., number of years of teaching experience, the approximate number of hours per week the teacher works with the reading coach and whether the school had a full or part time reading coach) were collected for analysis and presented in descriptive form. Results of the data analysis were described within the study's findings. 


\section{CHAPTER IV: DATA ANALYSIS AND INTERPRETATION}

The purpose of this study was to examine the importance of reading coach activities in improving reading instruction in West Virginia Title I Distinguished Schools as determined by K-3 reading teacher perceptions. In addition, the study investigated whether differences existed between the reading coach activities perceived by K-3 teachers as important to improving reading instruction and those activities perceived by K-3 teachers as being performed by reading coaches (referred to as reading mentor teachers in West Virginia).

Chapter 4 provides a description and analysis of the data collected utilizing the Reading First K-3 Classroom Reading Teacher Survey (see Appendix E). This chapter includes demographic statistics, provides data and key findings which address each of the study's three research questions, and concludes with a summary of the data.

\section{Demographic Data}

This study included a population of all 160 Reading First K-3 reading teachers working in West Virginia Title I Distinguished Schools. Two of the 73 returned surveys were eliminated since these respondents only completed the demographic section leaving the majority of the survey incomplete. Therefore, the final participant response rate was $44 \%$ or 71 of 160 participants. On several occasions participants chose to skip a question(s) offered as an option to the study's assurances which is required by West Virginia University. Therefore, it must be noted that there was an overall range of 62 to 71 teachers responded to the survey items. According to Suskie (1996) most professional researchers desire a $70 \%$ to $80 \%$ response rate and consider $50 \%$ minimally adequate. Therefore, a survey response rate of $44 \%$ is considered a limitation to this study. 
Section A of the survey requested respondents to provide demographic information regarding three areas: 1) the number of years as a classroom teacher, 2) the average number of hours per week the teacher spent working with the school's Reading First reading mentor teacher, and 3) whether the school's reading mentor teacher was assigned as a full or part time position. Table 1 includes data which reveal participant teaching experience (i.e., 0-4 years and $5+$ years) by frequency and percentage.

Table 1

Participant Teaching Experience by Frequency and Percentage

\begin{tabular}{lcc}
\hline Teaching Experience & Frequency & Percentage \\
\hline $0-4$ years & 11 & $15 \%$ \\
$5+$ years & 60 & $85 \%$ \\
\hline Total & 71 & $100 \%$ \\
\hline
\end{tabular}

As indicated by Table 1 , the data reveal that the majority or $85 \%$ of respondents ( 60 of 71) have five or more years of teaching experience. The remainder or $15 \%$ of respondents (11 of 71) have from zero to four years of classroom teaching experience.

Table 2 includes data pertaining to the approximate number of hours (i.e., less than 5 hours, 6-10 hours and 11+ hours) the participant spent working with the school's reading mentor teacher listed as a frequency and percentage. 
Table 2

Participant Hours Working With Reading Mentor Teacher by Frequency and Percentage

\begin{tabular}{lcc}
\hline Approximate Number of Hours & Frequency & Percentage \\
\hline Less than 5 hours & 52 & $73 \%$ \\
$6-10$ hours & 13 & $18 \%$ \\
$11+$ hours & 6 & $9 \%$ \\
\hline Total & 71 & $100 \%$ \\
\hline
\end{tabular}

As indicated in Table 2, the data reveal that the majority or $73 \%$ of respondents (52 of 71) spent, on average, less than 5 hours per week working with the school's Reading First reading mentor teacher. Another $18 \%$ (13 of 71) estimated spending an average of 6-10 hours per week working with the reading mentor teacher. And finally, 9\% (6 of 71) claimed to work with the reading mentor teacher approximately 11 plus hours per week.

Table 3 includes data pertaining to participant responses regarding the status of the school's reading mentor teacher (i.e., full or part time position) listed as a frequency and percentage.

Table 3

Reading Mentor Teacher Assignment by Frequency and Percentage

\begin{tabular}{lcc}
\hline Status of Reading Mentor Teacher & Frequency & Percentage \\
\hline Full Time & 58 & $83 \%$ \\
Part Time & 12 & $17 \%$ \\
\hline Total & 70 & $100 \%$ \\
\hline
\end{tabular}


As indicated in Table 3, the data reveal that the majority or $83 \%$ (58 of 70) of the participants worked in a school which was assigned a full time reading mentor teacher. An additional $17 \%$ (12 of 70) of the participants worked in a school which was assigned a part time reading mentor teacher.

An original intention of gathering demographic data was to consider running statistical correlations according to the demographic categories. However, the small number of participants within the demographic categories prevented further statistical analysis since it is likely no viable conclusions could be derived.

\section{Data Analysis and Key Findings}

The remainder of the survey (i.e., sections B through G) served to gather data for the purpose of addressing each of the study's three research questions. Sections B, C, and D asked respondents to select the importance rating that most accurately reflected their opinion regarding listed reading mentor teacher activities in improving reading instruction in three areas: Reading First administration, professional development, and instruction and assessment. Each teacher selected from a rating scale with a 1 representing low importance through a 5 representing high importance. Sections E, F, and G asked respondents to consider identical reading mentor teacher activities within the three areas and to indicate either, "yes, knowledge the reading mentor teacher performed this activity" or "no, no knowledge the reading mentor teacher performed this activity". Collected data were organized to address each of the three research questions.

\section{Research Question 1}

Research Question 1: How do K-3 reading teachers in Title I Distinguished Schools perceive the importance of the activities of reading coaches in the areas of: Reading First 
administration, professional development, and instruction and assessment in improving reading instruction?

The data analysis to address Research Question 1 involved data from survey sections B, $\mathrm{C}$, and D. These three sections of the survey included reading mentor teacher activities categorized into the three areas: Reading First administration (section B), professional development (section C), and instruction and assessment (section D). Survey respondents were asked to respond according to their perception of the importance of the listed reading mentor teacher activities in improving reading instruction. Responses were based on a rating scale with a 1 representing low importance through a 5 representing high importance. The data analysis involved several measures including the mean rating, standard deviation, and an analysis of variance. When significant differences of the components were determined through the analysis of variance, it became necessary to conduct a multiple comparison (i.e., Tukey) test to identify where the differences existed.

Section B of the survey asked respondents to rate the importance of Reading First administration reading mentor teacher activities in relation to improving reading instruction on a scale from 1 (lowest) through 5 (highest). Table 4 presents the Reading First administration reading mentor teacher activities, the participant response rate $(\mathrm{N})$, mean, and standard deviation. 
Table 4

Importance of Reading First Administration Activities

\begin{tabular}{|c|c|c|c|}
\hline & $N$ & Mean & $\begin{array}{l}\text { Standard } \\
\text { Deviation }\end{array}$ \\
\hline \multicolumn{4}{|l|}{ The reading mentor teacher ... } \\
\hline $\begin{array}{l}\text { B1. coordinates and assesses the daily operation } \\
\text { of the Reading First program. }\end{array}$ & 71 & 4.14 & 1.17 \\
\hline $\begin{array}{l}\text { B2. communicates a minimum of twice per } \\
\text { year with the school's assigned WVDE } \\
\text { reading cadre liaison. }\end{array}$ & 69 & 4.07 & 1.14 \\
\hline $\begin{array}{l}\text { B3. works with the school's assigned WVDE } \\
\text { reading cadre liaison to assist in the } \\
\text { administration of the Reading First } \\
\text { program. }\end{array}$ & 68 & 4.07 & 1.12 \\
\hline $\begin{array}{l}\text { B4. participates in the dissemination of Reading } \\
\text { First program development activities. }\end{array}$ & 68 & 4.35 & 0.97 \\
\hline $\begin{array}{l}\text { B5. maintains a flexible schedule for the purpose } \\
\text { of adequately addressing reading priorities. }\end{array}$ & 68 & 4.31 & 1.04 \\
\hline $\begin{array}{l}\text { B6. attends local, state, and national meetings } \\
\text { supportive of the administration of the } \\
\text { Reading First program. }\end{array}$ & 70 & 4.29 & 1.07 \\
\hline $\begin{array}{l}\text { B7. meets at least monthly with the principal } \\
\text { for program planning, implementation, } \\
\text { and evaluation purposes. }\end{array}$ & 68 & 4.29 & 1.08 \\
\hline
\end{tabular}

As indicated in Table 4, respondents rated the importance of all seven Reading First administration reading mentor teacher activities as important to improving reading instruction with a mean importance rating of above 4.00 (mean importance range of 4.35 to 4.07 ). Thus, the means indicate a strong skew, with most of the ratings at the high end of the 1 to 5 rating scale. The standard deviations show similar dispersion of importance ratings across the items (i.e., 1.17 to 0.97 ) with higher numbers indicating a greater dispersion of ratings and lower numbers indicating less dispersion of ratings. These activities can be ranked from the highest to the lowest mean importance rating: 
1) B4: The reading mentor teacher participates in the dissemination of Reading First program development activities (mean importance rating of 4.35).

2) B5: The reading mentor teacher maintains a flexible schedule for the purpose of adequately addressing reading priorities (mean importance rating of 4.31).

3) B6: The reading mentor teacher attends local, state, and national meetings supportive of the administration of the Reading First program (mean importance rating of 4.29).

4) B7: The reading mentor teacher meets at least monthly with the principal for program planning, implementation, and evaluation purposes (mean importance rating of 4.29).

5) B1: The reading mentor teacher coordinates and assesses the daily operation of the Reading First program (mean importance rating of 4.14).

6) B2: The reading mentor teacher communicates a minimum of twice per year with the school's assigned WVDE reading cadre liaison (mean importance rating of 4.07).

7) B3: The reading mentor teacher works with the school's assigned WVDE reading cadre liaison to assist in the administration of the Reading First program (mean importance rating of 4.07).

According to the data, participants perceive all seven of the Reading First administration reading mentor teacher activities to be important in improving reading instruction as evidenced with a mean improvement ranking of greater than 4.00 .

Finally, a within-subjects (repeated-measures) analysis of variance was computed to determine if there were differences in these Reading First administrative importance ratings. In 
this analysis, the seven Reading First administrative reading mentor coach activities constituted the independent variable. The dependent variable for the analysis of variance was the importance rating $(1=$ low importance through $5=$ high importance $)$. This analysis of variance yielded $F(6$, $405)=1.86, p=0.09$, which is not statistically significant. Since the analysis of variance did not yield a significant finding, it was not necessary to compute multiple comparisons of the individual means. Accordingly, the ratings of the seven Reading First administrative activities did not show statistically significant findings.

Overall the data reveal that K-3 teachers perceive all seven of the Reading First administrative reading mentor teacher activities as important in improving reading instruction as measured by a mean importance rating of above 4.00. These Reading First administrative reading mentor teacher activities included: participating in the dissemination of program development activities; maintaining a flexible schedule to adequately address reading priorities; attending local, state and national administrative meetings; meeting at least monthly with the principal for planning, implementation, and evaluation purposes; coordinating and assessing the daily operation of Reading First; communicating at least twice per year with the school's assigned WVDE reading cadre liaison; and working with the liaison to assist in the administration of the Reading First program.

Section $\mathrm{C}$ of the survey asked respondents to rate the importance of professional development reading mentor teacher activities in relation to improving reading instruction on a scale from 1 (lowest) through 5 (highest). Table 5 presents the professional development reading mentor teacher activities, the participant response rate $(\mathrm{N})$, mean, standard deviation, and identifies which activities had an individual means significantly different at the .01 level as determined through multiple comparison testing. Since the analysis of variance yielded a 
significant finding, it was necessary to compute a multiple comparison (i.e., Tukey) test of the individual means.

Table 5

Importance of Professional Development Activities

\begin{tabular}{|c|c|c|c|c|}
\hline & $N$ & Mean & $\begin{array}{l}\text { Standard } \\
\text { Deviation }\end{array}$ & $\begin{array}{c}* \text { Differs from } \\
p<.01\end{array}$ \\
\hline \multicolumn{5}{|l|}{ The reading mentor teacher } \\
\hline $\begin{array}{l}\text { C1. works with the school's assigned WVDE } \\
\text { reading cadre liaison at least twice per } \\
\text { year to assist in planning the school's } \\
\text { Reading First professional development. }\end{array}$ & 67 & 3.94 & 1.27 & $\mathrm{C} 4, \mathrm{C} 5, \mathrm{C} 6$ \\
\hline $\begin{array}{l}\text { C2. attends required state sponsored professional } \\
\text { development sessions. }\end{array}$ & 68 & 4.24 & 1.08 & \\
\hline $\begin{array}{l}\text { C3. attends } 100 \text { hours of required Reading } \\
\text { First professional development per year } \\
\text { with classroom teachers. }\end{array}$ & 68 & 4.26 & 1.17 & \\
\hline $\begin{array}{l}\text { C4. coordinates sustained, research-based } \\
\text { professional development within the school. }\end{array}$ & 68 & 4.47 & 0.95 & $\mathrm{C} 1, \mathrm{C} 8$ \\
\hline $\begin{array}{l}\text { C5. provides technical assistance (e.g., modeling, } \\
\text { administering student assessments, grouping } \\
\text { of students, alignment of assessment data } \\
\text { with instruction) to all K-3 reading teachers } \\
\text { (e.g., classroom, special education, Title I, } \\
\text { interventionists) during the school day. }\end{array}$ & 68 & 4.53 & 0.89 & $\mathrm{C} 1, \mathrm{C} 8$ \\
\hline $\begin{array}{l}\text { C6. provides technical assistance (e.g., modeling, } \\
\text { administering student assessments, grouping } \\
\text { of students, alignment of assessment data } \\
\text { with instruction) to all K-3 reading teachers } \\
\text { (e.g., classroom, special education, Title I, } \\
\text { interventionists) throughout the school year. }\end{array}$ & 69 & 4.41 & 1.05 & $\mathrm{C} 1, \mathrm{C} 8$ \\
\hline C7. individually coaches $\mathrm{K}-3$ reading teachers. & 69 & 4.25 & 1.16 & \\
\hline $\begin{array}{l}\text { C8. observes K-3 classroom teachers and } \\
\text { provides constructive feedback at least } \\
\text { once monthly. }\end{array}$ & 68 & 3.97 & 1.22 & $\mathrm{C} 4, \mathrm{C} 5, \mathrm{C} 6$ \\
\hline
\end{tabular}

*Based on Tukey Test

As indicated in Table 5, respondents rated the importance of all eight professional development reading mentor teacher activities as important to improving reading instruction with 
a mean importance rating range of 4.53 to 3.94. Respondents rated six of the eight professional development reading mentor activities in improving reading instruction as slightly more important in improving reading instruction as indicated with a rating of above 4.00. Thus, the means indicate a strong skew, with most of the ratings at the high end of the 1 to 5 rating scale. The standard deviations show similar dispersion of importance ratings across the items (i.e., 1.27 to 0.89 ) with higher numbers indicating a greater dispersion of ratings and lower numbers indicating less dispersion of ratings. These activities can be ranked from the highest to the lowest mean importance rating:

1) C5: The reading mentor teacher provides technical assistance (e.g., modeling, administering student assessments, grouping of students, alignment of assessment data with instruction) to all K-3 reading teachers (e.g., classroom, special education, Title I, interventionists) during the school day (mean importance rating of 4.53).

2) C4: The reading mentor teacher coordinates sustained, research-based professional development within the school (mean importance rating of 4.47).

3) C6: The reading mentor teacher provides technical assistance (e.g., modeling, administering student assessment, grouping of students, alignment of assessment data with instruction) to all K-3 reading teachers (e.g., classroom, special education, Title I interventionists) throughout the school year (mean importance rating of 4.41).

4) C3: The reading mentor teacher attends 100 hours of required Reading First professional development per year with classroom teachers (mean importance rating of 4.26).

5) C7: The reading mentor teacher individually coaches K-3 reading teachers (mean importance rating of 4.25). 
6) C2: The reading mentor teacher attends required state sponsored professional development sessions (mean importance rating of 4.24).

7) C8: The reading mentor teacher observes K-3 classroom teachers and provides constructive feedback at least once monthly (mean importance rating of 3.97).

8) C1: The reading mentor teacher works with the school's assigned WVDE reading cadre liaison at least twice per year to assist in planning the school's Reading First professional development (mean importance rating of 3.94).

According to the data, participants perceive all eight of the professional development reading mentor teacher activities to be important in improving reading instruction as evidenced with a mean improvement ranking above or slightly below 4.00. A within-subjects (repeatedmeasures) analysis of variance was computed to determine if there were differences in the professional development importance ratings. In this analysis, the eight professional development reading mentor teacher activities constituted the independent variable. The dependent variable for the analysis of variance was the importance rating $(1=$ low importance through $5=$ high importance). This analysis of variance yielded $F(7,469)=6.32, p=<.01$, which is statistically significant.

Since the analysis of variance yielded a significant finding, it was necessary to compute multiple comparisons of the individual means. Accordingly, multiple comparisons among the eight professional development reading mentor activities were computed using the Tukey Test. The statistical table (Hinkle, Wiersma, \& Jurs, 2003) indicated a critical value of 4.99 at the .01 level (df error within $=469 / \mathrm{r}=8$ ). Therefore, all comparisons with a critical value of $>4.99$ were considered statistically different from each other. In comparing each of the eight professional development reading mentor activities to each of the other activities, six significant differences 
were identified as indicated by the Tukey Test. Each of the six differences related to activities with a higher importance rating than $\mathrm{C} 1$ and $\mathrm{C} 8$ (i.e., 3.97 and 3.94 respectively). As indicated in Table 5, the six significant differences included:

1) C1: The reading mentor teacher works with the school's assigned WVDE reading cadre liaison at least twice per year to assist in planning the school's Reading First professional development was statistically different from $\mathrm{C} 4$ : The reading mentor teacher coordinates sustained, research-based professional development within the school (yielded a critical value of $6.16, p<.01$ ).

2) C1 (as stated above) was statistically different from C5: The reading mentor teacher provides technical assistance (e.g., modeling, administering student assessments, grouping of students, alignment of assessment data with instruction) to all K-3 reading teachers (e.g., classroom, special education, Title I, interventionists) during the school day (yielded a critical value of 6.86, $p<.01$ ).

3) C1 (as stated above) was statistically different from C6: The reading mentor teacher provides technical assistance (e.g., modeling, administering student assessments, grouping of students, alignment of assessment data with instruction) to all K-3 reading teachers (e.g., classroom, special education, Title I, interventionists) throughout the school year (yielded a critical value of 5.47, $p<.01$ ).

4) C8: The reading mentor teacher observes K-3 classroom teachers and provides constructive feedback at least once monthly was statistically different from C4: The reading mentor teacher coordinates sustained, research-based professional development within the school (yielded a critical value of 5.81, $p<.01$ ). 
5) C8 (as stated above) was significantly different from C5: The reading mentor teacher provides technical assistance (e.g., modeling, administering student assessments, grouping of students, alignment of assessment data with instruction) to all K-3 reading teachers (e.g., classroom, special education, Title I, interventionists) during the school day (yielded a critical value of $6.51, p<.01$ ).

6) C8 (as stated above) was statistically different from C6: The reading mentor teacher provides technical assistance (e.g., modeling, administering student assessments, grouping of students, alignment of assessment data with instruction) to all K-3 reading teachers (e.g., classroom, special education, Title I, interventionists) throughout the school year (yielded a critical value of 5.12, $p<.01$ ).

Overall respondents rated all of the eight professional development reading mentor teacher activities as important to improving reading instruction as indicated with a mean importance rating of above or slightly below 4.00. The professional development reading mentor teacher activities rated highest as indicated with a mean importance rating of 4.00 or above included: providing technical assistance to all K-3 reading teachers during the school day and throughout the school year; coordinating sustained, research-based professional development within the school; attending 100 hours of required professional development with classroom teachers; individually coaching K-3 reading teachers; and attending required state sponsored professional development sessions. The multiple comparison (i.e., Tukey) test further indicated that the importance rating of these six activities were statistically different in comparison to the majority of the other professional development activities.

Section D of the survey asked respondents to rate the importance of instruction and assessment reading mentor teacher activities in relation to improving reading instruction on a 
scale from 1 (lowest) through 5 (highest). Table 6 presents the instruction and assessment reading mentor teacher activities, the participant response rate $(\mathrm{N})$, mean, standard deviation, and identifies which activities had an individual means significantly different at the .01 level as determined through multiple comparison testing. Since the analysis of variance yielded a significant finding, it was necessary to compute a multiple comparison (i.e., Tukey) test of the individual means. 
Table 6

Importance of Instruction and Assessment Activities

\begin{tabular}{|c|c|c|c|c|}
\hline & $N$ & Mean & $\begin{array}{l}\text { Standard } \\
\text { Deviation }\end{array}$ & $\begin{array}{c}* \text { Differs from } \\
p<.01\end{array}$ \\
\hline \multicolumn{5}{|l|}{ The reading mentor teacher } \\
\hline $\begin{array}{l}\text { D1. assists the staff in selecting, securing } \\
\text { and explaining appropriate instructional } \\
\text { materials, strategies, and programs. }\end{array}$ & 68 & 4.24 & 1.01 & D4, D8 \\
\hline $\begin{array}{l}\text { D2. demonstrates a clear understanding of } \\
\text { appropriate student classroom behaviors } \\
\text { and instructional environment. }\end{array}$ & 68 & 4.25 & 0.94 & D4, D8 \\
\hline $\begin{array}{l}\text { D3. meets quarterly with the principal to } \\
\text { monitor the evaluation measurement } \\
\text { areas (i.e., student achievement, } \\
\text { teacher knowledge, effect of professional } \\
\text { development on classroom practice). }\end{array}$ & 65 & 4.00 & 1.09 & D8 \\
\hline $\begin{array}{l}\text { D4. meets quarterly with the central office } \\
\text { project director to monitor the evaluation } \\
\text { measurement areas (i.e., student achievement, } \\
\text { teacher knowledge, effect of professional } \\
\text { development on classroom practice). }\end{array}$ & 66 & 3.76 & 1.16 & $\begin{array}{l}\text { D1, D2, D5 } \\
\text { D6, D7, D8 }\end{array}$ \\
\hline $\begin{array}{l}\text { D5. serves as the school liaison for reading } \\
\text { assessment coordination. }\end{array}$ & 67 & 4.33 & 0.96 & D4, D8 \\
\hline $\begin{array}{l}\text { D6. assists teachers with the implementation } \\
\text { of content, skills, and strategies to promote } \\
\text { successful readers. }\end{array}$ & 68 & 4.34 & 1.00 & D4, D8 \\
\hline D7. models effective classroom instruction. & 68 & 4.21 & 1.15 & D4, D8 \\
\hline D8. participates in lesson videotaping. & 65 & 2.66 & 1.23 & $\begin{array}{l}\mathrm{D} 1, \mathrm{D} 2, \mathrm{D} 3, \mathrm{D} 4 \\
\mathrm{D} 5, \mathrm{D} 6, \mathrm{D} 7\end{array}$ \\
\hline
\end{tabular}

*Based on Tukey Test

As indicated in Table 6, respondents rated the importance of seven of the eight instruction and assessment reading mentor teacher activities as important to improving reading instruction with a mean importance rating range of 4.34 to 3.76 . Respondents rated one of the eight activities with an average importance rating of 2.66. Thus, the means indicate a strong skew, with most of the ratings at the high end of the 1 to 5 rating scale. The standard deviations 
show similar dispersion of importance ratings across the items (i.e., 1.23 to 0.94) with higher numbers indicating a greater dispersion of ratings and lower numbers indicating less dispersion of ratings. These activities can be ranked from the highest to the lowest mean importance rating:

1) D6: The reading mentor teacher assists teachers with the implementation of content, skills, and strategies to promote successful readers (mean importance rating of 4.34).

2) D5: The reading mentor teacher serves as the school liaison for reading assessment coordination (mean importance rating of 4.33).

3) D2: The reading mentor teacher demonstrates a clear understanding of appropriate student classroom behaviors and instructional environment (mean importance rating of 4.25).

4) D1: The reading mentor teacher assists the staff in selecting, securing, and explaining appropriate instructional materials, strategies, and programs (mean importance rating of 4.24).

5) D7: The reading mentor teacher models effective classroom instruction (mean importance rating of 4.21).

6) D3: The reading mentor teacher meets quarterly with the principal to monitor the evaluation measurement areas (i.e., student achievement, teacher knowledge, effect of professional development on classroom practice) (mean importance rating of 4.00).

7) D4: The reading mentor teacher meets quarterly with the central office project director to monitor the evaluation measurement areas (i.e., student achievement, teacher knowledge, effect of professional development on classroom practice) (mean importance rating of 3.76). 
8) D8: The reading mentor teacher participates in lesson videotaping (mean importance rating of 2.66).

According to the data, participants perceive seven of the eight professional development reading mentor teacher activities to be important in improving reading instruction as evidenced with a mean improvement ranking above or slightly below 4.00. One of the eight activities received an overall importance rating of 2.66 (i.e., participates in lesson videotaping) indicating that teachers perceive all other activities as more important in improving reading instruction.

A within-subjects (repeated-measures) analysis of variance was computed to determine if there were differences in the instruction and assessment ratings. In this analysis, the eight instruction and assessment reading mentor teacher activities constituted the independent variable. The dependent variable for the analysis of variance was the importance rating $(1=$ low importance through $5=$ high importance). This analysis of variance yielded $F(7,460)=46.34, p$ $=<.01$, which is statistically significant.

Since the analysis of variance yielded a significant finding, it was necessary to compute multiple comparisons of the individual means. Accordingly, multiple comparisons among the eight instruction and assessment reading mentor activities were computed using the Tukey Test. The statistical table (Hinkle, et al., 2003) indicated a critical value of 4.99 at the .01 level (df error within $=460 / \mathrm{r}=8$ ). Therefore, all comparisons with a critical value of $>4.99$ were considered statistically different from each other. In comparing each of the eight instruction and assessment reading mentor activities to each of the other activities, twelve significant differences were identified as indicated by the Tukey Test. Each of the twelve differences related to activities with a higher importance rating than D4 and D8 which also had the lowest mean 
importance rating (i.e., 3.76 and 2.66 respectively). As indicated in Table 6 , the twelve significant differences included:

1) D4: The reading mentor teacher meets quarterly with the central office project director to monitor the evaluation measurement areas (i.e., student achievement, teacher knowledge, effect of professional development on classroom practice) was statistically different from D1: The reading mentor teacher assists the staff in selecting, securing, and explaining appropriate instructional materials, strategies, and programs (yielded a critical value of 5.93, $p<.01$ ).

2) D4 (as stated above) was statistically different from D2: The reading mentor teacher demonstrates a clear understanding of appropriate student classroom behaviors and instructional environment (yielded a critical value of $6.05, p<.01$ ).

3) D4 (as stated above) was statistically different from D5: The reading mentor teacher serves as the school liaison for reading assessment coordination (yielded a critical value of $7.04, p<.01)$.

4) D4 (as stated above) was statistically different from D6: The reading mentor teacher assists teachers with the implementation of content, skills, and strategies to promote successful readers (yielded a critical value of $7.16, p<.01$ ).

5) D4 (as stated above) was statistically different from D7: The reading mentor teacher models effective classroom instruction (yielded a critical value of 5.56, $p<.01$ ).

6) D4 (as stated above) was statistically different from D8: The reading mentor teacher participates in lesson videotaping (yielded a critical value of $13.58, p<.01$ ).

7) D8: The reading mentor teacher participates in lesson videotaping was statistically different from D1: The reading mentor teacher assists the staff in selecting, securing, 
and explaining appropriate instructional materials, strategies, and programs (yielded a critical value of $19.51, p<.01)$.

8) D8 (as stated above) was statistically different from D2: The reading mentor teacher demonstrates a clear understanding of appropriate student classroom behaviors and instructional environment (yielded a critical value of 19.63, $p<.01$ ).

9) D8 (as stated above) was statistically different from D3: The reading mentor teacher meets quarterly with the principal to monitor the evaluation measurement areas (i.e., student achievement, teacher knowledge, effect of professional development on classroom practice) (yielded a critical value of $16.54, p<.01$ ).

10) D8 (as stated above) was statistically different from D5: The reading mentor teacher serves as the school liaison for reading assessment coordination (yielded a critical value of $20.62, p<.01)$.

11) D8 (as stated above) was statistically different from D6: The reading mentor teacher assists teachers with the implementation of content, skills, and strategies to promote successful readers (yielded a critical value of $20.74, p<.01$ ).

12) D8 (as stated above) was statistically different from $D 7$ : The reading mentor teacher models effective classroom instruction (yielded a critical value of 19.14, $p<.01$ ).

Overall respondents rated seven of the eight instruction and assessment reading mentor teacher activities as important to improving reading instruction with a mean importance rating of above or slightly below 4.00. These seven instruction and assessment reading mentor teacher activities included: assisting teachers with implementation of promoting successful readers; serving as the school liaison for reading assessment coordination; demonstrating a clear understanding of appropriate student classroom behaviors and instructional environment; 
assisting staff in selecting, securing, and explaining appropriate instructional materials, strategies, and programs; modeling effective classroom instruction; and meeting quarterly with the principal and central office coordinator to monitor evaluation measurement areas.

Respondents rated seven of the eight instruction and assessment reading mentor teacher activities as more important in improving reading instruction than activity D8. This activity, participating in lesson videotaping, had a mean importance rating of 2.66. The multiple comparison (i.e., Tukey) test further indicated that the importance rating of these two activities was statistically different in comparison to the majority of the other professional development activities.

\section{Research Question 2}

Research Question 2: What do reading coaches do in the areas of: Reading First administration, professional development, and instruction and assessment, as perceived by K-3 reading teachers in Reading First Title I Distinguished Schools?

The data analysis to address Research Question 2 involved a tabulation of responses from survey sections E, F, and G presented as both a frequency and a percentage. The data for section E show that the majority of participants (i.e., a response range of 97-80\%) responded "yes, knowledge the reading mentor teacher performed this activity" regarding Reading First administration reading mentor teacher activities. Table 7 shows the seven Reading First administration reading mentor teacher activities, the participant response rate $(\mathrm{N})$, and the number and percentage of "yes, knowledge the reading mentor teacher performed this activity" and "no, no knowledge the reading mentor teacher performed this activity" responses. 
Table 7

Knowledge the Reading Mentor Teacher Performed Reading First Administration Activities

\begin{tabular}{|c|c|c|c|}
\hline & $N$ & $\begin{array}{c}\text { No. }(\%) \\
\text { With Knowledge }\end{array}$ & $\begin{array}{c}\text { No. }(\%) \\
\text { Without Knowledge }\end{array}$ \\
\hline \multicolumn{4}{|l|}{ The reading mentor teacher... } \\
\hline $\begin{array}{l}\text { E1. coordinates and assesses } \\
\text { the daily operation of the } \\
\text { Reading First program. }\end{array}$ & 68 & $61(90 \%)$ & $7(10 \%)$ \\
\hline $\begin{array}{l}\text { E2. communicates a minimum } \\
\text { of twice per year with the } \\
\text { school's assigned WVDE } \\
\text { reading cadre liaison. }\end{array}$ & 67 & $60(90 \%)$ & $7(10 \%)$ \\
\hline $\begin{array}{l}\text { E3. works with the school's } \\
\text { assigned WVDE reading } \\
\text { cadre liaison to assist in } \\
\text { the administration of the } \\
\text { Reading First program. }\end{array}$ & 62 & $62(93 \%)$ & $5(7 \%)$ \\
\hline $\begin{array}{l}\text { E4. participates in the } \\
\text { dissemination of Reading } \\
\text { First program development } \\
\text { activities. }\end{array}$ & 67 & $64(96 \%)$ & $3(4 \%)$ \\
\hline $\begin{array}{l}\text { E5. maintains a flexible } \\
\text { schedule for the purpose } \\
\text { of adequately addressing } \\
\text { reading priorities. }\end{array}$ & 67 & $60(90 \%)$ & $7(10 \%)$ \\
\hline $\begin{array}{l}\text { E6. attends local, state, and } \\
\text { national meetings supportive } \\
\text { of the administration of the } \\
\text { Reading First program. }\end{array}$ & 68 & $66(97 \%)$ & $2(3 \%)$ \\
\hline $\begin{array}{l}\text { E7. meets at least monthly } \\
\text { with the principal for program } \\
\text { planning, implementation, } \\
\text { and evaluation purposes. }\end{array}$ & 66 & $53(80 \%)$ & $13(20 \%)$ \\
\hline
\end{tabular}

As indicated in Table 7, in responding to the seven Reading First administration reading mentor activities, $97 \%$ to $80 \%$ of respondents selected "yes, knowledge the reading mentor teacher performed this activity". These activities can be ranked from the highest to the lowest percentage of "yes" responses: 
1) E6: The reading mentor teacher attends local, state, and national meetings supportive of the administration of the Reading First program (97\% or 66 of 68 “yes” responses).

2) E4: The reading mentor teacher participates in the dissemination of Reading First program development activities (96\% or 64 of 67 “yes" responses).

3) E3: The reading mentor teacher works with the school's assigned WVDE reading cadre liaison to assist in the administration of the Reading First program (93\% or 62 of 67 "yes" responses).

4) E1: The reading mentor teacher coordinates and assesses the daily operation of the Reading First program (90\% or 61 of 68 “yes" responses).

5) E2: The reading mentor teacher communicates a minimum of twice per year with the school's assigned WVDE reading cadre liaison (90\% or 60 of 67 "yes" responses).

6) E5: The reading mentor teacher maintains a flexible schedule for the purpose of adequately addressing reading priorities (90\% or 60 of 67 “yes" responses).

7) E7: The reading mentor teacher meets at least monthly with the principal for program planning, implementation, and evaluation purposes (80\% or 53 of 66 responses).

According to the data, participants do have knowledge that reading mentor teachers are performing each of the seven Reading First administrative activities as indicated by an average "yes" response rate of $97 \%$ to $80 \%$. Only one of the activities (i.e., meeting monthly with the principal for program planning, implementation, and evaluation purposes) was perceived by respondents as less known to be performed by reading mentor teachers than the other Reading First administration activities as indicated by a mean of less than $90 \%$.

The data for section $\mathrm{F}$ show that the majority of participants (i.e., a response range of $94 \%$ to $82 \%$ ) responded "yes, knowledge the reading mentor teacher performed this activity" 
regarding professional development reading mentor teacher activities. Table 8 shows the eight professional development reading mentor teacher activities, the participant response rate $(\mathrm{N})$, and the number and percentage of "yes, knowledge the reading mentor teacher performed this activity" and "no, no knowledge the reading mentor teacher performed this activity" responses. 
Table 8

Knowledge the Reading Mentor Teacher Performed Professional Development Activities

\begin{tabular}{|c|c|c|c|}
\hline & $N$ & $\begin{array}{c}\text { No. }(\%) \\
\text { With Knowledge }\end{array}$ & $\begin{array}{c}\text { No. }(\%) \\
\text { Without Knowledge }\end{array}$ \\
\hline \multicolumn{4}{|l|}{ The reading mentor teacher... } \\
\hline $\begin{array}{l}\text { F1. works with the school's assigned WVDE } \\
\text { reading cadre liaison at least twice per } \\
\text { year to assist in planning the school's } \\
\text { Reading First professional development. }\end{array}$ & 66 & $54(82 \%)$ & $12(18 \%)$ \\
\hline $\begin{array}{l}\text { F2. attends required state sponsored } \\
\text { professional development sessions. }\end{array}$ & 68 & $63(93 \%)$ & $5(7 \%)$ \\
\hline $\begin{array}{l}\text { F3. attends } 100 \text { hours of required Reading First } \\
\text { professional development per year with } \\
\text { classroom teachers. }\end{array}$ & 67 & $56(84 \%)$ & $11(16 \%)$ \\
\hline $\begin{array}{l}\text { F4. coordinates sustained, research-based } \\
\text { professional development within the school. }\end{array}$ & 67 & $62(93 \%)$ & $5(7 \%)$ \\
\hline $\begin{array}{l}\text { F5. provides technical assistance (e.g., modeling, } \\
\text { administering student assessments, grouping } \\
\text { of students, alignment of assessment data } \\
\text { with instruction) to all K-3 reading teachers } \\
\text { (e.g., classroom, special education, Title I, } \\
\text { interventionists) during the school day. }\end{array}$ & 67 & $62(93 \%)$ & $5(7 \%)$ \\
\hline $\begin{array}{l}\text { F6. provides technical assistance (e.g., modeling, } \\
\text { administering student assessments, grouping } \\
\text { of students, alignment of assessment data } \\
\text { with instruction) to all K-3 reading teachers } \\
\text { (e.g., classroom, special education, Title I, } \\
\text { interventionists) throughout the school year. }\end{array}$ & 66 & $62(94 \%)$ & $4(6 \%)$ \\
\hline F7. individually coaches K-3 reading teachers. & 66 & $61(92 \%)$ & $5(8 \%)$ \\
\hline $\begin{array}{l}\text { F8. observes K- } 3 \text { classroom teachers and } \\
\text { provides constructive feedback at least } \\
\text { once monthly. }\end{array}$ & 67 & $60(90 \%)$ & $7(10 \%)$ \\
\hline
\end{tabular}

As indicated in Table 8, in responding to the eight professional development reading mentor teacher activities, $94 \%$ to $82 \%$ of respondents selected "yes, knowledge the reading mentor teacher performed this activity". These activities ranked from the highest to the lowest percentage of "yes" responses: 
1) F6: The reading mentor teacher provides technical assistance (e.g., modeling, administering student assessments, grouping of students, alignment of assessment data with instruction) to all K-3 reading teachers (e.g., classroom, special education, Title I, interventionists) throughout the school year (94\% or 62 of 66 "yes" responses).

2) F2: The reading mentor teacher attends required state sponsored professional development sessions (93\% or 63 of 68 “yes" responses).

3) F4: The reading mentor teacher coordinates sustained, research-based professional development within the school (93\% or 62 of 67 "yes" responses).

4) F5: The reading mentor teacher provides technical assistance (e.g., modeling, administering student assessments, grouping of students, alignment of assessment data with instruction) to all K-3 reading teachers (e.g., classroom, special education, Title I, interventionists) during the school day (93\% or 62 of 67 "yes" responses).

5) F7: The reading mentor teacher individually coaches K-3 reading teachers (92\% or 61 of 66 “yes" responses).

6) F8: The reading mentor teacher observes K-3 classroom teachers and provides constructive feedback at least monthly ( $90 \%$ or 60 of 67 "yes" responses).

7) F3: The reading mentor teacher works with the school's assigned WVDE reading cadre liaison at least twice per year to assist in planning the school's Reading First professional development ( $84 \%$ or 56 of 67 “yes" responses).

8) F1: The reading mentor teacher works with the school's assigned WVDE reading cadre liaison at least twice per year to assist in planning the school's Reading First professional development ( $82 \%$ or 54 of 66 "yes" responses). 
According to the data, participants do have knowledge that reading mentor teachers are performing each of the eight professional development reading mentor activities as indicated by an average "yes" response rate of $94 \%$ to $82 \%$. Only two of the activities (i.e., attends 100 hours of required Reading First professional development per year with classroom teachers, and works with the school's assigned WVDE reading cadre liaison at least twice per year to assist in planning the school's Reading First professional development) were perceived by respondents as less known to be performed by reading mentor teachers than the other professional development activities as indicated by a mean of less than $90 \%$.

The data for section $\mathrm{G}$ show that the majority of participants ( i.e., a response range of $95 \%$ to $69 \%$ ) responded "yes, knowledge the reading mentor teacher performed this activity" regarding instruction and assessment reading mentor teacher activities. Table 9 shows the eight instruction and assessment reading mentor teacher reading activities, the participant response rate $(\mathrm{N})$, and the number and percentage of "yes knowledge the reading mentor teacher performed this activity" and "no, no knowledge the reading mentor teacher performed this activity" responses. 
Table 9

Knowledge the Reading Mentor Teacher Performed Instruction and Assessment Activities

\begin{tabular}{|c|c|c|c|}
\hline & $N$ & $\begin{array}{c}\text { No. }(\%) \\
\text { With Knowledge }\end{array}$ & $\begin{array}{c}\text { No. }(\%) \\
\text { Without Knowledge }\end{array}$ \\
\hline \multicolumn{4}{|l|}{ The reading mentor teacher... } \\
\hline $\begin{array}{l}\text { G1. assists the staff in selecting, securing, } \\
\text { and explaining appropriate instructional } \\
\text { materials, strategies, and programs. }\end{array}$ & 67 & $62(93 \%)$ & $5(7 \%)$ \\
\hline $\begin{array}{l}\text { G2. demonstrates a clear understanding } \\
\text { of appropriate student classroom } \\
\text { behaviors and instructional } \\
\text { environment. }\end{array}$ & 66 & $63(95 \%)$ & $3(5 \%)$ \\
\hline $\begin{array}{l}\text { G3. meets quarterly with the principal } \\
\text { to monitor the evaluation measurement } \\
\text { areas (i.e., student achievement, } \\
\text { teacher knowledge, effect of professional } \\
\text { development on classroom practice). }\end{array}$ & 65 & $46(71 \%)$ & $19(29 \%)$ \\
\hline $\begin{array}{l}\text { G4. meets quarterly with the central office } \\
\text { project director to monitor the } \\
\text { evaluation measurement areas (i.e., } \\
\text { student achievement, teacher } \\
\text { knowledge, effect of professional } \\
\text { development on classroom practice). }\end{array}$ & 64 & $44(69 \%)$ & $20(31 \%)$ \\
\hline $\begin{array}{l}\text { G5. serves as the school liaison for reading } \\
\text { assessment coordination. }\end{array}$ & 64 & $57(89 \%)$ & $7(11 \%)$ \\
\hline $\begin{array}{l}\text { G6. assists teachers with the implementation } \\
\text { of content, skills, and strategies to } \\
\text { promote successful readers. }\end{array}$ & 66 & $60(91 \%)$ & $6(9 \%)$ \\
\hline G7. models effective classroom instruction. & 66 & $56(85 \%)$ & $10(15 \%)$ \\
\hline G8. participates in lesson videotaping. & 64 & $48(75 \%)$ & $16(25 \%)$ \\
\hline
\end{tabular}

As indicated in Table 9, in responding to the eight instruction and assessment reading mentor teacher activities $95 \%$ to $69 \%$ of respondents selected "yes, knowledge the reading mentor teacher performed this activity". These activities ranked from the highest to the lowest percentage of "yes" responses: 
1) G2: The reading mentor teacher demonstrates a clear understanding of appropriate student classroom behaviors and instructional environment (95\% or 63 of 66 "yes" responses).

2) G1: The reading mentor teacher assists the staff in selecting, securing, and explaining appropriate instructional materials, strategies, and programs (93\% or 62 of 67 "yes" responses).

3) G6: The reading mentor teacher assists teachers with the implementation of content, skills, and strategies to promote successful readers ( $91 \%$ or 60 of 66 “yes" responses).

4) G5: The reading mentor teacher serves as the school liaison for reading assessment coordination ( $89 \%$ or 57 of 64 "yes" responses).

5) G7: The reading mentor teacher models effective classroom instruction (85\% or 56 of 66 "yes" responses).

6) G8: The reading mentor teacher participates in lesson videotaping (75\% or 48 of 64 responses).

7) G3: The reading mentor teacher meets quarterly with the principal to monitor the evaluation measurement areas (i.e., student achievement, teacher knowledge, effect of professional development on classroom practice) ( $71 \%$ or 46 of 65 "yes" responses).

8) G4: The reading mentor teacher meets quarterly with the central office project director to monitor the evaluation measurement areas (i.e., student achievement, teacher knowledge, effect of professional development on classroom practice) (69\% or 44 of 64 responses).

According to the data, participants do have knowledge that reading mentor teachers are performing each of the eight instruction and assessment reading mentor teacher activities as 
indicated by an average "yes" response rate of $95 \%$ to $69 \%$. Four of the activities (i.e., modeling effective classroom instruction, participating in lesson videotaping, meeting quarterly with the principal and the central office project director to monitor evaluation measure areas) were perceived by respondents as less known to be performed by reading mentor teachers than the other instruction and assessment activities as indicated by a mean of less than $90 \%$.

\section{Research Question 3}

Research Question 3: What differences exist between the reading coach activities perceived by K-3 teachers as important to improving reading instruction and the activities performed by K-3 teachers?

The data analysis to address Research Question 3 involved a tabulation of responses from survey sections B, C, and D (mean importance rating per each coaching activity divided by the highest possible rating of 5) and sections E, F, and G (percentage of positive responses or a response of "yes, knowledge the reading mentor teacher performed this activity"). A comparison was made of participant responses to identical reading mentor teacher activities listed in sections B, C, and D (mean importance rating) and sections E, F, and G (percentage of "yes, knowledge the reading mentor teacher performed this activity" responses).

In making such comparisons it is important to have at least similarities between respondent importance ratings and knowledge of performance of the activity since the activities were identified based on an extensive review of the literature and a thorough examination of the State Reading First job description. Line chart graph figures are used to illustrate comparisons of respondent importance ratings and knowledge of performance of the reading mentor teacher activities for each of the three areas (i.e., Reading First administration, professional development, and instruction and assessment). The numbers located at the bottom of the line 
chart indicate the number of the coaching activity and the numbers located on the left side indicate the mean percentage of responses. A square symbol indicates the mean respondent importance rating and a triangle the knowledge of performance percentage. In comparing the lines across the line chart, parallel lines show consistency between respondent importance rating and knowledge of performance. Lines crossing in either direction indicate a discrepancy between the importance and knowledge of performance rating. Notice in Figure 1 and Figure 2 the lines indicating importance rating and knowledge of performance are, for the most part, parallel indicating a consistency between the importance rating and the knowledge of performance of the activity. However, in Figure 3 the lines indicating importance rating and knowledge of performance cross over several of the activities indicating a discrepancy.

Section B of the survey asked respondents to rate the importance of Reading First administration reading mentor teacher activities in relation to improving reading instruction on a scale from 1 (lowest) through 5 (highest). Section E of the survey asked respondents to select either "yes, knowledge the reading mentor teacher performed this activity" or "no, no knowledge the reading mentor teacher performed this activity". Figure 1 presents a comparison of the Reading First administration mean importance rating and the percentage of "yes" performance responses. 
Figure 1

Comparison of Reading First Administration Activities: Importance and Knowledge of Performance

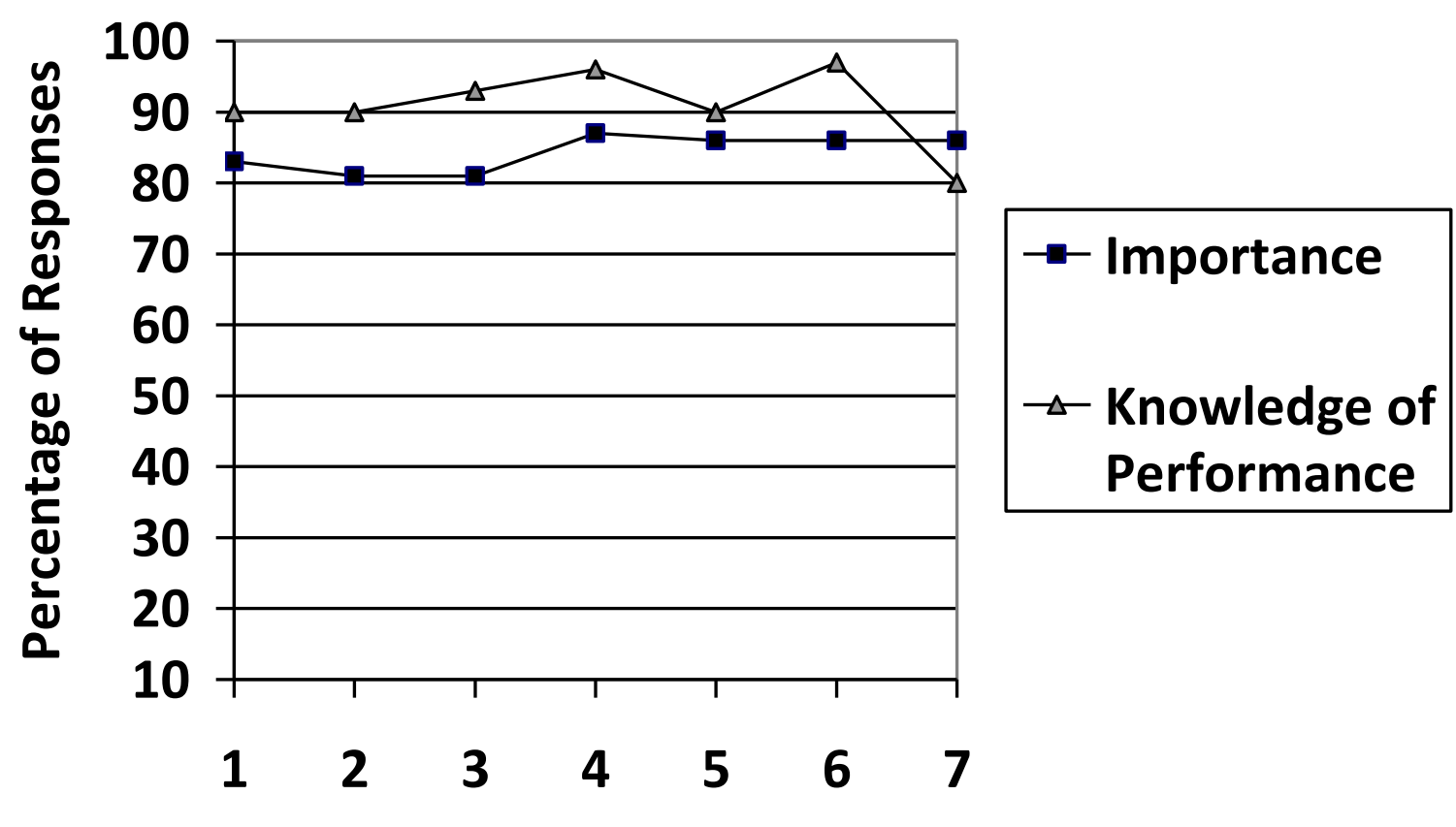

Coaching Activities

As indicated in the Figure 1 line chart, with one exception, there is a higher percentage of "yes" knowledge of performance responses than importance rating responses as indicated by the parallel lines. The six activities in which the data show consistency:

1) B1 to E1: The reading mentor teacher coordinates and assesses the daily operation of the Reading First program (mean importance rating $=83 \%$ and "yes" performance responses $=90 \%$.

2) B2 to E2: The reading mentor teacher communicates a minimum of twice per year with the school's assigned WVDE reading cadre liaison (mean importance rating = $81 \%$ and "yes" performance responses $=90 \%$ ). 
3) B3 to E3: The reading mentor teacher works with the school's assigned WVDE reading cadre liaison to assist in the administration of the Reading First program (mean importance rating $=81 \%$ and "yes" performance responses $=93 \%$ ).

4) B4 to E4: The reading mentor teacher participates in the dissemination of Reading First program development activities (mean importance rating $=87 \%$ and "yes" performance responses $=96 \%$ )

5) B5 to E5: The reading mentor teacher maintains a flexible schedule for the purpose of adequately addressing reading priorities (mean importance rating $=86 \%$ and "yes" performance responses $=90 \%$ )

6) B6 to E6: The reading mentor teacher attends local, state, and national meetings supportive of the administration of the Reading First program (mean importance rating $=86 \%$ and "yes" performance responses $=97 \%$ ).

The line chart further indicates one exception as indicated by a crossing of the lines. One of the Reading First administration reading mentor teacher activities yielded a higher mean importance rating than "yes" performance responses: B7 to E7: The reading mentor teacher meets at least monthly with the principal for program planning, implementation, and evaluation purposes (mean importance rating $=86 \%$ and "yes" performance responses $=80 \%$ ).

Section $\mathrm{C}$ of the survey asked respondents to rate the importance of professional development reading mentor teacher activities in relation to improving reading instruction on a scale from 1 (lowest) through 5 (highest). Section F of the survey asked respondents to select either "yes, knowledge the reading mentor teacher performed this activity" or "no, no knowledge the reading mentor teacher performed this activity". Figure 2 presents a comparison of the 
professional development mean importance rating and the percentage of "yes" performance responses.

Figure 2

Comparison of Professional Development Activities: Importance and Knowledge of Performance

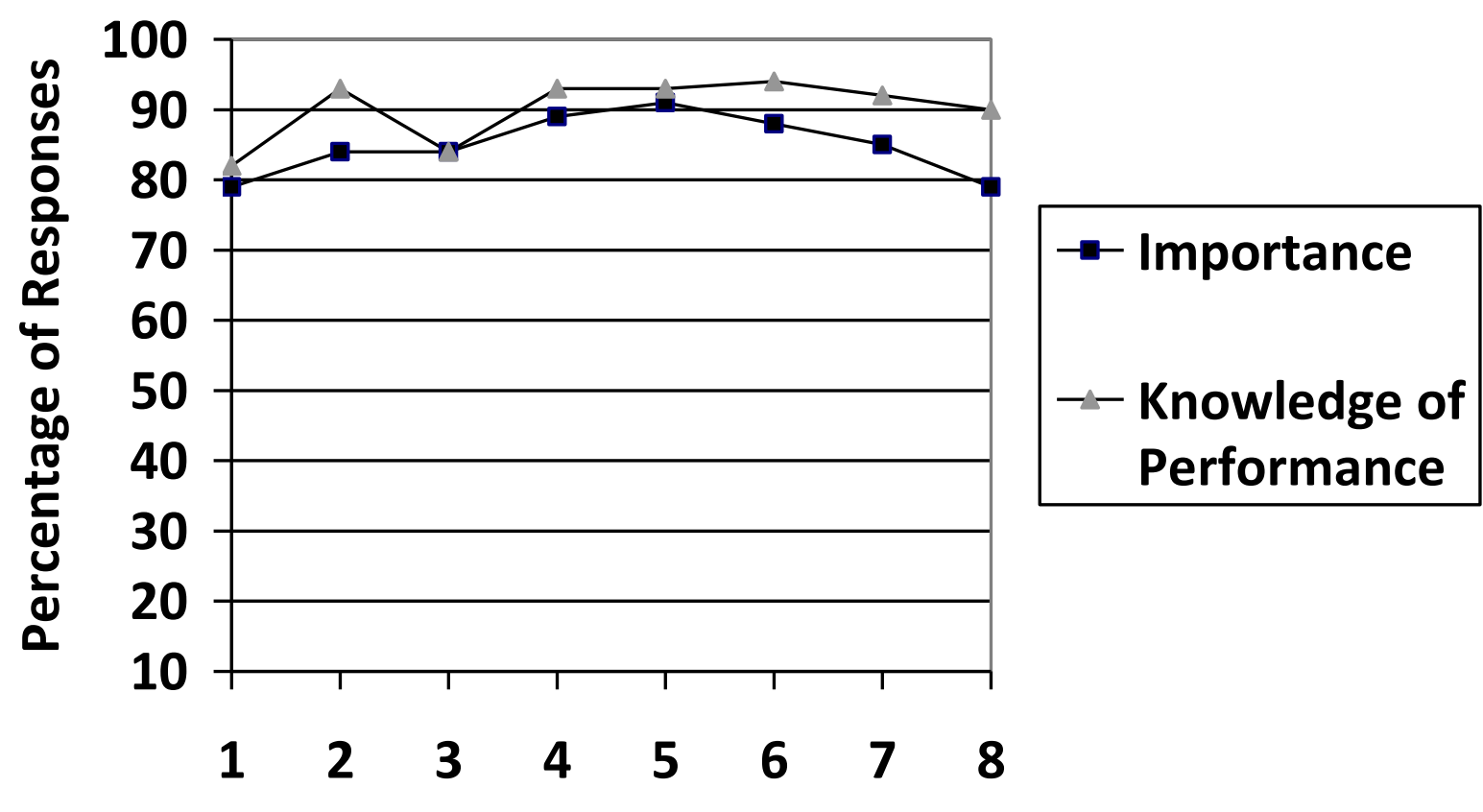

Coaching Activities

As indicated in the Figure 2 line chart, with one exception, there is a higher percentage of "yes" knowledge of performance responses than importance rating responses as indicated by the parallel lines. The seven activities in which the data show consistency:

1) C1 and F1: The reading mentor teacher works with the school's assigned WVDE liaison at least twice per year to assist in planning the school's Reading First professional development (mean importance rating $=79 \%$ and "yes" performance responses $=82 \%$. 
2) $\mathrm{C} 2$ and F2: The reading mentor teacher attends required state sponsored professional development sessions (mean importance rating $=84 \%$ and "yes" performance responses $=93 \%$ ).

3) C4 and F4: The reading mentor teacher coordinates sustained, research-based professional development within the school (mean importance rating $=89 \%$ and "yes" performance responses $=93 \%$ ).

4) C5 and F5: The reading mentor teacher provides technical assistance (e.g., modeling, administering student assessments, grouping of students, alignment of assessment data with instruction) to all K-3 reading teachers (e.g., classroom, special education, Title I, interventionists) during the school day (mean importance rating $=91 \%$ and “yes" performance responses $=93 \%$ ).

5) C6 and F6: The reading mentor teacher provides technical assistance (e.g., modeling, administering student assessments, grouping of students, alignment of assessment data with instruction) to all K-3 reading teachers (e.g., classroom, special education, Title I, interventionists) throughout the school year (mean importance rating $=88 \%$ and "yes" performance responses $=94 \%$ ).

6) $\mathrm{C} 7$ and F7: The reading mentor teacher individually coaches $\mathrm{K}-3$ reading teachers (mean importance rating $=85 \%$ and "yes" performance responses $=92 \%$ ).

7) C8 and F8: The reading mentor teacher observes K-3 classroom teachers and provides constructive feedback at least once monthly (mean importance rating $=79 \%$ and "yes" performance responses $=90 \%$ ).

The line chart also indicates one exception as indicated by touching lines. One of the 
professional development reading mentor teacher activities yielded the same mean importance rating as "yes" performance responses: C3 and F3: The reading mentor teacher attends 100 hours of required Reading First professional development per year with classroom teachers (mean importance rating $=84 \%$ and "yes" performance responses $=84 \%$ ).

Section D of the survey asked respondents to rate the importance of instruction and assessment reading mentor teacher activities in relation to improving reading instruction on a scale from 1 (lowest) through 5 (highest). Section $\mathrm{G}$ of the survey asked respondents to select either "yes, knowledge the reading mentor teacher performed this activity" or "no, no knowledge the reading mentor teacher performed this activity". Figure 3 presents a comparison of the instruction and assessment mean importance rating and the percentage of "yes" knowledge of performance responses. 
Figure 3

Comparison of Instruction and Assessment Activities: Importance and Knowledge of Performance

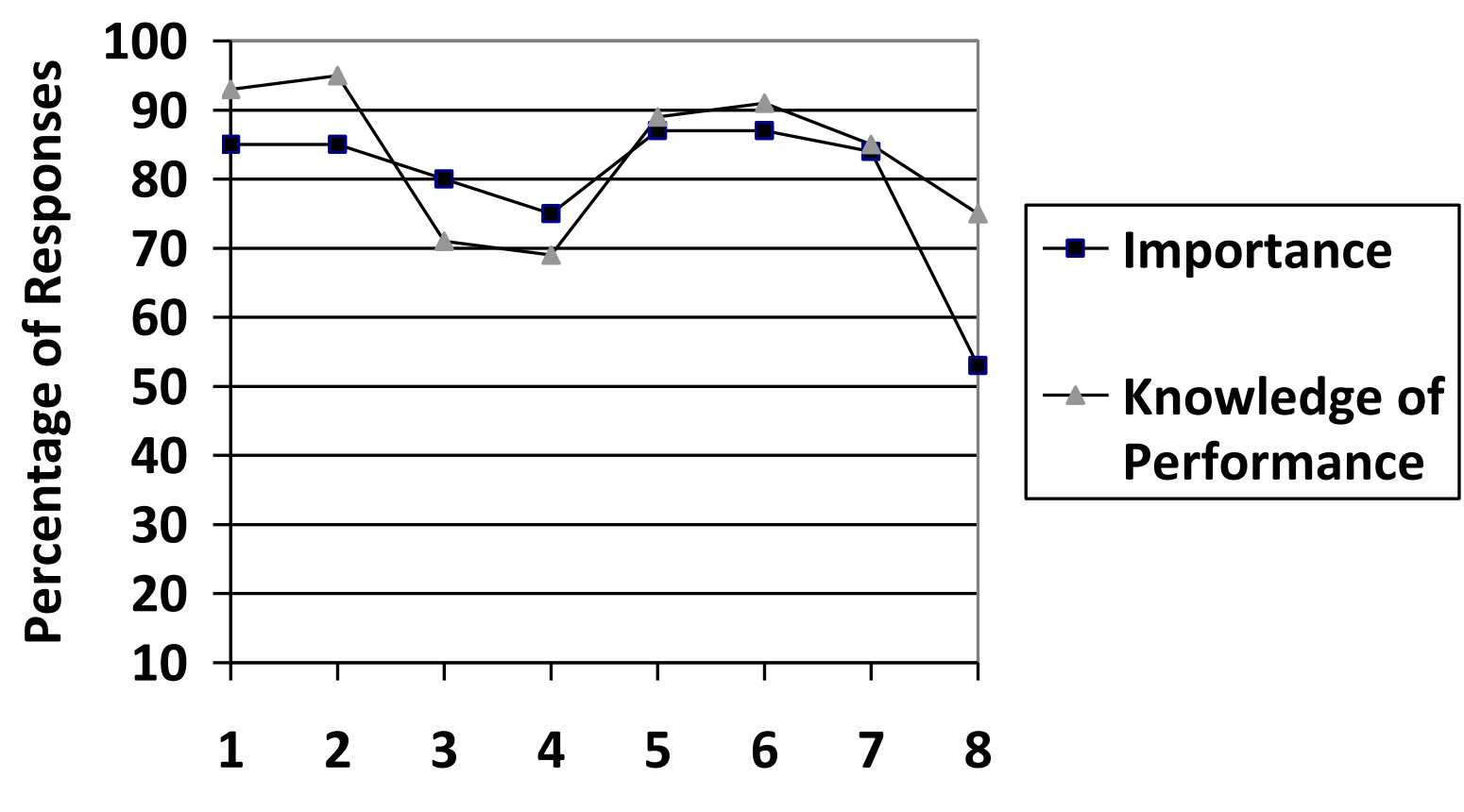

Coaching Activities

As indicated in the Figure 3 line chart, with two exceptions, there is a higher percentage of "yes" knowledge of performance responses than importance rating responses. The six activities in which the data show consistency:

1) D1 and G1: The reading mentor teacher assists the staff in selecting, securing, and explaining appropriate instructional materials, strategies, and programs (mean importance rating $=85 \%$ and "yes" performance responses $=93 \%$ ).

2) D2 and G2: The reading mentor teacher demonstrates a clear understanding of appropriate student classroom behaviors and instructional environment (mean importance rating $=85 \%$ and $\mathrm{G} 2=95 \%)$. 
3) D5 and G5: The reading mentor teacher serves as the school liaison for reading assessment coordination (importance rating $=87 \%$ and "yes" performance responses $=89 \%$.

4) D6 and G6: The reading mentor teacher assists teachers with the implementation of content, skills, and strategies to promote successful readers (importance rating $=87 \%$ and "yes" performance responses $=91 \%$ ).

5) D7 and G7: The reading mentor teacher models effective classroom instruction (importance rating $=84 \%$ and "yes" performance responses $=85 \%$ ).

6) D8 and G8: The reading mentor teacher participates in lesson videotaping (importance rating $=53 \%$ and "yes" performance responses $=75 \%$ ).

The line chart also indicates two exceptions. These two professional development reading mentor teacher activities yielded a higher mean importance rating than "yes" performance responses:

1) D3 and G3: The reading mentor teacher meets quarterly with the principal to monitor the evaluation measurement areas (i.e., student achievement, teacher knowledge, effect of professional development on classroom practice) (mean importance rating $=80 \%$ and "yes" performance responses $=71 \%$ ).

2) D4 and G4: The reading mentor teacher meets quarterly with the central office project director to monitor the evaluation measurement areas (i.e., student achievement, teacher knowledge, effect of professional development on classroom practice) (mean importance rating =75\% and "yes" performance responses $=69 \%$.

Two other comparison differences in sections D and G are also worth note. First, D7 and 
G7, “The reading mentor teacher models effective classroom instruction”, yielded only one percentage point more in comparing importance to "yes" responses ( $D 7=84 \%$ and G7 $=85 \%$ ). Secondly, D8 and G8, "The reading mentor teacher participates in lesson videotaping" (D8 = $54 \%$ and G8 $=75 \%$ ) resulted in the largest difference between importance rating and "yes" knowledge of performance responses of activities in all three categories.

As revealed in the Figure 3 line chart, the data show that the majority of the lines representing importance rating and knowledge of performance of the activity are parallel indicating a consistency between responses. In particular, six of the eight instruction and assessment knowledge of performance responses yielded a higher percentage of overall responses than the mean importance rating. The data also show that two of the lines cross indicating a discrepancy between knowledge of performance and importance rating. These two exceptions (i.e., meeting quarterly with the principal and the central office project director to monitor the evaluation measurement areas) yielded a higher mean importance rating than "yes" performance responses. In addition, two other comparisons pertaining to the instruction and assessment reading mentor teacher activities were discovered. First, modeling effective classroom instruction, yielded only one percentage point more in comparing importance to "yes" responses. Secondly, participating in lesson videotaping resulted in the largest difference between importance rating and "yes" knowledge of performance responses.

\section{Summary}

A population of 160 K-3 reading teachers working in Title I Distinguished Schools throughout West Virginia were invited to participate in this survey research study which yielded a $44 \%$ response rate. The purpose of the study was to examine teacher perceptions regarding the importance of reading mentor teacher activities in improving reading instruction. The study 
further examined whether differences existed between the reading coach activities perceived by K-3 teachers as important to improving reading instruction and the activities performed by reading mentor coaches. Data for the study were collected electronically through the utilization of Survey Monkey to both distribute and collect survey responses from the participants. The Reading First K-3 Classroom Reading Teacher Survey served as the survey instrument.

Data were collected from participants regarding demographics and to specifically address the three research questions. Research Question 1 involved an analysis of several measurements including the number of participant responses $(\mathrm{N})$, mean, standard deviation, and an analysis of variance. A multiple comparison (i.e., Tukey) test was conducted when significant differences were determined through the analysis of variance for the purpose of providing specific data regarding where the differences existed. Research Question 2 involved a tabulation of responses presented as both a frequency and a percentage. Research Question 3 involved a tabulation of the mean importance rating converted to a percentage (mean importance rating per each coaching activity divided by the highest possible rating of 5) and the percentage of positive or "yes" knowledge of performance responses regarding teacher knowledge that the reading mentor teacher performed the reading mentor teacher activities.

Data collected to address Research Question 1 reveal that the majority of listed reading mentor teacher activities were considered important by respondents to improving reading instruction as indicated with the mean importance rating of each section (i.e., Reading First administration activities yielded a range of responses from 4.35 to 4.07 , professional development activities 4.53 to 3.94 , and instruction and assessment activities 4.34 to 2.66 ).

The standard deviations show similar dispersion of importance ratings across the items (i.e., Reading First administration activities yielded a standard deviation of 1.17 to 0.97 , 
professional development activities 1.27 to 0.89 to, instruction and assessment activities 0.94 to 1.23) with higher numbers indicating a greater dispersion of ratings and lower numbers indicating less dispersion of ratings.

A with-in subjects (repeated-measures) analysis of variance was computed for each of the three categories resulting in significant differences of the components within two of the categories (i.e., professional development and instruction and assessment). A multiple comparison (i.e., Tukey) test further indicated where the differences existed. The Tukey test revealed statistically significant differences among the professional development activities and the instruction and assessment activities.

Data collected to address Research Question 2 reveal that the majority of participants responded "yes, knowledge the reading mentor teacher performed this activity" as indicated from an analysis of the percentage of "yes" and "no" responses (Reading First administration yielded a range of responses from $97 \%$ to $80 \%$, professional development $94 \%$ to $82 \%$, and instruction and assessment $95 \%$ to $69 \%$ ). A few of the responses yielded an $80 \%$ or less overall "yes" response. These activities included: meeting at least monthly with the principal for program planning, implementation, and evaluation purposes (Reading First administration); and participation in lesson videotaping and meeting quarterly with the principal and central office project director to monitor evaluation measurement areas (instruction and assessment).

With relatively few exceptions, data collected to address Research Question 3 for each of the three areas reveal a higher percentage of "yes, knowledge the reading mentor teacher performed the activity" than the mean percentage of importance responses. Data from respondents to the instruction and assessment activities reveal the largest difference between the percentage of "yes" responses and importance rating responses. 


\section{CHAPTER V: SUMMARY, CONCLUSION, DISCUSSION, AND RECOMMENDATIONS}

This chapter will include a summary, study conclusion, discussion, and recommendations based on the major findings of the study.

\section{Summary}

This study was designed to examine the importance of reading coach activities in improving reading instruction in West Virginia Title I Distinguished Schools as determined by K-3 reading teacher perceptions. The study further investigated whether differences existed between the reading coach activities perceived by K-3 teachers as important to improving reading instruction and those activities perceived by K-3 teachers as being performed by reading coaches. The data were collected through the utilization of a survey instrument, the Reading First K-3 Classroom Reading Teacher Survey developed specifically for this study. The reading coach activities found in the survey instrument were identified based on a comprehensive review of the literature and the West Virginia Reading First Mentor Teacher Model Job Description. Survey responses regarding the perceptions of K-3 teachers provide the basis for several conclusions.

\section{Research Question 1}

Research Question 1: How do K-3 reading teachers in Title I Distinguished Schools perceive the importance of the activities of reading coaches in the areas of: Reading First administration, professional development, and instruction and assessment in improving reading instruction?

The data reveal the following pertaining to participant ratings of reading coach activities in improving reading instruction (with a 1 indicating low importance through a 5 indicating high importance): the seven Reading First administration activities were rated above a 4.00 (i.e., 4.35 
to 4.07 ), the eight professional development activities were rated above or slightly below a 4.00 (i.e., 4.53 to 3.94), and six of the eight instruction and assessment activities were rated at or above 4.00 (i.e., 4.34.to 4.00) with the remaining two rated lowest within all of the categories (i.e., 3.76 and 2.66).

Based on the data and with few exceptions, participants in this study considered the reading coach activities in each of the three areas (i.e. Reading First administration, professional development, and instruction and assessment) as important to improving reading instruction. Two activities, both in the instruction and assessment category, received the lowest overall mean rating within all categories suggesting participants considered these activities as less important than the others (i.e., meets quarterly with the central office project director to monitor the evaluation measurement areas, and participates in lesson videotaping). This indicates that teachers perceived these activities as slightly less important in improving reading instruction. The latter mentioned activity, participates in lesson videotaping, was rated lowest overall among all categories indicating that teachers perceive this activity as less important than all other coaching activities in improving reading instruction.

There are no other studies pertaining to the perceptions of classroom reading teachers in relation to the importance of reading coach activities in improving instruction. However, there are two similar dissertation studies. The first was conducted by Conway (2006) and examined teacher attitudes, perceptions, and practices in reading instruction based on teacher experience and school demographics. Findings of the study provided evidence that coaches made a difference in how teachers perceived their work with students, effective practices, student performance, the implementation of new instructional techniques, and reassessing their instruction. Moreover, evidence within the results of the study supported the use of coaches to 
provide professional development. The second study was conducted by Fillman (2005) and involved teacher interviews pertaining to the perceptions of teachers regarding the role of the Reading First reading coach. Teacher participants were interviewed throughout a one year period (beginning, middle, and end of year) using open-ended questions. Themes similar to those identified in this study emerged from the analysis of the interview data in relation to teacher perceptions regarding the coach's role. The reading coach activities identified were fewer in number, but included activities representing each of the three categories examined in this study (i.e., Reading First Administration, professional development, and instruction and assessment). In particular, teachers perceived the coach's role to include: ensuring grant fidelity, modeling instruction, and coordination of assessments.

Finally, in another similar study pertaining to reading coaches in Florida's middle schools, the majority of teachers reported that the school's reading coach had a positive effect on improving their reading instructional practice (Marsh, McCombs, Lockwood, Martorell, Gershwin, Naftel, Le, Shea, Barney, \& Crego, 2008).

\section{Research Question 2}

Research Question 2: What do reading coaches do in the areas of: Reading First administration, professional development, and instruction and assessment, as perceived by K-3 reading teachers in Reading First Title I Distinguished Schools?

The data reveal that the majority of K-3 reading teachers participating in this study responded "yes, knowledge the reading mentor teacher performed this activity" in response to the school's reading mentor teacher in the areas of Reading First administration, professional development, and instruction and assessment (overall "yes" knowledge of performance response rate of 95\% to 69\%). By category: Reading First administration activities yielded a response 
range of $90 \%$ to $80 \%$ of "yes" responses to the seven activities, professional development activities yielded a response range of $94 \%$ to $82 \%$ of "yes" responses to the eight activities, and instruction and assessment activities yielded a response range of $95 \%$ to $69 \%$ of "yes" responses to the eight activities.

These data suggest that the majority of K-3 reading teachers participating in this study have knowledge that the school's reading mentor teacher performs activities in the areas of Reading First administration, professional development, and instruction and assessment. Some activities, however, were less known to be performed by coaches than others as indicated by a lower percentage of overall "yes" knowledge of performance responses. Given the results of the study, it is evident K-3 teachers participating in this study are cognizant of the performance of these particular reading coach activities within their schools and are utilizing their time attending to coaching activities considered important by K-3 teachers to improving reading instruction.

There are no other studies relating to the duties of reading coaches who work in Title I Distinguished Schools. However, a similar dissertation study was conducted by Christy (2007) examining what principals of Title I Distinguished Schools in Virginia do to develop and sustain successful reading programs. Findings suggested that principals in these schools were performing similar activities as those identified for reading coaches in this study. While not specifically categorized into the three areas of reading administration, professional development, and instruction and assessment, the identified duties are similarly related to the three categories. For example, principals participated in on-going data analysis to drive instructional decision making, secured reading instructional resources for teachers, empowered teachers, facilitated common planning time, and communicated expectations of literacy instruction. The study also revealed principal leadership duties which targeted on-going professional development. It was 
found that the majority of the principal duties identified in the area of professional development were similar to reading coach duties recognized in this study (e.g., facilitation of long-term professional development in implementing a building-wide literacy program, arrangement of professional development during the school day at the school site, and involvement of the entire faculty in the study of common literacy-related books).

A study of reading coaches in Florida's middle schools conducted by Marsh, et al. (2008) found that these reading coaches typically divided their time among similar activities (to this study), including formally working with teachers, informal coaching, administrative duties, data analysis, and non-coaching duties. The state of Florida provides districts with a model job description outlining basic coach qualifications, duties, and the suggestion that at least half the reading coaches' time is spent working directly with teachers.

Two coaching studies mentioned earlier in the literature review section by Elmore (1997) and Neufeld and Roper (2003) showed similar results. A key finding of Elmore's (1997) influential coaching professional development study was that change in improving instruction depends on effective professional development which is based on a clear set of principles, activities, and structures. Likewise, Neufeld and Roper (2003), in an extensive examination of professional development involving coaching in four large American cities, concluded that coaching can improve several areas of instruction (e.g., school-based professional development, implementation of classroom strategies, shared instructional practices between peers and coaches, development of a school culture focusing on instruction, and using reflection of data to drive instructional practice). 


\section{Research Question 3}

Research Question 3: What differences exist between the reading coach activities perceived by K-3 teachers as important to improving reading instruction and the activities performed by reading coaches?

The data reveal that K-3 teachers participating in this study rated the majority of reading coach activities in the areas of Reading First administration, professional development, and instruction and assessment with an overall higher percentage of "yes, knowledge the reading mentor teacher performed this activity" responses than percentage of mean importance responses. There were only four exceptions where the overall mean percentage rating of importance of the activity in improving reading instruction was rated higher than the overall percentage of "yes, knowledge of performance" responses:

- meets at least monthly with the principal for program planning, implementation, and evaluation purposes (Reading First administration: mean importance rating $=86 \%$ and "yes" performance responses $=80 \%$ ).

- attends 100 hours of required Reading First professional development per year with classroom teachers (professional development: mean importance rating $=86 \%$ and "yes" performance responses $=84 \%$ ).

- meets quarterly with the principal to monitor the evaluation measurement areas (instruction and assessment: mean importance rating $=80 \%$ and "yes" performance responses $=71 \%)$.

- meets quarterly with the central office project director to monitor the evaluation measurement areas (instruction and assessment: mean importance rating $=75 \%$ and "yes" performance responses $=69 \%$ ). 
This data suggest that K-3 teachers perceive the majority of the listed reading coach activities to be important to improving reading instruction. Moreover, the majority of respondents indicated "yes" they had knowledge the reading mentor teacher performed the identical activity. Such positive responses suggest that K-3 teachers are in agreement with the literature review indicating the importance of these coaching activities in improving reading instruction. Further, K-3 teachers responded positively when asked if they had knowledge the reading mentor teacher performed the identical reading coach activities suggesting that the activities are indeed occurring in these Reading First classrooms.

There are no studies which specifically compare whether differences exist between K-3 teacher perceptions pertaining to the importance of reading coach activities and whether the activities are known to be performed by coaches working in the school.

\section{Study Conclusion}

The findings of this study indicate that Reading First K-3 teachers working in Title I Distinguished Schools in West Virginia perceive reading coach activities to be important in improving reading and they are knowledgeable the activities are performed by reading coaches within their schools.

\section{Discussion}

In initiating this study coaching was considered as an option to addressing the issue of effective distributed leadership whereas others within the school assume the leadership role. Today's principal is expected to embody a multitude of exemplary skills and characteristics. However, teaching and learning can be described as a knowledge-intensive endeavor making the performance of such complex tasks impossible without effective distribution of leadership (Elmore, 2000). The largely positive results of this study suggest that K-3 reading teachers, those 
working on the front lines of instruction, perceive the defined reading coach activities as important to improving instruction. In addition, these K-3 teachers responded favorably overall regarding the performance of these activities by coaches within their schools.

All of the K-3 teachers participating in this study work in schools which have consistently been measured as high performing. This is evidenced by their recognition as a West Virginia Title I Distinguished School. Besides implementing a Reading First program, the recognition as a Title I Distinguished School was the main reason for the selection of these schools to participate in this study. Since study participants are working in schools which have experienced academic success as evidenced by their "distinguished" recognition, it is important to consider their perceptions in working with reading coaches. The success of the respondents and the data derived from the survey appears to align with the contention of Barr, et al. (2003a) regarding coaching as a promising example of distributed leadership which provides sustained support by focusing on building continuous improvement of teacher instructional capacity and student learning.

What can be derived from the conclusions of the perceptions of these teachers who work in distinguished schools and how can this information assist to improve other schools? Overall the results of this study are a positive indication regarding how West Virginia's Reading First coaches have spent their time in the state's Title I Distinguished Schools and seems logical as a consideration for distributed leadership practice. Why are these results a positive indication? The reading coach activities selected to include in the study's survey instrument were carefully selected beginning with a thorough review of the West Virginia Reading Mentor Teacher Job Description. In addition, these particular activities included a thorough review of the research. Based on their responses, the K-3 teachers in this study consider these particular reading coach 
activities as important to improving reading instruction and are also aware that reading coaches perform these activities within their schools.

Perhaps the most promising finding of the study pertains to differences existing between K-3 teacher perceptions regarding the importance of the reading activities in improving instruction and the activities performed by the coaches. The data show a higher overall percentage of responses indicating the teachers have knowledge the reading coach performed the majority of reading coach activities in comparison to the percentage of mean importance responses. These results indicate that Reading First K-3 teachers in Title I Distinguished Schools in West Virginia perceive these reading coach activities as important in improving reading instruction and they are knowledgeable the activities are performed by reading coaches within their schools. These positive responses suggest that K-3 teachers are in agreement with the literature review indicating the importance of each reading coach activity in improving reading instruction. K-3 teachers also responded positively when asked if they had knowledge the reading coach performed the activity further suggesting these research supported activities are occurring in Reading First classrooms. Considering these findings and similar research pertaining to the defined coaching activities, it appears promising that these coaching activities are included in the West Virginia Reading Mentor Teacher Job Description.

While the majority of responses were positive, it is also important to consider lower rated activities (i.e., importance rating in improving reading instruction, percentage of "yes" performance responses, and comparison of importance and performance responses). In reflecting upon the importance of the reading coach activities, the majority were rated at the higher end of the rating scale. Only two instruction and assessment reading coach activities were rated as less important than the others. The first activity, "meets quarterly with the central office project 
director to monitor the evaluation measurement areas", was rated next to the lowest of all activities (3.76). What are possible reasons this coaching activity was rated next to the lowest overall by respondents? First, K-3 reading teachers may perceive school-based professional development to be more effective when led by the principal and reading coach than by others outside of the school. Second, K-3 reading teachers participating in the study simply may have not witnessed inclusion of the central office project director in monitoring the evaluation areas of Reading First. Third, the district's central office project director may not be actively involved with monitoring the evaluation areas of Reading First as expected from the state level.

The second activity, "participates in lesson videotaping", was rated the lowest (2.66) and well below all of the other reading coach activities in terms of importance in improving reading instruction. There are several possible reasons for the lower rating. First, K-3 teachers may not have actually participated in lesson videotaping or seen the benefits firsthand. Second, K-3 teachers may have had a negative experience with lesson videotaping such as associating the experience with formal teacher evaluation.

In reflecting upon whether K-3 participants had knowledge the reading coach was performing the activities, the majority responded "yes, knowledge the reading coach performed the activity". Three instruction and assessment coaching activities received the lowest "yes" responses with an overall positive response rating of less than $80 \%$ suggesting these activities are less known to be performed by reading coaches. The first activity, "participates in lesson videotaping", received the third lowest percentage of overall "yes" performance responses of all activities ( $75 \%$ of "yes" performance responses).

The second activity, "meets quarterly with the principal to monitor the evaluation measurement areas", received the second lowest percentage of overall "yes" performance 
responses of all activities ( $71 \%$ of "yes" performance responses). There are several possible reasons for the lower "yes" performance rating. First, K-3 reading teachers participating in the study may simply have not witnessed inclusion of the principal in monitoring the evaluation areas of Reading First. Second, the principal may not be actively involved with monitoring the evaluation areas of Reading First as expected from the state level.

The third activity, "meets quarterly with the central office project director to monitor the evaluation measurement areas", received the lowest percentage of overall "yes" performance responses of all activities (69\% of "yes" performance responses). Noticeably, the two reading coach activities which received the lowest overall importance rating in improving reading instruction also received the lowest "yes" performance responses (i.e., "participates in lesson videotaping" and "meets quarterly with the central office project director to monitor the evaluation measurement areas").

The final research question pertained to whether differences existed between the reading coach activities perceived by respondents as important to improving reading instruction and those performed by reading coaches. K-3 teachers rated the majority of reading coach activities with an overall higher percentage of "yes, knowledge the reading coach performed this activity" than the percentage of mean importance responses. Three coaching activities (one from the Reading First administration and two from the instruction and assessment categories) received an overall higher percentage of mean importance responses than percentage of "yes" knowledge of performance responses. This suggests K-3 teachers consider these four coaching activities as important to improving reading instruction, but are less known to be performed by reading coaches. The first two activities related to the role of the school's principal: 1) "meets at least monthly with the principal for program planning, implementation, and evaluation purposes" 
(mean importance rating $=86 \%$ and "yes" performance responses $=80 \%$ ); and 2 ) "meets quarterly with the principal to monitor the evaluation measurement areas" (mean importance rating $=80 \%$ and "yes" performance responses $=71 \%$ ). The third activity related to the role of the central office project director, "meets quarterly with the central office project director to monitor the evaluation measurement areas" (mean importance rating $=75 \%$ and "yes" performance responses $=69 \%$ ). Again, it is possible these K-3 teachers simply may have not witnessed their school's principal working with the reading coach for program planning, implementation, and evaluation measurement purposes.

Finally, one of the activities, "attends 100 hours of required Reading First professional development per year with classroom teachers" received the same mean importance rating and "yes" knowledge of performance responses at 84\%. This suggests the majority of K-3 teachers agree that this activity is important in improving reading instruction and are equally witnessing the performance of the activity by the school's reading coach.

\section{Recommendations for Administrators and Policy Makers}

This study involved a closer examination of the reading coach component included in the federal Reading First program in select Reading First Title I Distinguished Schools in West Virginia. The final decision has been made by Congress to discontinue funding of the Reading First program; however, this does not mean the important work of improving reading instruction has concluded. The challenge of promoting quality reading instruction continues to be a challenge across the nation. Therefore, recommendations for next steps in promoting successful instructional practices aimed to ensure children are proficient readers must be considered for educational leaders, both administrators and policy makers at all levels - federal, state and local. It is difficult, if not impossible, to separate coaching from overall professional development 
activities. For as Neufeld and Roper (2006) contend, coaching, in combination with other professional development strategies is a credible way to increase a school's instructional capacity. Therefore, recommendations offered at federal, state, and local levels pertaining to this coaching study also include other strategies for encouraging positive change in reading instruction.

\section{Federal Level Recommendations}

1) Reading is an important skill for everyone and must continue to be at the forefront of the national agenda. It is critical to clearly communicate the national intent of assisting states and local education agencies in the important work of improving reading instruction to include quality reading coaches.

2) Most state and local education agencies lack the resources to support the changes necessary to successfully improve reading instruction in schools across the nation. Therefore, adequate funding for reading coaches as an important component of professional development is critical.

3) Provide technical assistance to state educational agencies to build their capacity in improving reading instruction (e.g., sustained, professional development focusing on building the capacity of districts to improve reading instruction through, among other professional development activities, the utilization of reading coaches).

\section{State Level Recommendations}

1) Make the improvement of reading instruction a statewide priority beginning and continuing with statewide communication from state chief instructional leaders to district superintendents, principals, and teachers. 
2) Support districts in the reading improvement effort by providing adequate state resources both in terms of funding and personnel.

3) Employ a certified and highly motivated state level reading specialist to lead the effort in assisting districts to build capacity in improving reading instruction and to support statewide technical assistance.

4) Allow the accessibility of an adequate amount of funding to support the efforts of the state reading specialist in providing sustained professional development to state level reading liaisons (reading specialists from across the state who continuously assist schools and coaches in effectively implementing research-based instructional practices whose membership is made up of district reading specialists, principals, and reading coaches).

5) Focus the professional development of reading coaches on the three categories of activities (i.e., Reading First administration, professional development, and instruction and assessment) which are considered important to the improvement of reading instruction. Professional development must also stress ensuring coaches understand the importance of their role in a distributed leadership position.

6) Develop the reading and administrative skills of principals who supervise reading coaches to enable adequate support of the coaching position.

\section{Local Recommendations}

1) Advertise school reading coach positions based on the West Virginia Reading Mentor Teacher Model Job Description which encourages highly qualified candidates and outlines research supported coaching responsibilities and activities.

2) Hire highly qualified reading coaches (i.e., masters in reading or certified as a reading specialist) with successful experience in working with adults whenever possible. Provide 
sustained mentoring and support when it is necessary to hire non-highly qualified coaches placed on temporary permit.

3) Hire principals knowledgeable of the processes of improving reading instruction and those who can adequately support the school's reading coach. Provide sustained mentoring and support when it is necessary to hire a principal with limited knowledge of reading instruction.

4) Place reading coaches in schools based on both enrollment and student needs to allow adequate time for the coach to work regularly with all reading teachers (e.g., full time coaching positions in schools with a large enrollment or schools with more need and part time coaching positions in schools with low enrollment or schools with less need).

5) Develop a pool of qualified reading coaches especially in those districts struggling to employ highly qualified coaches (e.g., work with higher education to develop reading coach cohorts, reimburse tuition costs, make courses available to coaches in rural areas via online classes or contract professors to travel to the district).

\section{Recommendations for Further Research}

The findings of this study were based on the completion of a survey by Reading First K-3 teachers working in Title I Distinguished Schools. Conducting additional research would provide a more in-depth snapshot of the perceptions of K-3 teachers who work with reading coaches. It is important to note that funding from Reading First will be completely phased out at the conclusion of the 2009-2010 school year. Regardless, quality research must be considered as new programs are initiated to address the inclusion of coaches as an important component of reading professional development. Four recommendations are offered for further research: 
1) Researchers could consider a more in-depth investigation of this study using a qualitative design to specifically examine teacher relationships with coaches and how coaches assist to improve instructional practice.

2) Researchers could duplicate this study to examine the perceptions of Reading First K-3 teachers working in Title I non-distinguished schools and compare the perceptions for similarities and differences to those of teachers working in distinguished schools.

3) Researchers could conduct a similar study to examine the perceptions of Reading First principals working with reading coaches in Title I distinguished and non-distinguished schools and compare for similarities and differences.

4) Researchers must consider a study consisting of quantitative and qualitative designs of any large scale national, state, or local level effort which includes reading coaches as a component of improving reading instruction. The results are important for consideration in the on-going effort of continuous improvement of reading instruction. 


\section{References}

Andrews, D., Nonnecke, B., \& Preece, J. (2003). Conducting research on the Internet: Online surveys design, development, and implementation guidelines. International Journal of Human-Computer Interaction, 16, 2, 185-210.

Barr, K., Simmons, B., \& Zarrow, J. (2003a). Instructional coaching: Professional development strategies that improve instruction. Providence, RI: Annenberg Institute for School Reform.

Barr, K., Simmons, B., \& Zarrow, J. (2003b). School coaching in context: A case study in capacity building. Paper presented at the American Educational Research Association annual meeting, Chicago.

Bennett, N., Harvey, J., Wise, C., \& Woods, P. (Spring, 2003). Distributed leadership: Full Report. Retrieved February 15, 2009, from http://www.nationalcollege.org.uk/docinfo?id=17151\&filename=distributed-leadershipfull-report.pdf

Berger, J. (2006, November 15). She found abuses in U.S. plan for reading. The New York Times. Retrieved February 6, 2008, from http://www.nytimes.com/2006/11/15/education/15education.html

Brownstein, A. (2008, January 24). In latest budget, Reading First joins Even Start on injured list. Thompson Publishing News Brief. Retrieved March 28, 2008, from http://www.thompson.com/public/newsbrief.jsp?cat=EDUCATION\&id=1716

Christy, J. (2007). Literacy leadership in Virginia's Title I elementary schools: Developing and sustaining successful reading programs. Dissertation Abstracts International, 68, 08A. (ISBN No. 978-0-549-20718-4) 
Coggins, C., Stoddard, P., \& Cutler, E. (2003). Improving instructional capacity through fieldbased reform coaches. Paper presented at the American Educational Research Association annual meeting, Chicago.

Coleman, J.S., Campbell, E., Hobson, C., McPartland, J., Mood., A., Weinfeld, F., \& York, R. (1966). Equality of educational opportunity. Washington, D.C: U.S. Office of Education, National Center for Educational Statistics.

Conway, J.M. (2006). A correlation study about coaching and teachers' attitudes, perceptions, and practices in reading instruction. Dissertation Abstracts International, 67, 11A. (ISBN No. 978-0-542-97532-5)

Darling-Hammond, L., \& McLaughlin, M. (1995). Policies that support professional development in an era of reform. Phi Delta Kappan, 76(8), 597-604.

Elmore, R. F. (1997). Investing in teacher learning: Staff development and instructional improvement in community school district 2, New York City. Paper prepared for the National Commission on Teaching and America's Future by the Consortium for Policy Research in Education.

Elmore, R.F. (2000). Building a new structure for school leadership. Washington, D.C.: Albert Shanker Institute.

Feller, B. (2006, September 23). Audit finds ethical lapses in U. S. Reading First program. Associated Press. Retrieved February 6, 2008, from http://www.washingtonpost.com/wpdyn/content/article/2006/09/22/AR2006092201356.html?nav=rss_education\#

Fillman, R.M. (2005). The role of a Reading First coach in a rural Pennsylvania school district 
as perceived by the teachers and the administrators. Dissertation Abstracts

International, 68, 05A. (Acession No. AA13261892)

Fricke, A., Bachtinger, M.T., \& Reips, U.D. (1999). Financial incentives, personal information and drop-out rates in online studies. Retrieved December 20, 2008, from http://www.psychologie.uzh.ch/sowi/reips/books/tband99/pdfs/a h/frick.pdf

Gay, L.R., Mills, G.E., \& Airasian, P. (2006). Educational research: Competencies for analysis and applications. Upper Saddle River, NJ: Pearson Education, Inc.

Grunwald, M. (2006, October 1). Billions for an inside game on reading. Washington Post. Retrieved February 6, 2008, from: http://www.washingtonpost.com/wpdyn/content/article/2006/09/29/AR2006092901333.html

Hinkle, D., Wiersma, W., \& Jurs, S. (2003). Applied statistics for the behavioral sciences. Boston, MA: Houghton Mifflin Company.

Kowal, J., \& Steiner, L. (September, 2007). Issue Brief: Instructional Coaching. The Center for Comprehensive School Reform. Retrieved March 22, 2009, from: http://www.centerforcsri.org/files/CenterIssueBriefSept07Coaching.pdf

Lazar, J., \& Preece, J. (1999). Designing and implementing web-based surveys. Journal of Computer Information Systems, 39(4), 63-67.

Leithwood, K. \& Jantzi, D. (2000). The relative effects of principal and teacher sources of leadership on student engagement with school. Educational Administration Quarterly. (35), 679-706.

Leithwood, K., Louis, K.S., Anderson, S., \& Wahlstorm, K. (2004). How leadership influences student learning: Review of research. Minneapolis, MN: 
Center for Applied Research, University of Minnesota.

Lezotte, L. (1996). Effective schools: Past, present, and future. Retrieved October 8, 2009 from: http://www.aepweb.org/summit/09_Presentations/Effective_Schools_Lezotte.pdf

Lezotte, L., \& Barcroft, B.A. (1985). School improvement based on effective schools research: A promising approach for economically disadvantaged and minority students. Journal of Negro Education, 54(3), 301-312.

Lyons, C., \& Pinnell, G. (2001). Systems for change in literacy education: A guide to professional development. Portsmouth, NH: Heinemann.

Marsh, J., McCombs, J., Lockwood, J.R., Martorell, D.G., Gershwin, S., Naftel, S., Le, V., Shea, M., Barney, H., \& Crego, A. (2008). Supporting literacy across the sunshine state: A study of Florida middle school reading coaches. Washington, D.C.: Rand Corporation.

Miller, E. (1995). The old model of staff development survives in a world where everything else has changed. The Harvard Education Letter. 11(1), 1-3.

National Assessment of Educational Progress (1981). Reading, thinking, writing: A report on the 1979-1980 assessment. Denver: NAEP.

National Assessment of Educational Progress (1995). NAEP 1994 reading: A first look-findings from the National Assessment of Educational Progress (Revised Edition). Washington, D.C: U.S. Government Printing Office.

National Association of State Title I Directors. (2008). Why join the distinguished Title I schools program? Retrieved October 4, 2008, from http://www.nationaltitleiassociation.org/?page=DS National Council of Teachers of English. (2002). Annual position statement: On the Reading First initiative. Retrieved February 13, 2008, from 
http://www.ncte.org/positions/statements/readingfirst

Neufeld, B. \& Roper, D. (June, 2003). Coaching: A strategy for developing instructional capacity, promises, and practicalities. Washington, DC: Aspen Institute Program on Education and Providence, RI: Annenberg Institute for School Reform.

No Child Left Behind Act of 2001, Pub. L. No. 107-110, 115 Stat. 1425 (2002).

No Child Left Behind Compliance Insider. (2008, December). IES: Reading first helps decoding, not comprehension. Horsham, PA: LRP Publications.

Office of Inspector General. OIG Audit Report: The Reading First Program's Grant Application Process Final Inspection Report. Washington, D.C.: September, 2006.

Ohanian, S. (2005). Special report: Reading First under fire: IG targets conflicts of interest, limits on local control. Retrieved February 13, 2008, from http://susanohanian.org/show_research.php?id=94

Olson, C. (October, 1997). The Reading Excellence Act: How congress can encourage proven methods of instruction in the classroom. Retrieved on March 6, 2008, from http://www.heritage.org/Research/Education/EM500.cfm

Oppermann, M. (1995). E-mail surveys: Potentials and pitfalls. Marketing Research, 7(3), 28. Pustejovsky, J., Spillane, J.P., Heaton, R.M., \& Lewis, J.W. (2008, June 18). Understanding teacher leadership in middle school mathematics: A collaborative research effort. Unpublished manuscript, Northwestern University and The University of Nebraska Lincoln.

Reyhner, J. (2003). Phonics versus whole language. Retrieved January 14, 2008, From http://jan.ucc.nau.edu/ jar/Reading_Wars.html

Reynolds, R., Woods, R., \& Baker, J. (2007). Handbook of research on electronic surveys and 
measurements. Spring Arbor, MI: Information Science Reference.

Saris, W.E. (1991). Computer-assisted interviewing. New Berry Park: Sage.

Schmidt, W.C. (1997). World-wide web survey research: Benefits, potential problems, and solutions. Behavior Research Methods, Instruments, and Computers, 29(2), 274-279.

School Laws of West Virginia, §18A-4-2 (2007).

Slavin, R.E., \& Madden, N. (1994). Preventing early school failure. Boston: Allyn and Bacon.

Snow, C.E., Burns, S.M., \& Griffin. (1998). Preventing reading difficulties in young children. Washington, DC: National Academy Press.

Spillane, J. (2006). Distributed leadership. San Francisco: Jossey-Bass.

Stager, G. (2006, October 4). Shocked! shocked! Reading First plagued by corporate welfare, cronyism and demoralization. The Pulse District Administrative Magazine. Retrieved February 6, 2008, from http://www.districtadministration.com/pulse/commentpost.aspx?news=no\&postid=17185

Suskie, L. (1996). Survey research: What works for the institutional researcher. Itacha, NY: Northeast Association for Institutional Research.

Sweeney, J. (1996). The century of miseducation of American teachers. Retrieved January 14, 2008, from http://www.nrrf.org/essay_Century_of_Miseducation.html

Swoboda, S.J., Muehlberger, N., Weitkunat, R., \& Schneeweiss, S. (1997). Web-based surveys by direct mailing: An innovative way of collecting data. Social Science Computer Review, 15(3).

Taylor, B. (2002, January). The effective school process: Alive and well. Phi Delta Kappan, 83(5), 375-78). 
Title I Monitor. (2008, September). Reading First faces precarious future. Washington, D.C.: Thompson Publishing Group, Inc.

United States Department of Education. (1999). The Reading Excellence Act. Retrieved on March 6, 2008, from http://www.ed.gov/inits/FY99/1-read.html

United States Department of Education. (2002, April). Guidance for the Reading First Program. Washington, DC: Author.

United States Department of Education. (2006, July). Reading First implementation evaluation:

Interim report. Washington, D.C.: Education Publications Center.

United States Department of Education (2007). Reading First awards. Retrieved January

8, 2008, from http://www.ed.gov/news/pressreleases/2003/07/07212003.html

United States Department of Education (2008, October). Reading First implementation

evaluation: Final report. Washington, D.C.: Education Publications Center.

United States Department of Health and Human Services. (2000, December). Report of the

National Reading Panel: Teaching children to read. (NIH Publication No. 00-4754).

Washington, D.C.

Web Center for Social Research. (2006). Research methods knowledge base. Retrieved

December 20, 2008, from http://www.socialresearchmethods.net/kb/

Western Regional Educational Laboratory. (2000). Teachers who learn, kids who

achieve: A look at schools with model professional development. San Francisco:

WestEd.

West Virginia Department of Education. (2002). West Virginia Reading First grant application.

Charleston, WV: Author.

West Virginia Department of Education. (2008). Title I distinguished schools. Retrieved 
October 4, 2008, from http://wvde.state.wv.us/titlei/distinguished.html

Yun, G.W., \& Trumbo, C.W. (2000, September). Comparative response to a survey executed by post, e-mail, \& web form. Journal of Mediated Communication. 


\section{Appendix A \\ West Virginia Reading First Mentor Teacher \\ Model Job Description}

POSITON: Reading Mentor Teacher (RMT)

\section{QUALIFICATIONS/CERTIFICATION}

1. Must have a degree in Elementary Education with five (5) years teaching experience in reading/language arts

2. Must have a Master's Degree in Reading

3. Must have prior specialized training delivered or sponsored by the West Virginia Department of Education

4. Verification of expertise in scientifically based reading research components in relation to the instructional program, strategies, materials, intervention, and administration of assessment

5. Verification of reading workshops/seminars attended and presented

6. Involvement in curriculum development at school, local and state levels

7. Evidence of previous leadership/supervision capabilities

\section{PERFORMANCE / RESPONSIBILITIES:}

The Reading Mentor Teacher's primary responsibility will be to provide technical assistance in the Reading First school site to every K-3 teacher during the school day and throughout the school year for the duration of the Reading First Grant Period.

Roles and Responsibilities as set forth in the WVDE Reading First Grant:

1. Attend 26 days of professional training over a 2-year period, as follows: 5 days - summer, 4 days- fall, 4 days- spring;

2. Attend the 100 hours of required professional development per year with classroom teachers (72 hours in addition to 28 hours required by the state) and 42 hours required in year one of the project;

3. Communicate regularly with a WVDE Reading Cadre Liaison to assist in planning and administration of the school's reading program and professional development;

4. Individually coach regular and special education teachers;

5. Meet quarterly with the project director and principal to monitor the evaluation measurement areas of (1) student achievement, (2) teacher knowledge, (3) effect of professional development on classroom instruction;

6. Assist teachers needing assistance in implementing content, skills and strategies to promote successful student readers;

7. Observe K-3 classroom teachers and provide constructive feedback;

8. Model effective classroom instruction;

9. Coordinate and assess the daily operation of the Reading First Program;

10. Assist staff in selecting/securing/explaining appropriate instructional materials, strategies, and programs;

11. Attend local, state, and national meetings supportive of Reading First;

12. Participate in lesson videotaping, list serve, and dissemination of Reading First Program development activities;

13. Meet regularly (monthly or more often) with principal and program director for program planning, implementation, and evaluation;

14. Coordinate ongoing and sustained professional development within the school;

15. Serve as the school liaison for assessment coordination;

16. Demonstrate a clear understanding of appropriate student classroom behaviors; and

17. Maintain flexible scheduling (West Virginia Department of Education, 2002). 


\section{Appendix B \\ West Virginia Reading First Schools}

West Virginia Reading First LEA and School Subgrants:(42 schools located in 26 LEAs)

\begin{tabular}{|c|c|}
\hline Local Educational Agency & School \\
\hline Calvin & *Arnette Elementary \\
\hline Calvin & *Pleasant ViewSchool \\
\hline Duncan & Duncan County Elementary \\
\hline Fresno & *Meadows Elementary \\
\hline Fresno & $*$ Scarlett Elementary \\
\hline Gilmore & *Normandy Elementary \\
\hline Gilmore & *Sandyville Elementary \\
\hline Hampton & Hampton Elementary \\
\hline Harper & *East Harper Elementary \\
\hline Kellyville & *Alfordtown Elementary \\
\hline Kellyville & $*$ Bradford Elementary \\
\hline Kellyville & Charles White Elementary \\
\hline Kellyville & +Sidenville Elementary \\
\hline Lundell & Lundell East Elementary \\
\hline Lundell & Lundell South Elementary \\
\hline Lucas & Mountain Top K-8 School \\
\hline Lucas & *Lucas Elementary \\
\hline McDermit & +McDermit Elementary \\
\hline Martin & $*$ Martin Primary \\
\hline Martin & Martin Intermediate \\
\hline Melton & *Melton Elementary \\
\hline Melton & *Oakdale K-8 \\
\hline Michael & Michael Primary Middle \\
\hline Mingette & *+Burke Elementary \\
\hline Mingette & $*+$ Kertell Elementary \\
\hline Moundsville & Brookside Elementary \\
\hline Moundsville & Riverside Elementary \\
\hline Nichollson & Chapman Elementary \\
\hline Nichollson & Mount Lamont Elementary \\
\hline Patten & Bluefied Central K-8 \\
\hline Patten & *Hillsville Elementary \\
\hline Princeton & Terrace Park K-8 School \\
\hline Princeton & *Princeton Elementary \\
\hline Radford & Radford Elementary Middle \\
\hline Sumner & *Shinston Elementary \\
\hline Tunden & *Tunden West Elementary \\
\hline Tunden & *Tunden East Elementary \\
\hline Upton & Central Primary \\
\hline Upton & Upton Intermediate \\
\hline Webner & +Webner Springs Elementary \\
\hline Williamstown & Williamstown School \\
\hline Windell & $*+$ Windell County Primary \\
\hline
\end{tabular}


Appendix C

West Virginia Reading First K-3 Reading Teachers

Working in Title I Distinguished Schools

21 schools located in 14 LEAs

\begin{tabular}{|c|c|c|c|c|c|c|}
\hline \multirow[t]{2}{*}{ County } & \multirow[t]{2}{*}{ School } & \multicolumn{4}{|c|}{$\begin{array}{c}\text { \# of K-3 Reading } \\
\text { Teachers }\end{array}$} & \multirow{2}{*}{$\begin{array}{c}\text { Total \# of } \\
\text { K-3 } \\
\text { Teachers }\end{array}$} \\
\hline & & $K$ & 1 & 2 & 3 & \\
\hline Calvin & Arnette Elementary & 2 & 2 & 2 & 2 & 8 \\
\hline Calvin & Pleasant View School & 2 & 2 & 2 & 2 & 8 \\
\hline Fresno & Meadows Elementary & 2 & 1 & 2 & 1.5 & 6.5 \\
\hline Fresno & Scarlett Elementary & 1 & 1 & 1 & 1 & 4 \\
\hline Gilmore & Normandy Elementary & 1 & 1 & 1 & 1 & 4 \\
\hline Gilmore & Sandyville Elementary & 1 & 1 & 1 & 1 & 4 \\
\hline Harper & East Harper Elementary & 2 & 3 & 2 & 3 & 10 \\
\hline Kellyville & Alfordtown Elementary & 2 & 1 & 1 & 2 & 6 \\
\hline Kellyville & Bradford Elementary & 2 & 2 & 3 & 2 & 9 \\
\hline Lucas & Lucas Elementary & 2 & 2 & 2 & 2 & 8 \\
\hline Martin & Martin Primary & 4 & 4 & 4 & I & 12 \\
\hline Mingette & Burke Elementary & 2 & 2 & 2 & 3 & 9 \\
\hline Mingette & Kertell Elementary & 2 & 3 & 2 & 2 & 9 \\
\hline Melton & Melton Elementary & 2.5 & 2 & 2 & 2 & 8.5 \\
\hline Melton & Oakdale K-8 School & 1 & 1 & 1 & 1 & 4 \\
\hline Patten & Hillsville Elementary & 1 & 1 & 1 & 1 & 4 \\
\hline Princeton & Princeton Elementary & 2 & 2 & 2 & 2 & 8 \\
\hline Sumner & Shinston Elementary & 2 & 3 & 2 & 2 & 9 \\
\hline Tunden & Tunden West Elementary & 1 & 1 & 1 & 1 & 4 \\
\hline Tunden & Tunden East Elementary & 3 & 3 & 3 & 2 & 11 \\
\hline Windell & Windell County Primary & 3 & 3 & 4 & 4 & 14 \\
\hline \multicolumn{2}{|c|}{ Total K-3 Teachers } & 40.5 & 41 & 41 & 37.5 & 160 \\
\hline
\end{tabular}




\section{Appendix D \\ K-3 Classroom Reading Teacher Survey Introduction}

Introduction: My name is Karen Davies and as partial fulfillment of the Leadership Studies doctoral program at West Virginia University I am required to conduct a research-based study focusing on improving educational leadership practice. The purpose of my study is to examine the perceptions of K-3 reading teachers regarding the activities of Reading First coaches to improve reading instruction. A benefit of your participation in this study is the opportunity to express your perception regarding whether the incorporation of a reading coach is a valuable support role in assisting to improve reading instruction. This research will be conducted under the direction of Dr. Helen Hazi, Professor of Educational Leadership Studies at West Virginia University.

Assurances: The following assurances, as required by West Virginia University, will be respected: participation in the study is voluntary; information will be kept confidential; and the participant may refuse to participate, quit at any time, or skip questions with no negative effect in employment status. Further, West Virginia University's Institutional Review Board acknowledgement for this research is on file.

Survey Description: This survey includes 3 major components and each section has its own directions. You are to complete the survey based on all of your experiences working with the Reading First reading mentor teacher at your school.

Participants may obtain a copy of final research results upon request from the researcher (contact information below). Questions regarding survey completion should be directed to Karen Davies at kdavies@suddenlink.net or (304)549-9752.

Thank you for taking the time to complete this survey. Your input is valuable and appreciated. 


\section{Appendix E \\ Reading First K-3 Classroom Reading Teacher Survey}

Section A Directions: Check the box that most accurately reflects your response following each question.

\section{Demographic Information}

A1. Including the current school year, how many years have you been a classroom teacher?

$\square 0-4$ years $\square 5+$ years

A2. On average, what is the number of hours per week that you spend working with the school's Reading First reading mentor teacher? $\square$ Less than 5 hours $\square$ 6-10 hours $\square 11+$ hours

A3. Is your school's Reading First reading mentor teacher assigned as a full or part time position?

$\square$ Full time (assigned to one school) $\square$ Part time (part time position at one school or assigned to two schools)

Section B Directions: For each statement below, check the box that most accurately reflects your opinion regarding each listed reading mentor teacher activity in improving reading instruction with a 1 representing low importance through a 5 representing high importance.

$\begin{array}{cc}1= & 5= \\ \text { Low } & \text { High } \\ \text { Importance } & \text { Importance }\end{array}$

\section{Reading First Administration}

The reading mentor teacher...

B1. coordinates and assesses the daily operation of the Reading First program.

B2. communicates a minimum of twice per year with the school's assigned WVDE reading cadre liaison.

B3. works with the school's assigned WVDE reading cadre liaison to assist in the administration of the Reading First program.

B4. participates in the dissemination of Reading First program development activities.

B5. maintains a flexible schedule for the purpose of adequately addressing reading priorities.

B6. attends local, state, and national meetings supportive of the administration of the Reading First program.

B7. meets at least monthly with the principal for program planning, implementation, and evaluation purposes. 
Section C Directions: For each statement below, check the box that most accurately reflects your opinion regarding each listed reading mentor teacher activity in improving reading instruction with a 1 representing low importance through a 5 representing high importance.

\begin{tabular}{ccc}
\hline & $1=$ & $5=$ \\
Low & High \\
Importance & Importance \\
\hline
\end{tabular}

\section{Professional Development}

The reading mentor teacher...

C1. works with the school's assigned WVDE reading cadre liaison at least

$1 \square \quad 2 \square \quad 3 \square$ twice per year to assist in planning the school's Reading First professional development.

C2. attends required state sponsored professional development sessions.

C3. attends 100 hours of required Reading First professional development per year with classroom teachers.

C4. coordinates sustained, research-based professional development within the school.

C5. provides technical assistance (e.g., modeling, administering student assessments, grouping of students, alignment of assessment data with instruction) to all K-3 reading teachers (e.g., classroom, special education, Title I, interventionists) during the school day.

C6. provides technical assistance (e.g., modeling, administering student assessments, grouping of students, alignment of assessment data with instruction) to all K-3 reading teachers (e.g., classroom, special education, Title I, interventionists) throughout the school year.

\begin{tabular}{|c|c|c|c|}
\hline $1 \square$ & $2 \square$ & $3 \square$ & $4 \square$ \\
\hline $1 \square$ & $2 \square$ & $3 \square$ & $4 \square$ \\
\hline $1 \square$ & $2 \square$ & $3 \square$ & $4 \square$ \\
\hline $1 \square$ & $2 \square$ & $3 \square$ & $4 \square$ \\
\hline
\end{tabular}

2 3 4 5 


\section{Instruction and Assessment}

The reading mentor teacher...

D1. assists the staff in selecting, securing, and explaining appropriate instructional materials, strategies, and programs.

D2. demonstrates a clear understanding of appropriate student classroom behaviors and instructional environment.

D3. meets quarterly with the principal to monitor the evaluation measurement areas (i.e., student achievement, teacher knowledge, effect of professional development on classroom practice).

D4. meets quarterly with the central office project director to monitor the evaluation measurement areas (i.e., student achievement, teacher knowledge, effect of professional development on classroom practice).

D5. serves as the school liaison for reading assessment coordination.

D6. assists teachers with the implementation of content, skills, and strategies to promote successful readers.

D7. models effective classroom instruction.

D8. participates in lesson videotaping.

$1 \square$

2

$3 \square$

$4 \square$

$5 \square$

$1 \square \quad 2 \square \quad 3 \square$

$4 \square$

$5 \square$
$5 \square$

$5 \square$ 
Section E Directions: For each statement below, check either "yes" (I have knowledge the reading mentor teacher performed this activity) or "no" (I have no knowledge the reading mentor teacher performed this activity) regarding the listed activities.

\section{Yes $=\quad$ No $=$}

Knowledge the Reading Mentor No Knowledge the Reading Mentor

Teacher Performed this Activity Teacher Performed this Activity

\section{Reading First Administration}

The reading mentor teacher...

E1. coordinates and assesses the daily

Yes

No $\square$

operation of the Reading First

program.

E2. communicates a minimum of twice per year with the school's assigned WVDE reading cadre liaison.

E3. works with the school's assigned WVDE reading cadre liaison to assist in the administration of the Reading First program.

E4. participates in the dissemination of Reading First program development activities.

E5. maintains a flexible schedule for the purpose of adequately addressing reading priorities.

E6. attends local, state, and national meetings supportive of the administration of the Reading First program.

E7. meets at least monthly with the principal Yes No

Yes

No

Yes

No $\square$

Yes

No $\square$ for program planning, implementation, and evaluation purposes.
Yes

Yes

No $\square$

No $\square$ 
Section F Directions: For each statement below, check either "yes" (I have knowledge the reading mentor teacher performed this activity) or "no" (I have no knowledge the reading mentor teacher performed this activity) regarding the listed activities.

Yes = No =

Knowledge the Reading Mentor No Knowledge the Reading Mentor

Teacher Performed this Activity Teacher Performed this Activity

\section{Professional Development}

The reading mentor teacher...

F1. works with the school's assigned

Yes $\square$

No $\square$

WVDE reading cadre liaison at least

twice per year to assist in planning

the school's Reading First professional

development.

F2. attends required state sponsored

Yes

No $\square$

professional development sessions.

F3. attends 100 hours of required Reading

First professional development per year

Yes

No $\square$

with classroom teachers.

F4. coordinates sustained, research-based

Yes

No $\square$

professional development within the

school.

F5. provides technical assistance (e.g., modeling,

Yes

No $\square$

administering student assessments, grouping

of students, alignment of assessment data with

instruction) to all K-3 reading teachers (e.g.,

classroom, special education, Title I,

interventionists) during the school day.

F6. provides technical assistance (e.g., modeling,

Yes

No

administering student assessments, grouping

of students, alignment of assessment data with

instruction) to all K-3 reading teachers (e.g.,

classroom, special education, Title I,

interventionists) throughout the school year.

F7. individually coaches K-3 reading teachers.

Yes

No $\square$

F8. observes K-3 classroom teachers and

Yes

No $\square$

once monthly. 
Section G Directions: For each statement below, check either "yes" (I have knowledge the reading mentor teacher performed this activity) or "no" (I have no knowledge the reading mentor teacher performed this activity) regarding the listed activities.

\section{Yes $=$}

Knowledge the Reading Mentor Teacher Performed this Activity
No $=$

No Knowledge the Reading Mentor Teacher Performed this Activity

\section{Instruction and Assessment}

The reading mentor teacher ...

G1. assists the staff in selecting, securing, and explaining appropriate instructional materials, strategies, and programs.

G2. demonstrates a clear understanding of appropriate student classroom behaviors and instructional environment.

G3. meets quarterly with the principal Yes No $\square$ to monitor the evaluation measurement areas (i.e., student achievement, teacher knowledge, effect of professional development on classroom practice).

G4. meets quarterly with the central office project director to monitor the evaluation measurement areas (i.e., student achievement, teacher knowledge, effect of professional development on classroom practice).

G5. serves as the school liaison for reading assessment coordination.

G6. assists teachers with the implementation

of content, skills, and strategies to promote successful readers.

G7. models effective classroom instruction.

Yes

No

G8. participates in lesson videotaping.

Yes $\square$

No

Thank you for taking the time to complete this survey. Your input is valuable and appreciated. Please click the submit button upon survey completion. 


\section{Appendix F \\ Survey Development Matrix}

\begin{tabular}{|c|c|c|}
\hline Survey Statement & $\begin{array}{c}\text { Job description } \\
\text { Item \# }\end{array}$ & Support in the Literature \\
\hline \multicolumn{3}{|c|}{ Reading First Administration (Sections B and E) } \\
\hline \multicolumn{3}{|l|}{ The reading mentor teacher... } \\
\hline $\begin{array}{l}\text { 1. coordinates and assesses the } \\
\text { daily operation of the Reading } \\
\text { First program. }\end{array}$ & $\# 9$ & \multirow{7}{*}{$\begin{array}{l}\text { - Coaching supports collective, interconnected } \\
\text { leadership across a school system. Effective } \\
\text { coaching distributes leadership to support } \\
\text { goals of effective principals by keeping the } \\
\text { focus on teaching and learning (Lyons \& } \\
\text { Pinnell, 2001). }\end{array}$} \\
\hline $\begin{array}{l}* 2 \text {. communicates with the } \\
\text { school's assigned WVDE reading } \\
\text { cadre liaison. }\end{array}$ & $\# 3$ & \\
\hline $\begin{array}{l}\text { *3. works with the school's } \\
\text { assigned WVDE reading cadre } \\
\text { liaison to assist in the } \\
\text { administration of the Reading First } \\
\text { program. }\end{array}$ & $\# 3$ & \\
\hline $\begin{array}{l}\text { 4. participates in the dissemination } \\
\text { of Reading First program } \\
\text { development activities. }\end{array}$ & $\begin{array}{l}\# 12 \\
\text { "Dissemination of RF } \\
\text { program development } \\
\text { activities" is mutually } \\
\text { exclusive }\end{array}$ & \\
\hline $\begin{array}{l}* 5 \text {. maintains a flexible schedule } \\
\text { for the purpose of adequately } \\
\text { addressing reading priorities. }\end{array}$ & $\# 17$ & \\
\hline $\begin{array}{l}\text { 6. attends local, state, and national } \\
\text { meetings supportive of the Reading } \\
\text { First program. }\end{array}$ & $\# 11$ & \\
\hline $\begin{array}{l}* 7 \text {. meets at least monthly with the } \\
\text { principal for program planning, } \\
\text { implementation, and evaluation } \\
\text { purposes. }\end{array}$ & $\# 13$ & \\
\hline \multicolumn{3}{|c|}{ Professional Development (Sections C and F) } \\
\hline \multicolumn{3}{|l|}{ The reading mentor teacher... } \\
\hline $\begin{array}{l}* 1 \text {. works with the school's } \\
\text { WVDE reading cadre liaison to } \\
\text { assist in planning the school 's } \\
\text { Reading First professional } \\
\text { development activities. }\end{array}$ & $\begin{array}{c}\# 3 \\
\text { "Planning" is mutually } \\
\text { exclusive }\end{array}$ & \multirow{4}{*}{$\begin{array}{l}\text { - Research suggests that professional } \\
\text { development opportunities are most effective } \\
\text { when offered at the school level, embedded } \\
\text { into daily instruction, and when it increases } \\
\text { teacher theoretical understanding of their work } \\
\text { (Miller, 1995). } \\
\text { - Support for teachers in improving teaching and } \\
\text { learning are more effective when tailored to } \\
\text { meet needs identified by teachers and when the } \\
\text { approach is collaborative and inquiry-based } \\
\text { (Darling-Hammond \& McLaughlin 1995). } \\
\text { - The principles of instructional coaching are } \\
\text { grounded in research which focuses on }\end{array}$} \\
\hline $\begin{array}{l}* 2 \text {. attends required state } \\
\text { sponsored professional } \\
\text { development sessions. }\end{array}$ & \#s $1 \& 2$ & \\
\hline $\begin{array}{l}\text { *3. attends } 100 \text { hours of required } \\
\text { Reading First professional } \\
\text { development per year with } \\
\text { classroom teachers. }\end{array}$ & $\# 2$ & \\
\hline $\begin{array}{l}\text { 4. coordinates sustained, research- } \\
\text { based professional development } \\
\text { within the school. }\end{array}$ & $\# 14$ & \\
\hline
\end{tabular}




\begin{tabular}{|c|c|c|}
\hline $\begin{array}{l}* 5 \text {. provides technical assistance to } \\
\text { all K-3 reading teachers (e.g., } \\
\text { classroom, special education, Title } \\
\text { I, interventionists, speech teachers) } \\
\text { during the school day. }\end{array}$ & $\begin{array}{l}\text { Listed in Performance/ } \\
\text { Responsibilities } \\
\left(1^{\text {st }} \text { paragraph }\right) \\
\text { "During the school } \\
\text { day" is mutually } \\
\text { exclusive } \\
\end{array}$ & \multirow{4}{*}{$\begin{array}{l}\text { effective professional development and } \\
\text { professional learning communities. } \\
\text { Instructional coaching appears promising since } \\
\text { its purpose is designed to blend effective } \\
\text { professional development with school-specific } \\
\text { content and climate needs (Barr, et al., 2003a). } \\
\text { - There is growing evidence that coaching can } \\
\text { improve school-based professional } \\
\text { development to better address teachers' and } \\
\text { principals' learning needs based on students' } \\
\text { needs (Neufeld \& Roper, 2003). }\end{array}$} \\
\hline $\begin{array}{l}\text { *6. provides technical assistance to } \\
\text { all K-3 reading teachers throughout } \\
\text { the school year. }\end{array}$ & $\begin{array}{l}\text { Listed in Performance/ } \\
\text { Responsibilities } \\
\left(1^{\text {st }} \text { paragraph }\right) \\
\text { "Throughout the school } \\
\text { year" is mutually } \\
\text { exclusive }\end{array}$ & \\
\hline $\begin{array}{l}* 7 . \text { individually coaches } \mathrm{K}-3 \\
\text { reading teachers. }\end{array}$ & $\# 4$ & \\
\hline $\begin{array}{l}\text { 8. observes K-3 classroom teachers } \\
\text { and provides constructive } \\
\text { feedback. }\end{array}$ & $\# 7$ & \\
\hline \multicolumn{3}{|c|}{ Instruction and Assessment (Sections D and G) } \\
\hline \multicolumn{3}{|l|}{ The reading mentor teacher... } \\
\hline $\begin{array}{l}\text { 1. assists the staff in selecting, } \\
\text { securing, and explaining } \\
\text { appropriate instructional materials, } \\
\text { strategies, and programs. }\end{array}$ & $\# 10$ & $\begin{array}{l}\text { Neufeld and Roper (2003) concluded that } \\
\text { coaching, in combination with other } \\
\text { professional development strategies, is a } \\
\text { plausible way to increase a school's }\end{array}$ \\
\hline $\begin{array}{l}\text { 2. demonstrates a clear } \\
\text { understanding of appropriate } \\
\text { student classroom behaviors. }\end{array}$ & \#16 & $\begin{array}{l}\text { instructional capacity. } \\
\text { - Researchers argue that although coaching } \\
\text { alone does not have the capacity to lead such a } \\
\text { result; there is growing evidence that coaching } \\
\text { can improve instruction by producing the } \\
\text { following outcomes: } \\
\text { Improved school-based professional } \\
\text { development which better addresses } \\
\text { teachers' and principals' learning needs } \\
\text { based on students' needs. } \\
\text { Teacher learning which carries over into } \\
\text { classroom practice as the coach assists } \\
\text { teachers to implement learned strategies. } \\
\text { Willingness among teachers to share } \\
\text { instructional practices with one another } \\
\text { and seek learning opportunities from both } \\
\text { peers and coaches and to assume } \\
\text { collective responsibility for the learning of } \\
\text { all students (Neufeld \& Roper, 2003). } \\
\text { - Effective coaching encourages collaborative, } \\
\text { reflective practice. Coaching shifts } \\
\text { professional learning from direct instruction } \\
\text { outside the context of practice (e.g., delivered } \\
\text { as workshops and conferences) to realistic } \\
\text { instructional practice in the classroom. The } \\
\text { majority of studies show that instructional } \\
\text { coaching leads to improvements in } \\
\text { instructional capacity (e.g., teachers apply }\end{array}$ \\
\hline
\end{tabular}




\begin{tabular}{|c|c|c|}
\hline & & $\begin{array}{l}\text { learning more deeply, frequently, and } \\
\text { consistently than when working in isolation, } \\
\text { improve their capacity for reflection, and work } \\
\text { more collaboratively with peers) (Neufeld \& } \\
\text { Roper, 2003). } \\
\text { - Daily use of new learning strategies in } \\
\text { classrooms and the sharing of schoolwide } \\
\text { responsibilities increase when colleagues, } \\
\text { guided by a coach, collaborate and hold each } \\
\text { other accountable for improved teaching and } \\
\text { learning. Since coaching takes place in a } \\
\text { natural classroom setting, opportunities for } \\
\text { observation, learning, and experimentation can } \\
\text { occur in real situations (Barr, Simmons, \& } \\
\text { Zarrow, 2003b; Coggins, Cutler, \& Stoddard, } \\
\text { 2003; Neufeld \& Roper, 2003; Western } \\
\text { Regional Educational Laboratory, 2000) }\end{array}$ \\
\hline $\begin{array}{l}\text { *3. meets quarterly with the } \\
\text { principal to monitor the evaluation } \\
\text { measurement areas (i.e., student } \\
\text { achievement, teacher knowledge, } \\
\text { effect of professional development } \\
\text { on classroom practice). }\end{array}$ & $\# 5$ & \multirow{6}{*}{$\begin{array}{l}\text { - There is growing evidence that coaching can } \\
\text { improve instruction by producing a school } \\
\text { culture in which instruction is the focus of } \\
\text { teacher and principal discussion, teachers and } \\
\text { principals reflect on instructional practices and } \\
\text { its impact on students and use achievement } \\
\text { data to drive instructional improvement } \\
\text { (Neufeld \& Roper, 2003). } \\
\text { - A focus on content encourages the use of data } \\
\text { analysis to inform practice. Successful } \\
\text { coaching programs are data driven and, } \\
\text { therefore, responsive to specific learner needs. } \\
\text { A data driven coaching program assists in } \\
\text { creating coherence within a school by focusing } \\
\text { on strategic areas of need suggested by } \\
\text { evidence (Barr, et al., 2003b). }\end{array}$} \\
\hline $\begin{array}{l}* 4 . \text { meets quarterly with the central } \\
\text { office project director to monitor } \\
\text { the evaluation measurement areas } \\
\text { (i.e., student achievement, teacher } \\
\text { knowledge, effect of professional } \\
\text { development on classroom } \\
\text { practice). }\end{array}$ & $\# 13$ & \\
\hline $\begin{array}{l}\text { 5. serves as the school liaison for } \\
\text { reading assessment coordination. }\end{array}$ & $\# 15$ & \\
\hline $\begin{array}{l}* 6 \text {. assists teachers with the } \\
\text { implementation of content, skills, } \\
\text { and strategies to promote } \\
\text { successful readers. }\end{array}$ & \#6 & \\
\hline $\begin{array}{l}\text { 7. models effective classroom } \\
\text { instruction. }\end{array}$ & $\# 8$ & \\
\hline $\begin{array}{l}\text { 8. participates in lesson } \\
\text { videotaping. }\end{array}$ & $\# 12$ & \\
\hline
\end{tabular}

* Indicates a revision made from the Reading First mentor teacher job description for reliability purposes. 


\section{Appendix G \\ Panel of Experts E-mail}

\section{Dear Expert Panel Member -}

Thank you for agreeing to serve on a panel of experts to review my dissertation survey instrument. As you know, I am conducting a research study for the purpose of examining the perceptions of Reading First K-3 teachers regarding the activities performed by reading coaches in improving reading instruction. The data collected is a critical component of my doctoral dissertation which will be conducted under the direction of Dr. Helen Hazi, Professor of Educational Leadership Studies at West Virginia University.

The purpose of the survey review by a committee of experts is to establish the validity of the study survey instrument. Validity is defined as the degree to which the instrument measures what it is intended to measure (e.g., items relate to the topic, mutually exclusive questions or statements).

The study includes three research questions:

1) How do K-3 reading teachers in Title I Distinguished Schools perceive the importance of the activities of reading coaches in the areas of: Reading First administration, professional development, and instruction and assessment in improving reading instruction?

2) What do reading coaches do in the areas of: Reading First administration, professional development, and instruction and assessment, as perceived by K-3 reading teachers in Reading First Title I Distinguished Schools?

3) What differences exist between the reading coach activities perceived by K-3 teachers as important to improving reading instruction and the activities observed by K-3 teachers?

Please review the directions prior to completing the survey review. Your input is appreciated.

Sincerely,

Helen Hazi, Principal Investigator

Educational Leadership Professor

(304)293-1885

Helen.Hazi@mail.wvu.edu
Karen Davies, Primary Contact

Doctoral Student

(304)549-9752

kdavies@suddenlink.net 


\section{Appendix H \\ Panel of Experts Survey Directions}

Survey Development Information: In addition to the Reading First K-3 Classroom Teacher Survey are two attachments which may be referenced to assist with the review of the survey instrument: the Survey Development Matrix (Appendix E); and the West Virginia Reading First Mentor Teacher Model Job Description (Appendix A).

The development of the survey instrument was based upon a comprehensive review of the literature and specific job responsibilities as defined in the West Virginia Reading First Model Job Description. The Survey Development Matrix includes a breakdown of reading coach activities as derived from the model job description and shows alignment with reading research. The reading coach activities are classified into three categories: Reading First administration, professional development, and instruction and assessment.

The survey includes 3 major categories: 1) demographics (section A); 2) importance rating - teachers rate listed reading coach activities in relation to improving reading instruction from a low of 1 through a high of 5 (sections B-D); and 3) observation of coaching practice - teachers respond either "yes" that the listed activity is practiced by the reading coach or "no" that the activity was not observed or practiced by the reading coach (sections E-G). Note: Refer to comment number 4 under directions below regarding sections E-G).

\section{Directions:}

1) Review the following sections of the survey and consider the alignment to the three research questions:

- Section A contains demographic information and does not align to any of the research questions.

- Sections B-D aligns with Research Question 1: How do K-3 reading teachers in Title I Distinguished Schools perceive the importance of the activities of reading coaches in the areas of: Reading First administration, professional development, and instruction and assessment in improving reading instruction?

- Sections E-G aligns with Research Question 2: What do reading coaches do in the areas of: Reading First administration, professional development, and instruction and assessment, as perceived by K-3 reading teachers in Reading First Title I Distinguished Schools?

- An analysis of sections B-D and E-G will be completed to address Research Question 3: What differences exist between the reading coach activities perceived by K-3 teachers as important to improving reading instruction and the activities observed by K-3 teachers?

2) Refer to the Survey Development Matrix and the West Virginia Reading First Mentor Teacher Model Job Description to consider each survey question or statement in relation to the following 3 questions:

1. Does the question or statement adequately address the study research questions?

2. Does the question or statement contain the necessary information to enable an adequate response by the participant?

3. Is the question or statement biased or worded to encourage a particular response?

3) Questions 1 and 2 involve a "yes" or "no" response. If your response is "yes" no further response is needed. If your response is "no" use the "add comment" function in Microsoft Word to note your recommendation. Question 3 will involve no response" or a recommendation. Use the "add comment" 
function to make recommendations pertaining to question three. The "add comment" function can be activated in Microsoft Word by clicking review and new comment.

4) A comment made by my doctoral committee was to consider changes to the two responses in sections E-G from "yes" (reading coach activity observed) or "no" (reading coach activity not observed) to "yes" ("yes, knowledge the reading coach practiced this activity) or "no" ("no knowledge the reading coach practiced this activity". There are several questions where this may be the case. Include your recommendation regarding this possible amendment.

5) Send the survey as an attachment with comments to: Karen Davies, kdavies@ suddenlink.net in your responding e-mail.

If you have questions contact me using the e-mail address provided above or by phone at (304) 549-9752.

Thank you for taking the time to review this survey instrument. Your input is appreciated.

Sincerely,

Helen Hazi, Principal Investigator

Educational Leadership Professor

(304)293-1885

Helen.Hazi@mail.wvu.edu
Karen Davies, Primary Contact

Doctoral Student

(304)549-9752

kdavies@suddenlink.net

Attachments: Reading First K-3 Classroom Reading Teacher Survey

Survey Development Matrix

West Virginia Reading First Mentor Teacher Model Job Description 


\section{Appendix I \\ Panel of Experts Feedback Matrix}

\begin{tabular}{|c|c|c|c|}
\hline Panel Member & Positive Comments & $\begin{array}{c}\text { Feedback/ } \\
\text { Response to Feedback }\end{array}$ & $\begin{array}{l}\text { * Recommendation Regarding } \\
\text { Directions to Sections E-G }\end{array}$ \\
\hline $\begin{array}{l}\text { Sharon Vaughn, } \\
\text { National Expert }\end{array}$ & $\begin{array}{l}\text { Survey items are worded well } \\
\text { and cover the key Reading } \\
\text { First areas. }\end{array}$ & $\begin{array}{l}\text { Feedback: Suggestion to provide more } \\
\text { opportunity for precise answers rather than fixed } \\
\text { answers. For example, check the box representing } \\
\text { the number of years as a classroom teacher and } \\
\text { include more items (i.e., 1-2, 3-4, 5-6, 7-10, more } \\
\text { than 10). } \\
\text { Response to Feedback: Demographic data will } \\
\text { be collected in section A for the purpose of } \\
\text { providing descriptive information regarding } \\
\text { survey participants. It has been determined that a } \\
\text { statistical analysis would not result in valuable } \\
\text { information. Therefore, this amendment will not } \\
\text { be considered. }\end{array}$ & $\begin{array}{l}\text { Yes, likes the idea of making this } \\
\text { change. }\end{array}$ \\
\hline $\begin{array}{l}\text { Beverly Kingery, } \\
\text { State Expert }\end{array}$ & $\begin{array}{l}\text { The survey clearly reflects the } \\
\text { goals of the Reading First } \\
\text { program. }\end{array}$ & Feedback: None provided. & $\begin{array}{l}\text { Agrees with the suggested } \\
\text { amendment. }\end{array}$ \\
\hline $\begin{array}{l}\text { Jane Massi, } \\
\text { State Expert }\end{array}$ & None provided. & $\begin{array}{l}\text { Feedback: Several items (i.e., B2, B3, C1, E2, } \\
\text { E3, F1) align with the research questions, } \\
\text { however, the activities may not apply to the } \\
\text { 2008-2009 school year. The WVDE Reading } \\
\text { Cadre has recently not been actively involved } \\
\text { with Reading First (i.e., visiting schools and } \\
\text { participating in Reading First professional } \\
\text { development activities). } \\
\text { Response to Feedback: The following } \\
\text { amendment was made based on this } \\
\text { recommendation: 1) the survey cover letter will } \\
\text { include the following clarification, "The survey is } \\
\text { to be completed in reference to your combined } \\
\text { years of experience in working with the school's } \\
\text { Reading First reading mentor teacher". }\end{array}$ & $\begin{array}{l}\text { Agrees with the suggested } \\
\text { amendment. There are many } \\
\text { instances when individuals } \\
\text { completing this survey would } \\
\text { have no knowledge the activity } \\
\text { was performed. }\end{array}$ \\
\hline & & & $\begin{array}{l}\text { Response to Feedback: All } \\
\text { panel members agreed that } \\
\text { survey participants may not have } \\
\text { knowledge regarding whether } \\
\text { the school's reading coach } \\
\text { performed some of the listed } \\
\text { coaching activities as indicated } \\
\text { in sections E-G. Therefore, the } \\
\text { responses were amended to } \\
\text { "yes" ("yes, knowledge the } \\
\text { reading coach practiced this } \\
\text { activity) or "no" (no knowledge } \\
\text { the reading coach practiced this } \\
\text { activity"). }\end{array}$ \\
\hline
\end{tabular}

*The panel was asked to include their recommendation regarding the consideration of changes to the two responses in section E-G from "yes" (reading coach activity observed) or "no" (reading coach activity not observed) to "yes" ("yes, knowledge the reading coach practiced this activity") or "no" (no knowledge the reading coach practiced this activity"). There are several questions where this may be the case. 


\section{Appendix $\mathbf{J}$ \\ Superintendent Survey Letter Request \\ WestVirginiaUniversity \\ College of Human Resources and Education}

Dear Superintendent:

My name is Karen Davies and I am sending this letter to inform you that your county's Reading First K-3 teachers working in Title I Distinguished schools will soon be invited to participate in a research study. The purpose of the study is to examine the perceptions of Reading First K-3 teachers regarding the activities performed by reading coaches in improving reading instruction. The Reading First K-3 reading teachers will be invited by letter sent to one of your schools to participate in an electronic survey. The data collected is a critical component of my doctoral dissertation which will be conducted under the direction of Dr. Helen Hazi, Professor of Educational Leadership Studies at West Virginia University.

The following assurances, as required by West Virginia University, will be respected: participation in the study is voluntary; information will be kept confidential; and the participant may refuse to participate, quit at any time, or skip any questions with no negative effect in employment status. Also note that West Virginia University's Institutional Review Board acknowledgement for this research is on file.

Please contact me if there are concerns or questions regarding this research study. They can be addressed to kdavies@suddenlink.net or (304)549-9752. Thank you.

Sincerely,

Helen Hazi, Principal Investigator Educational Leadership Professor (304)293-1885

Helen.Hazi@mail.wvu.edu

\author{
Karen Davies, Primary Contact \\ Doctoral Student \\ (304)549-9752 \\ kdavies@suddenlink.net
}

\author{
Educational Leadership Studies \\ 608 Allen Hall \\ PO Box 6122 \\ Morgantown, WV 26506-6122
}

Equal Opportunity/Affirmative Action Institution 


\section{Appendix K \\ K-3 Teacher Survey Request Letter \\ WestVirginiaUniversity \\ College of Human Resources and Education}

Dear K-3 Teacher:

My name is Karen Davies and I am writing to request your participation in a survey research study focusing on the perceptions of Reading First K-3 teachers in working with reading coaches. The purpose of the study is to examine the perceptions of $\mathrm{K}-3$ reading teachers regarding the activities of Reading First coaches to improve reading instruction. A benefit of your participation in this study is the opportunity to express your perception regarding whether the incorporation of a reading coach is a valuable support role in assisting to improve reading instruction. The data collected is a critical component of my doctoral dissertation which will be conducted under the direction of Dr. Helen Hazi, Professor of Educational Leadership Studies at West Virginia University.

The following assurances, as required by West Virginia University, will be respected: participation in the study is voluntary; information will be kept confidential; and the participant may refuse to participate, quit at any time, or skip any questions with no negative effect in employment status. Further, West Virginia University's Institutional Review Board acknowledgement for this research is on file.

I realize the timing of this request is occurring at a busy time of year. Therefore, an Ipod Touch will be offered as a participation incentive. Teachers who submit a completed electronic survey within the first two weeks of the survey window will be provided with four chances to win the Ipod Touch. Teachers who submit a completed electronic survey within the final two weeks will be provided one chance to win the Ipod Touch.

The on-line survey will take approximately 20 minutes to complete. A follow-up e-mail will be sent to you and will include a link to access the survey site.

Participants may obtain a copy of final research results upon request from the researcher (contact information is provided below). Questions regarding the research study or other contents of this letter can be addressed to kdavies@suddenlink.net or (304)549-9752. Thank you for your consideration in this request.

Sincerely,

Helen Hazi, Principal Investigator Educational Leadership Professor
Karen Davies, Primary Contact Doctoral Student
Phone: 304-293-3707

Fax: 304-293-2279
Educational Leadership Studies

608 Allen Hall

PO Box 6122

Morgantown, WV 26506-6122
Equal Opportunity/Atfirmative Action Institution

\section{John \\ $\mathrm{H}$. Digitally signed by John

